Aus der Klinik für Neurologie

(Prof. Dr. med. M. Bähr)

der Medizinischen Fakultät der Universität Göttingen

\title{
Analyse der Diagnosekriterien der Creutzfeldt-Jakob-Erkrankung in Deutschland
}

\author{
INAUGURAL-DISSERTATION \\ zur Erlangung des Doktorgrades \\ der Medizinischen Fakultät der \\ Georg-August-Universität zu Göttingen
}

vorgelegt von

Mareike Susanne Laux

aus

Bamberg

Göttingen 2020 
Dekan:

Referentin:

Ko-Referentin:

Drittreferent:
Prof. Dr. med. W. Brück

Prof. Dr. med. I. Zerr

Prof. Dr. Brit Mollenhauer

Prof. Dr. Ralf Dressel

Datum der mündlichen Prüfung: 30.11.2021 
Hiermit erkläre ich, die Dissertation mit dem Titel "Analyse der Diagnosekriterien der Creutzfeldt-Jakob-Erkrankung in Deutschland" eigenständig angefertigt und keine anderen als die von mir angegebenen Quellen und Hilfsmittel verwendet zu haben.

Göttingen, den 25.11.2021 


\section{INHALT}

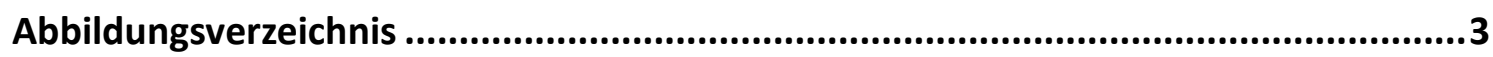

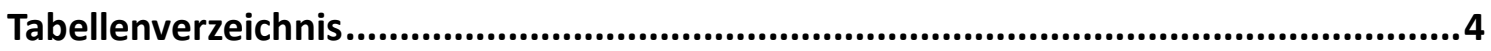

Abkürzungsverzeichnis ........................................................................................6

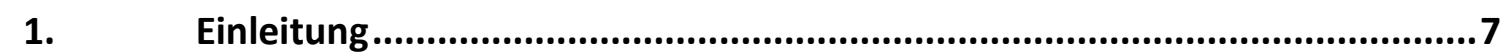

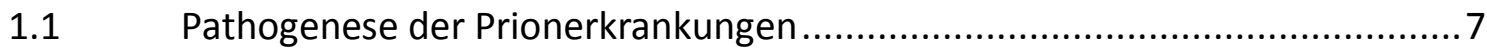

$1.2 \quad$ Epidemiologie der Creutzfeldt-Jakob-Erkrankung.................................9

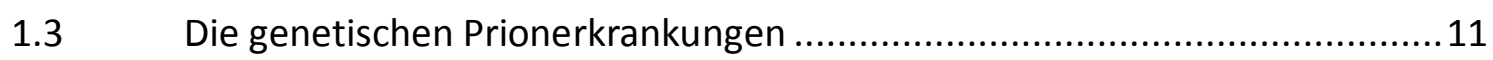

1.4 Klinische Symptomatik der Creutzfeldt-Jakob-Erkrankung........................12

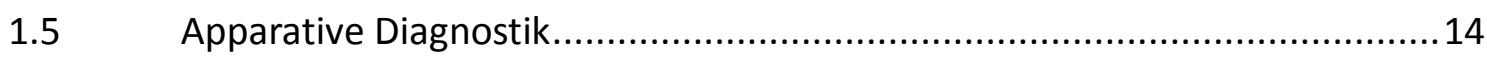

1.6 Neuropathologische Diagnostik der Creutzfeldt-Jakob-Erkrankung ..............18

1.7 Molekulare Subtypen der Creutzfeldt-Jakob-Erkrankung..........................18

1.8 Diagnosekriterien für die sporadische Creutzfeldt-Jakob-Erkrankung ...........21

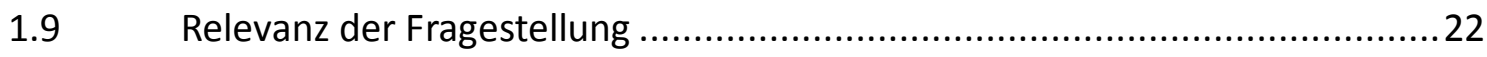

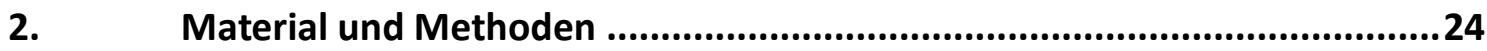

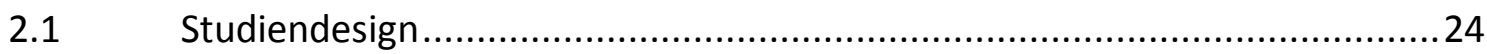

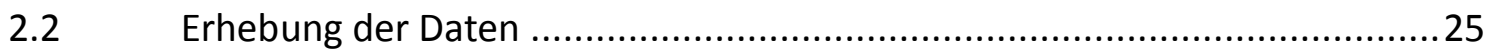

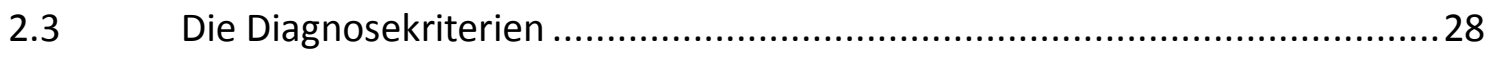

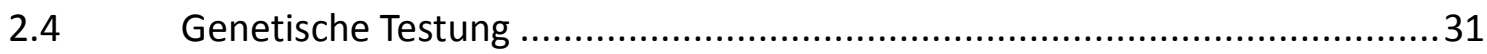

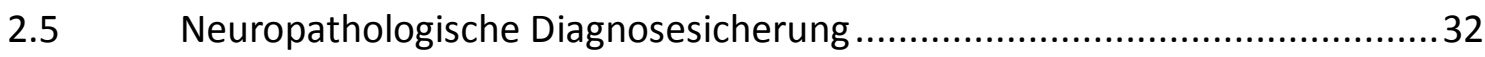

2.6 Statistische Auswertung der Daten ................................................... 33

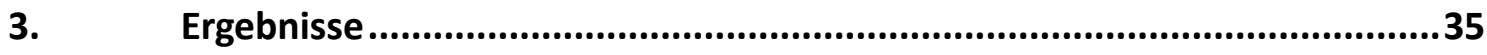

3.1 Deskriptive Statistik der untersuchten Patientenkollektive........................35

3.2 Molekulare Subtypen des Patientenkollektivs ............................................36

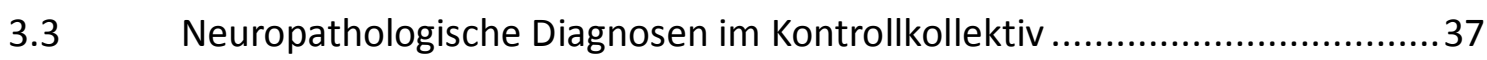

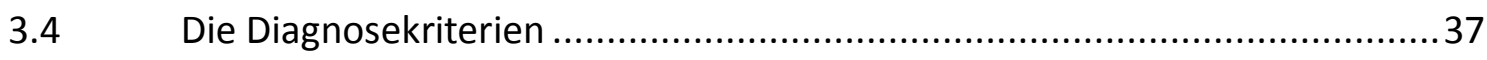

3.5 Häufigkeiten der klinischen Symptomatik .......................................... 38

Analyse der apparativen Diagnostik ................................................ 41 
3.7 Zeitliche Aspekte bei der Diagnosestellung einer Creutzfeldt-Jakob-

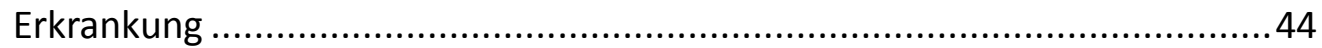

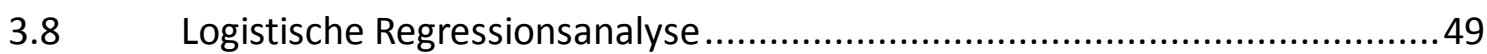

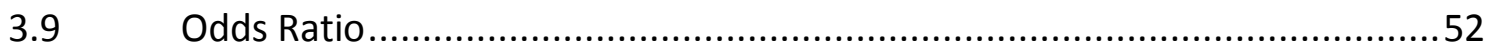

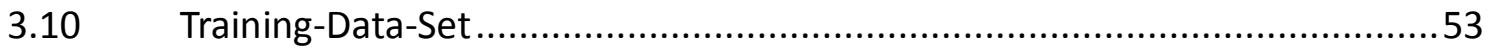

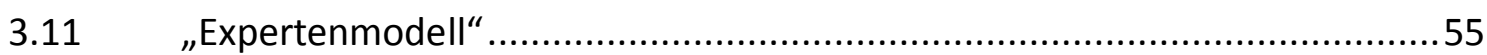

3.12 Neu entwickelte Diagnosekriterien für die sporadische Creutzfeldt-Jakob-

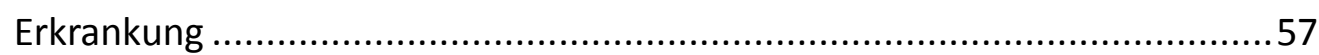

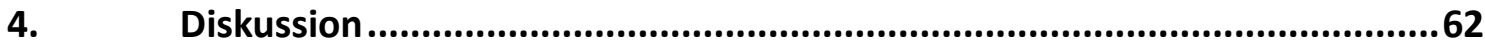

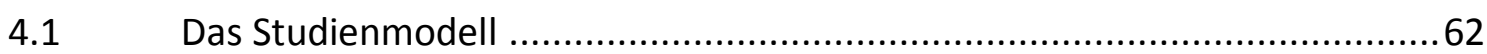

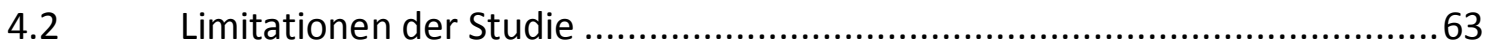

4.3 Deskriptive Analyse des Patientenkollektivs.............................................64

4.4 Molekulare Subtypen der Creutzfeldt-Jakob-Erkrankung............................65

4.5 Die Diagnosekriterien der DGN von 2012 …............................................66

4.6 Zeitliche Aspekte bei der Diagnosestellung einer Creutzfeldt-Jakob-

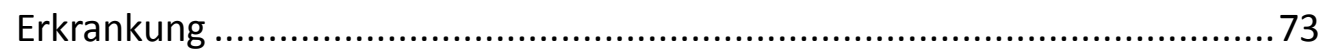

4.7 Ergebnisse der logistischen Regressionsanalyse ...................................76

4.8 Die „neu entwickelten Diagnosekriterien“ .............................................79

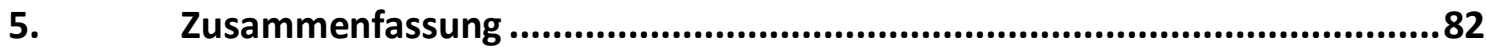

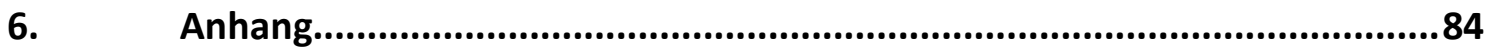

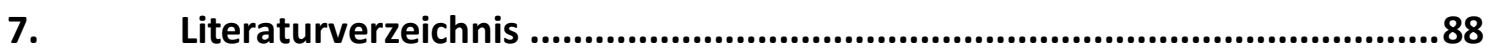




\section{ABBILDUNGSVERZEICHNIS}

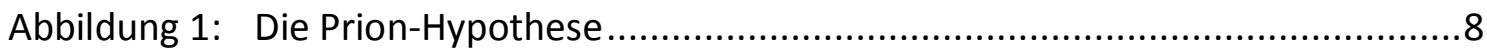

Abbildung 2: Graphische Darstellung Auswertung RT-QuIC ....................................31

Abbildung 3: Zeitpunkt der Liquorpunktion im Krankheitsverlauf ...........................45

Abbildung 4: Zeitpunkt der Diagnosestellung im Krankheitsverlauf im Fallkollektiv (rückblickend) nach DGN Leitlinie 2012 .....................46

Abbildung 5: Zeitpunkt der Diagnosestellung im Krankheitsverlauf im Kontrollkollektiv (rückblickend) nach DGN Leitlinie 2012 .................47

Abbildung 6: ROC-Kurve für das „endgültige Modell“ ...........................................54

Abbildung 7: ROC-Kurve für das „Experten-Modell“ ...........................................56

Abbildung 8: Neue Diagnosekriterien Diagnosestellung nach Dritteln......................59

Abbildung 9: Vergleich Zeitpunkt der Diagnosestellung DGN 2012 und neu entwickelte Kriterien (prozentual) .......................................60

Abbildung 10: Vergleich Zeitpunkt der Diagnosestellung aktuelle und neu entwickelte Kriterien für den VV2-Subtyp .............................61

Abbildung 11: Entwicklung der Probeneingänge und der positiven Befunde 1993-2019, graphisch 


\section{TABELLENVERZEICHNIS}

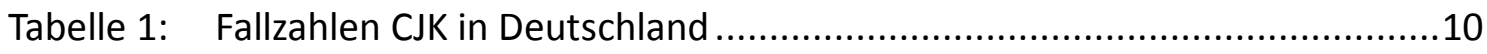

Tabelle 2: Klinische Diagnosekriterien der CJK in Deutschland gemäß DGN 2012 .....22

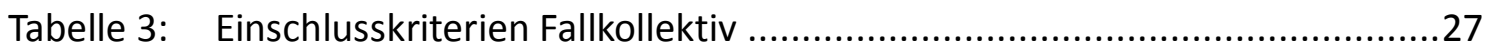

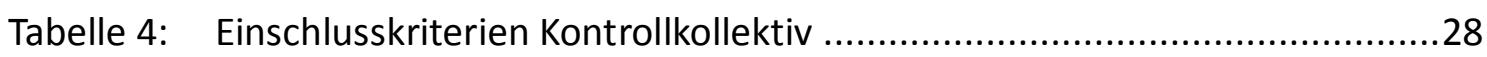

Tabelle 5: Neuropathologische Kriterien für die CJK und andere Prionerkrankungen (nach Budka 2003) ......................................33

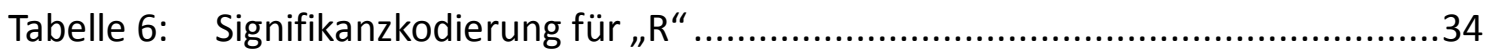

Tabelle 7: Verteilung des Genotyps im Fall- und Kontrollkollektiv ..........................36

Tabelle 8: Verteilung molekularer Subtypen im Fallkollektiv ....................................36

Tabelle 9: Neuropathologische Diagnosen im Kontrollkollektiv ..............................37

Tabelle 10: Auftreten klinischer Symptomatik im Krankheitsverlauf nach Dritteln ......41

Tabelle 11: Sensitivität und Spezifität EEG ….......................................................42

Tabelle 12: Sensitivität und Spezifität cMRT …................................................42

Tabelle 13: Sensitivität und Spezifität Proteine 14-3-3 ..........................................43

Tabelle 14: Sensitivität und Spezifität Gesamt-tau ................................................43

Tabelle 15: Sensitivität und Spezifität RT-QuIC .....................................................44

Tabelle 16: Sensitivität und Spezifität der Diagnosekriterien (DGN 2012)

rückblickend betrachtet.

Tabelle 17: Sensitivität und Spezifität der Diagnosekriterien (DGN 2012)

zum Zeitpunkt der Liquorpunktion

Tabelle 18: Sensitivität und Spezifität der Diagnosekriterien zum Zeitpunkt der LP mit RT-QuIC

Tabelle 19: Werte des Akaike Informationskriteriums für verschiedene Modelle der logistischen Regressionsanalyse .50

Tabelle 20: Ergebnisse der logistischen Regressionsanalyse für das „endgültige Modell“ .51

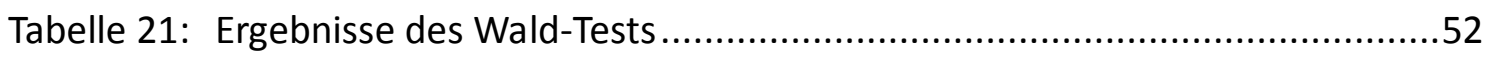

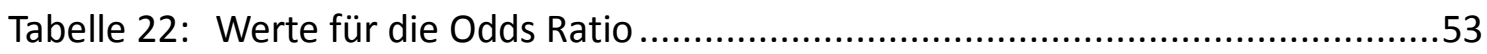

Tabelle 23: Kreuzvalidierung Training-Data-Set für das „endgültige Modell“...............54

Tabelle 24: Sensitivität, Spezifität und Genauigkeit „endgültiges Modell“ ...................55

Tabelle 25: Ergebnisse logistische Regressionsanalyse „Expertenmodell“ ...................56

Tabelle 26: Kreuzvalidierung Training-Data-Set für das „Expertenmodell“ ..................57 
Tabelle 27: Sensitivität, Spezifität und Genauigkeit „Expertenmodell“

Tabelle 28: Sensitivität und Spezifität der" neu entwickelten" Kriterien im Vergleich zu den Kriterien der DGN 2012

Tabelle 29: Klinische Klassifikationskriterien der sporadischen CJK 2018 (modifiziert nach DGN Leitlinie CJK 2018).

Tabelle 30: WHO-Diagnosekriterien für die sporadische CJK 2018

(modifiziert nach Center of Disease Control and Prevention)

Tabelle 31: Entwicklung der Probeneingänge und der positiven Befunde 1993-2019 tabellarisch 86 


\section{ABKÜRZUNGSVERZEICHNIS}

\begin{tabular}{ll} 
AIC & Akaike information criterion \\
BSE & Bovine spongiforme Enzephalopathie \\
CJK & Creutzfeldt-Jakob-Krankheit \\
CMRT & Kraniale Magnet-Resonanz-Tomografie \\
DGN & Deutsche Gesellschaft für Neurologie \\
DWI & diffusion weighted imaging \\
EEG & Elektroenzephalogramm \\
FFI & fatal familial insomnia, letale familiäre Insomnie \\
FLAIR & fluid attenuated inversion recovery \\
gCJK & Genetische Creutzfeldt-Jakob-Krankheit \\
GSSS & Gerstmann-Sträussler-Scheinker-Syndrom \\
iCJK & latrogene Creutzfeldt-Jakob-Krankheit \\
log. & Logistisch \\
LP & Liquorpunktion \\
NRZ & Nationales Referenzzentrum f. transmissible spongiforme Enzephalopa- \\
& thien \\
PPW & Positiv prädiktiver Wert \\
PRNP & Prionproteingen \\
PrP & Prionprotein \\
PrPC & Prionprotein zellulär \\
PrPSc & Prionprotein scrapie \\
PSWC & periodic sharp wave complexes \\
rfu & relative fluorescence units \\
ROC & reciever operating characteristics \\
RT-QuIC & real-time quaking-induced conversion \\
SCJK & Sporadische Creutzfeldt-Jakob-Krankheit \\
TSE & Transmissible spongiforme Enzephalopathie \\
UMG & Universitätsmedizin Göttingen \\
VCJK & Variante Creutzfeldt-Jakob-Krankheit \\
WHO & World Health Organization \\
ZNS & Zentralnervensystem \\
\hline
\end{tabular}




\section{EINLEITUNG}

Die Creutzfeldt-Jakob-Erkrankung ist eine seltene und unheilbare neurodegenerative Erkrankung aus der Gruppe der Prionerkrankungen. Diese wurden zunächst bei Schafen und Ziegen, später auch bei Rindern und anderen Säugetieren beschrieben. Die humanen Prionerkrankungen werden in sporadische, erworbene und hereditäre unterteilt, wobei die sporadische CJK die häufigste Form darstellt.

Die Erkrankung beim Menschen wurde erstmals 1920 durch H.G. Creutzfeldt (Creutzfeldt 1920) und 1921 durch A. Jakob (Jakob 1921) beschrieben. Diese stellten unabhängig voneinander unter dem Namen der spastischen Pseudosklerose ein Erkrankungsbild mit einem raschen Verlauf und komplexer neurologischer Symptomatik vor.

\subsection{Pathogenese der Prionerkrankungen}

Die Prionerkrankungen sind transmissible spongiforme Enzephalopathien. Lange Zeit ging man bei dem Krankheitsbild von einer slow virus infection als Ursache für die CJK aus. 1982 beschrieb Stanley Prusiner erstmals das proteinaceous infectious agent (Prion) als Auslöser für neurodegenerative Erkrankungen. Hierbei handelt es sich um eine nukleinsäurefreie Eiweißstruktur, die aus aggregiertem Prionprotein besteht (Prusiner 1982).

Physiologisch ist das Prionprotein ( $\mathrm{Pr}^{\mathrm{c}}$ ) Funktionsträger bei der Signalübertragung an Membranen und Synapsen (Mouillet-Richard et al. 2000) sowie bei der Zelladhäsion und beim Schutz vor oxidativem Stress (Hu et al. 2008; Westergard et al. 2007).

Als wichtigstes Ereignis der Pathogenese der Prionerkrankungen wird, nach heutigem Stand der Wissenschaft, die Umfaltung des physiologischen Prionproteins aus einer $\alpha$ helical Anordnung in eine ß-Faltblattstruktur zum pathogenen Prionprotein dem sogenannten Prionprotein Scrapie (PrPSc) (Prusiner 1982) angenommen. Dadurch kann das „kranke“ Prionprotein zum einen seine physiologischen Aufgaben nicht mehr erfüllen, zum anderen führt die Änderung der Teriärstruktur zu einer Resistenz gegenüber dem Enzym Proteinase- $K$, welches unter physiologischen Bedingungen das membranständige Prionprotein aufspaltet und somit abbaubar macht. Diese Resistenz führt in der Folge zu einer Akkumulation des neurotoxischen $\operatorname{PrP}^{S c}$ (Cohen und Prusiner 1998). 
Da das Prionprotein keinen Nukleinsäurekern besitzt und sich somit nicht selbst replizieren kann, wurde lange über den Mechanismus der Infektiosität spekuliert (Prusiner 1982). Wesentlich scheint die hohe Aggregationsneigung des $\operatorname{PrP}^{\mathrm{Sc}} \mathrm{zu}$ sein, wobei das $\mathrm{PrP}^{\mathrm{Sc}}$ den Anstoß zum Umfaltungsprozess von gesundem Prionprotein in die pathologische Form gibt. Der genaue Mechanismus dieses Vorgangs ist nach wie vor ungeklärt. Durch diese Eigenschaft kommt es jedoch zu einer Potenzierung des anfallenden pathologischen Prionproteins, die den raschen Verlauf der Erkrankung erklären kann (Parchi und Saverioni 2012).

Ebenfalls nicht abschließend geklärt sind die pathophysiologischen Prozesse, die auf zellulärer Ebene zum neuronalen Zelluntergang führen. Hier wird aktuell die Theorie diskutiert, dass es durch die Ablagerungen des $\operatorname{PrP}^{S c}$ zu Veränderungen der Zellmembran kommt, die einen lonenaustausch zwischen intra- und extrazellulärem Raum ermöglichen, wodurch der Zelltod initiiert und eine Ausbreitung des PrP ${ }^{\mathrm{Sc}}$ ermöglicht wird (Glatzel et al. 2015).

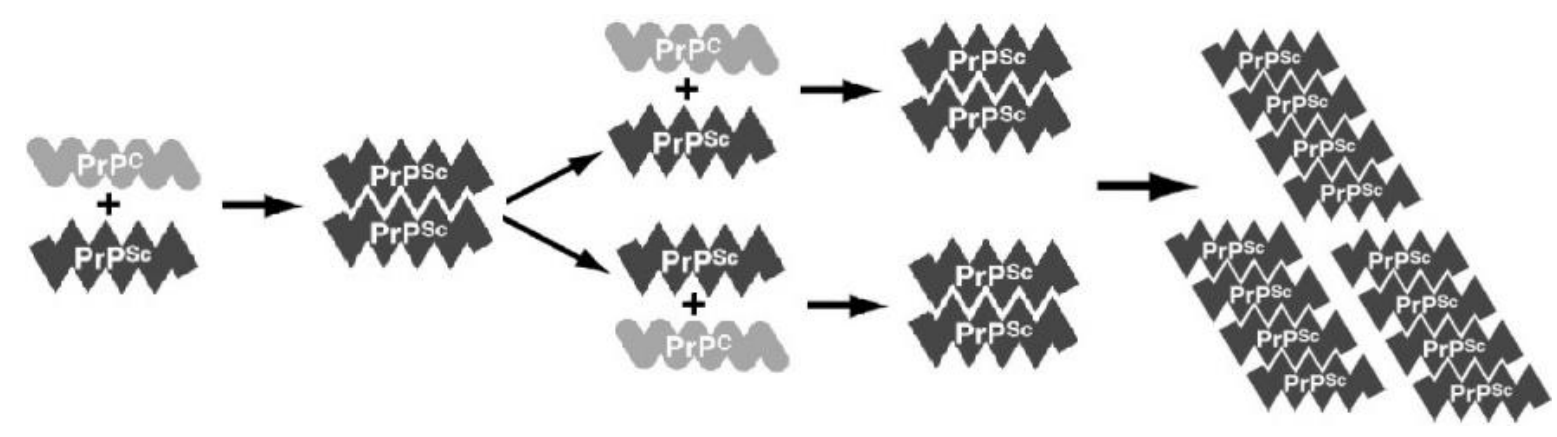

Abbildung 1: Die Prion-Hypothese (modifiziert nach McKintosh et al. (2003))

Aus der oben genannter Pathogenese resultiert ein massiver neuronaler Zelluntergang, der sich in der neuropathologischen Begutachtung als klassische Trias aus spongiformer Vakuolisierung des Gehirngewebes, astrozytärer Gliose sowie Ablagerung der PrPsc Plaques darstellt (Parchi und Saverioni 2012; Colby und Prusiner 2011).

Während die Ursachen für eine genetische (gCJK), eine iatrogene (iCJK) und die neue Variante der CJK (VCJK), die durch den Verzehr des Fleisches von Rinder, die an einer bovinen spongiformen Enzephalopathie (BSE) erkrankt waren, übertragen wird, bekannt sind, gibt es bisher kaum Hinweise auf die ursächlichen Faktoren einer sporadischen CJK ( $\mathrm{SCJK})$. 
Mit der Frage nach dem Auslöser der sporadischen CJK haben sich bisher einige epidemiologische Studien zur Eruierung potenzieller Risikofaktoren beschäftigt (Ruegger et al. 2009; Kittner et al. 2009), ohne jedoch zu einem Ergebnis zu kommen.

\subsection{Epidemiologie der Creutzfeldt-Jakob-Erkrankung}

Die Inzidenz beträgt weltweit 0,10 bis 0,15 Fälle pro 100.000 Einwohner (Ladogana et al. 2005). In Deutschland erkrankten im Jahr 2019120 Patienten neu an einer Prionerkrankung (sCJK, gCJK, iCJK, letale familiäre Insomnie (FFI), Gerstmann-Sträussler-Scheinker Syndrom (GSSS)), dies entspricht einer Inzidenz von 1,4 Fällen pro 1.000.000 Einwohner. Statistisch gesehen entfällt mit 97\% der Großteil der Erkrankungen auf die sporadische CJK (NRZ für TSE).

Seit Beginn der Aufzeichnung des nationalen Referenzzentrums (NRZ) für transmissible spongiforme Enzephalopathien (TSE) im Jahr 1993 zeigt sich eine Zunahme der Inzidenz für Prionerkrankungen von 0,7 Fälle pro 1.000.000 auf bis zu 1,9 Fälle pro 1.000.000 Einwohner im Jahre 2012 (NRZ für TSE 2020). Im fachlichen Diskurs scheint dieser Trend am ehesten mit der Verbesserung der diagnostischen Möglichkeiten, intensivierter epidemiologischer Erfassung der Fälle sowie einer höheren Lebenserwartung zusammenzuhängen; eine tatsächliche Zunahme von Erkrankungsfällen scheint unwahrscheinlich (Mackenzie und Will 2017). Zuletzt lag die Inzident im Jahr 2019 bei 1,4 Fällen pro 1.000.000 Einwohnern. 
Tabelle 1: Fallzahlen CJK in Deutschland

Jahr Si- Wahrschein- Mögli- GSSS FFI Genetische latro- vCJK Inzidenz chere liche CJK che

CJK

gen

CJK CJK

\begin{tabular}{|c|c|c|c|c|c|c|c|c|c|}
\hline 1993 & 26 & 4 & 4 & 1 & 0 & 0 & 0 & 0 & 0,7 \\
\hline 1994 & 45 & 27 & 16 & 0 & 2 & 5 & 1 & 0 & 0,9 \\
\hline 1995 & 64 & 23 & 9 & 2 & 2 & 2 & 0 & 0 & 1,1 \\
\hline 1996 & 55 & 34 & 9 & 3 & 5 & 5 & 1 & 0 & 1,1 \\
\hline 1997 & 73 & 34 & 13 & 1 & 2 & 6 & 1 & 0 & 1,3 \\
\hline 1998 & 63 & 53 & 11 & 1 & 3 & 7 & 0 & 0 & 1,4 \\
\hline 1999 & 68 & 35 & 5 & 0 & 1 & 9 & 1 & 0 & 1,3 \\
\hline 2000 & 60 & 49 & 4 & 2 & 3 & 7 & 1 & 0 & 1,3 \\
\hline 2001 & 69 & 56 & 10 & 0 & 4 & 8 & 0 & 0 & 1,5 \\
\hline 2002 & 52 & 45 & 6 & 1 & 2 & 7 & 0 & 0 & 1,2 \\
\hline 2003 & 56 & 61 & 7 & 1 & 1 & 4 & 3 & 0 & 1,4 \\
\hline 2004 & 79 & 57 & 4 & 1 & 4 & 4 & 0 & 0 & 1,7 \\
\hline 2005 & 75 & 69 & 7 & 0 & 5 & 8 & 1 & 0 & 1,8 \\
\hline 2006 & 62 & 80 & 7 & 0 & 4 & 6 & 2 & 0 & 1,7 \\
\hline 2007 & 51 & 86 & 14 & 0 & 3 & 1 & 0 & 0 & 1,7 \\
\hline 2008 & 60 & 77 & 8 & 0 & 4 & 3 & 0 & 0 & 1,7 \\
\hline 2009 & 53 & 73 & 9 & 2 & 4 & 2 & 0 & 0 & 1,5 \\
\hline 2010 & 45 & 90 & 1 & 0 & 4 & 7 & 0 & 0 & 1,6 \\
\hline 2011 & 52 & 99 & 2 & 1 & 2 & 2 & 0 & 0 & 1,8 \\
\hline 2012 & 56 & 97 & 3 & 1 & 2 & 2 & 0 & 0 & 1,9 \\
\hline 2013 & 42 & 96 & 4 & 2 & 5 & 4 & 0 & 0 & 1,7 \\
\hline 2014 & 27 & 105 & 0 & 1 & 2 & 2 & 0 & 0 & 1,6 \\
\hline 2015 & 32 & 91 & 2 & 0 & 3 & 1 & 0 & 0 & 1,5 \\
\hline 2016 & 41 & 106 & 6 & 0 & 3 & 1 & 0 & 0 & 1,8 \\
\hline 2017 & 30 & 102 & 1 & 1 & 1 & 0 & 0 & 0 & 1,6 \\
\hline 2018 & 28 & 78 & 2 & 2 & 1 & 2 & 0 & 0 & 1,3 \\
\hline 2019 & 30 & 86 & 1 & 1 & 0 & 2 & 0 & 0 & 1,4 \\
\hline
\end{tabular}

GSSS= Gerstmann-Sträussler-Scheinker Syndrom; FFI= letale familiäre Insomnie; iatrogen = iatrogene CJK; vCJK= Variante CJK

(Fallzahlenbericht NRZ für TSE Stand 17.04.2020; Die Tabelle wurde vom NRZ für TSE erstellt und freundlicherweise für die Veröffentlichung in dieser Dissertation zur Verfügung gestellt) 


\subsection{Die genetischen Prionerkrankungen}

Den genetischen Formen der Prionerkrankung liegen verschiedene Mutationen im Prionproteingen (PRNP) zu Grunde, welches auf dem kurzen Arm des Chromosoms 20 lokalisiert ist (Oesch et al. 1985). Der Erbgang ist stets autosomal dominant und wird durch Insertions- oder Punktmutationen verursacht (Mead et al. 2006). Die weltweit häufigsten Mutationen, die zu einer familiären CJK führen, sind die E200K- und die V210I Mutationen (Kovács et al. 2005).

Epidemiologisch machen genetische Prionerkrankungen in der Regel 10 bis $15 \%$ der Prionerkrankungen pro Jahr aus. In der Gruppe der genetischen Prionerkrankungen stellt die familiäre Creutzfeldt-Jakob-Erkrankung mit 64\% aller genetischen Prionerkrankungen die größte Gruppe dar. Die FFI ist mit einem Anteil von 26\% der genetischen Erkrankungen sehr selten und GSSS mit einem Anteil von 10\% der genetischen Fälle eine Rarität (Schelzke und Zerr 2010).

\subsection{1 latrogene CJK}

Die Übertragbarkeit von Prionerkrankung von Mensch zu Mensch mittels kontaminiertem Operationsbesteck bei Gehirnoperationen, Corneatransplantationen und kontaminierten Dura-Mater-Transplantaten sowie mittels Hormonpräparaten aus Leichenhypophysen erkrankter Patienten ist seit 1974 bekannt (Will 2003; Brown et al. 2000).

Für die iatrogene CJK wurden seit Beginn der Aufzeichnung der Daten durch das NRZ für TSE in Deutschland im Jahr 1993 insgesamt elf Fälle berichtet, in denen Patienten nach stattgehabten neurochirurgischen oder ophthalmologischen Operationen Symptome einer CJK entwickelt hatten. Der letzte bestätigte Fall einer iatrogenen CJK wurde 2006 erfasst (s. Tabelle 1).

\subsubsection{Variante CJK}

Die Variante der CJK wird mit der bovinen spongiformen Enzephalopathie assoziiert und mutmaßlich durch den Verzehr von Fleisch erkrankter Tiere übertragen, wobei der endgültige Übertragungsmechanismus nicht abschließend geklärt ist (Will 2003). Weltweit beträgt die Prävalenz der VCJK ca. 3\%. In Deutschland konnte bisher kein Fall einer Variante CJK identifiziert werden (s. Tabelle 1). 
Eine Übertragung der vCJK durch Bluttransfusionen wurde beobachtet, zusätzlich ließ sich bei Patienten mit einer VCJK abnormes Prionprotein ( $\mathrm{PrP}^{\mathrm{Sc}}$ ) im peripheren lymphatischen Gewebe nachweisen (Dietz et al. 2007; Seitz et al. 2007).

\subsection{Klinische Symptomatik der Creutzfeldt-Jakob-Erkrankung}

Der klinische Verlauf der Creutzfeldt-Jakob-Erkrankung ist - neben anderen Ursachen auch aufgrund eines Polymorphismus am Codon 129 des Prionproteingens häufig sehr variabel (Parchi et al. 1999). Im Folgenden soll zunächst ein Überblick über die mögliche klinische Symptomatik gegeben werden, wie sie im Rahmen einer CJK beobachtet bzw. wie sie in den Diagnosekriterien berücksichtigt wird.

Prodromal können unspezifische Veränderungen, wie etwa Wesensänderungen, allgemeine Schwäche, trockener Reizhusten, Ess- und Schlafstörungen sowie vermehrtes Schwitzen, auftreten (Poser et al. 1997; Zerr und Poser 2001).

Die rasch progrediente dementielle Entwicklung ist die Schlüsselsymptomatik für die Diagnose einer Creutzfeldt-Jakob-Erkrankung (Brown et al. 1994). Bei einer Demenz sind mehrere höhere kortikale Funktionen, insbesondere Gedächtnis, Orientierung, Sprache und Entscheidungsfähigkeit, beeinträchtigt, wobei die Beeinträchtigungen länger als sechs Monate bestehen müssen (Masuhr et al. 2013). Für die Diagnosestellung einer wahrscheinlichen oder möglichen CJK ist nach den Diagnosekriterien der Deutschen Gesellschaft für Neurologie (DGN) das Vorliegen eine Demenz zwingend erforderlich (DGN 2012 und DGN 2018). Als progressive Demenz gilt in der Regel ein rasch fortschreitender kognitiver Verfall von einer Dauer kürzer als zwei Jahren (Paterson et al. 2012). Die dementielle Entwicklung ist häufig eines der ersten Symptome bei CJK-Patienten, kann aber auch zu jedem anderen Zeitpunkt der Erkrankung auftreten. Das Auftreten der Demenz im Krankheitsverlauf ist v. a. vom molekularen Subtyp der Erkrankung abhängig (Zerr und Poser 2002).

Die im Weiteren beschriebene Symptomatik gibt lediglich einen Überblick über die im Rahmen der Arbeit der Surveillance der TSE am häufigsten berichteten Symptome. Jede weitere zerebellare, extrapyramidale oder pyramidale Symptomatik erfüllt die Kriterien zur Diagnosestellung einer CJK ebenfalls. 
Neben den kognitiven Einschränkungen tritt in der Regel auch eine Bewegungsstörung auf. Diese ist zunächst meist zerebellar bedingt und wird als Gang-, Rumpf- und/oder Extremitätenataxie beschrieben. Aber auch zerebellar bedingte Sprach-, Schluck und Augenbewegungsstörungen treten auf. Als gleichwertiges Symptom wird eine kortikale Sehstörung oder Blindheit gewertet (Parchi et al. 1996; Zerr und Poser 2002; Weber et al. 1997b).

Extrapyramidal-motorisch ist häufig eine rigorose Tonuserhöhung mit oder ohne Zahnradphänomen auffällig. Ebenso werden Ruhetremor oder Hyperkinesien beobachtet. Gleichwertig wird hier eine pyramidale Symptomatik mit positiven Pyramidenbahnzeichen und anderen pathologischen Reflexen (z. B. Greifreflex), Hemiparese oder Reflexdifferenz gewertet (Zerr und Poser 2002).

Myoklonien können im Rahmen einer CJK fokal, aber auch generalisiert auftreten. Typischerweise sind sie stimulussensitiv. Wichtig ist hier die Abgrenzung zum generalisierten epileptischen Anfall (Grand-mal-Anfall), der im Rahmen einer CJK selten beobachtet wird (Will und Matthews 1984; Zerr und Poser 2002).

Im späten Stadium der Erkrankung tritt ein akinetischer Mutismus auf. Dieser ist durch einen kompletten Sprachverlust sowie die völlige Bewegungsunfähigkeit gekennzeichnet. Differenzialdiagnostisch müssen hier ein Locked-In-Syndrom, ein apallisches Syndrom und eine Katatonie abgegrenzt werden (Otto et al. 1998; Zerr und Poser 2002). 


\subsection{Apparative Diagnostik}

In diesem Abschnitt soll näher auf die apparative Diagnostik eingegangen werden, die für die Diagnosestellung einer CJK sinnvoll und notwendig ist.

\subsubsection{EEG-Veränderungen bei der sCJK}

Die pathognomonischen Veränderungen im EEG, welche als Diagnosekriterium für die CJK herangezogen werden können, sind die sogenannten periodic sharp wave complexes (PSWC). Gemäß der Veröffentlichung von BJ Steinhoff aus dem Jahr 1998 werden PSWCs als mono-, bi- oder triphasische scharfe Wellen oder seltener als Poly-Spike-Wave- Komplexe und Slow-Wave-Komplexe beschrieben (Steinhoff et al. 1998). Die Komplexe haben definitionsgemäß eine Dauer von 100-160 ms und treten mit einer Frequenz von 0,5-2 pro Sekunde auf (Wieser et al. 2006). Bei der Heranziehung des EEG als Diagnosekriterium sollte auf die Periodizität als typisches Merkmal ein besonderes Augenmerk gelegt werden. (Steinhoff et al. 1998) Zusätzlich ist in der Regel eine Verlangsamung des Grundrhythmus im Sinne einer Allgemeinveränderung zu verzeichnen; diese ist jedoch unspezifisch und tritt im Rahmen einer Vielzahl von Erkrankungen auf. Ein unauffälliges EEG schließt eine CJK weitestgehend aus (Wieser et al. 2006).

Im zeitlichen Verlauf der Erkrankung zeigen sich im frühen Stadium zunächst eine Allgemeinveränderung des EEGs (unspezifische Verlangsamung der Grundaktivität mit diffus eingestreuten Theta- und Deltawellen) und lokalisierte Komplexe. Mit Fortschreiten der Erkrankung treten dann generalisiert über alle Hirnarealen PSWC auf. Das Vollbild der generalisierten bzw. lateralisierten periodischen Sharp-Wave-Komplexe zeigt sich in der Regel erst im mittleren bis späten Stadium der Erkrankung und geht im Endstadium der Erkrankung bzw. präfinal wieder verloren (Steinhoff et al. 1998).

Die Angaben über die Sensitivität und Spezifität der typischen EEG Veränderungen variiert zwischen 67\% (Steinhoff et al. 2004)und 66\% Sensitivität (Zerr et al. 2000) sowie zwischen Werten von 86\% (Steinhoff et al. 2004) und 74\% (Zerr et al. 2000) für die Spezifität. Der positiv prädiktive Wert (PPW) wird mit 93\% (Zerr et al. 2000) und 95\% (Steinhoff et al. 2004) angegeben. 


\subsubsection{CMRT-Befunde bei der SCJK}

Das cMRT als technische Zusatzdiagnostik wurde als letzte Neuerung 2010 in die offiziellen Diagnosekriterien aufgenommen. Basierend auf den Ergebnissen einer Multicenterstudie zu cMRT-Veränderungen bei Patienten mit einer Creutzfeldt-Jakob-Erkrankung (Zerr et al. 2009) gelten gemäß den Leitlinien der DGN Hyperintensitäten in den Basalganglien, also Nucleus caudatus und Putamen und/oder in mindestens zwei kortikalen Regionen von parietal bis okzipital reichend, als Diagnosekriterium (DGN 2012 und DGN 2018). Hyperintensität in anderen kortikalen Hirnregionen wurden auf Grund von Voruntersuchungen ausgenommen, da sich für diese Regionen eine schlechte Diskrimination zwischen tatsächlichen CJK-Fällen und falsch positiven Befunden in der Kontrollgruppe ergab, was sich in niedrigen Werten für die Spezifität widerspiegelt (Krasnianski et al. 2008).

In der klinischen Praxis müssen, wie auch bei positiven Protein 14-3-3 Befunden, relevante Differenzialdiagnosen ausgeschlossen werden, die sowohl zu ähnlichen Befunde im cMRT führen als auch der klinischen Symptomatik einer CJK ähneln können. Hierzu zählen entzündliche Prozesse des zentralen Nervensystems, insbesondere die autoimmunologisch vermittelten und viralen Encephalitiden, sowie hypoxische Hirnschädigungen, epileptische Geschehen und Ischämien (Krasnianski et al. 2004; Zerr et al. 2009). Im Rahmen dieser Differenzialdiagnosen ist eine Diskriminierung bzw. Zuordnung der Befunde nicht möglich.

\subsubsection{Liquordiagnostik}

Die Liquordiagnostik ist nicht erst seit Einführung der Proteine 14-3-3 Analyse die essentielle Untersuchung bei Verdacht auf das Vorliegen einer CJK. Neben den Proteinen 14-3-3 gibt es weitere Parameter in der Liquordiagnostik, die bei der Diagnosefindung hilfreich sein können und in diesem Abschnitt näher beleuchtet werden sollen. 


\subsubsection{Routinediagnostik}

Die konventionelle Liquordiagnostik zeigt sich bei Patienten mit einer CJK bezüglich erhöhter Zellzahl oder weiteren Hinweisen auf ein akut entzündliches Geschehen unauffällig. In einzelnen Fällen können jedoch eine leicht Schrankenstörung sowie oligoklonale Banden ohne intrathekale IgG-Synthese nachgewiesen werden (Weber et al. 1997b).

\subsubsection{Protein 14-3-3}

Das Protein 14-3-3 ist ein astrozytäres Protein und als zerebraler Schadensmarker bei akutem Untergang von Gehirngewebe im Liquor zu finden (Gmitterová et al. 2009). Neben der Creutzfeldt-Jakob-Erkrankung und weiteren Prionerkrankungen kommt es u. a. auch bei zerebralen Ischämien, epileptischen oder entzündlichen Geschehen, hypoxischen Hirnschädigungen sowie zerebralen Tumorgeschehen oder jeder anderen Pathologie, die mit einem raschen zerebralen Zelluntergang einhergeht, zum vermehrten Anfallen von Protein 14-3-3 und somit zu dessen positiver Bestimmung im Liquor (Zerr et al. 1998). Da das Protein 14-3-3 ebenfalls in Erythrozyten vorkommt (Boston et al. 1982), kann auch eine artifizielle Blutbeimengung zum Liquor zur falsch positiven Bestimmung des Destruktionsmarkers führen. Dennoch kommt der Bestimmung der Proteine 14-3-3 im Liquor mittels Immunoassay in der Diagnostik der Creutzfeldt-Jakob-Erkrankung ein wichtiger Stellenwert zu. Die Sensitivität für diesen Immunoassay zum Nachweis pathologisch erhöhter Werte für das Protein 14-3-3 im Liquor ergab in einer Untersuchung von G. Hsich einen Wert von 96\%. Die Spezifität für diesen Test wurde mit einem Wert von $99 \%$ ermittelt (Hsich et al. 1996). In weiteren retrospektiven Untersuchungen zum Protein 14-3-3 als Biomarker in der Diagnostik der CJK zeigten sich eine Spezifität von 93\% $(92,8 \%)$ und eine Sensitivität von $94 \%$ bei wahrscheinlichen oder pathologisch gesicherten Fällen. Somit ergibt sich ein ebenfalls hoher positiver prädiktiver Wert von $94,7 \%$ für das Protein 14-3-3. Der negativ prädiktive Wert wurde in derselben Untersuchung mit 92,4\% angegeben. Ein negatives Ergebnis für das Protein 14-3-3 schließt also eine CJK nicht aus (Zerr et al. 1998). In einer aktuelleren Untersuchung von M. Schmitz et al. (2016) konnten Validität und Stabilität der Proteine 14-3-3 unter verschiedenen Gewin- 
nungs-, Aufbewahrungs- und Transportbedingungen bestätigt werden, so dass die Proteine 14-3-3 als zuverlässiger Biomarker in der Diagnosestellung einer Prionerkrankung nicht mehr wegzudenken sind.

\subsubsection{Gesamt-tau}

Neben dem Protein 14-3-3 als sehr spezifischer Marker für die Abgrenzung einer CJK von anderen neurodegenerativen Erkrankungen kann auch das Gesamt-tau bei der Diagnosestellung einer Prionerkrankung hilfreich sein.

Das Tauprotein wird als Bestandteil des Zytoskeletts bei jeglicher Hirngewebsschädigung freigesetzt und zählt somit ebenfalls zu den unspezifischen Destruktionsmarken im Liquor (Weingarten et al. 1975). Da auf Grund der Pathophysiologie der Prionerkrankungen rasch viel Hirngewebe untergeht, kommt es zu einem starken Anstieg des im Liquor nachweisbaren Tauprotein auf mehr als das Dreifache des oberen Referenzwertes (>1300pg/ml). Nicht selten übersteigen die Werte das Zehnfache des oberen Referenzwertes (Otto et al. 1997; Sanchez-Juan et al. 2006). Erhöhte Werte sind jedoch, wie bei den Proteinen 14-3-3 auch bei epileptischen Geschehen, zerebralen Ischämien, entzündlichen Geschehen, zerebralen Tumorerkrankungen oder hypoxischen Hirngewebsschädigungen zu beobachten (Zerr et al. 2002). Bei massiv erhöhten Gesamt-tau-Werten ohne Hinweis auf eine der oben genannten akuten Hirngewebsschädigungen sollte differenzialdiagnostisch auch an eine neurodegenerative Erkrankung gedacht werden. In Kombination mit dem Protein 14-3-3 kann das Gesamt-tau insbesondere zur Abgrenzung einer Demenz vom Alzheimer Typ richtungsweisend sein (Skillbäck et al. 2014). Hier zeigen neuere Untersuchungen, dass insbesondere das nicht phosphorylierte Tau hilfreich bei der Unterscheidung zwischen einer Alzheimer Demenz und einer CJK sein könnte (Ermann et al. 2018).

\subsubsection{PrPSc-Aggregationsassay}

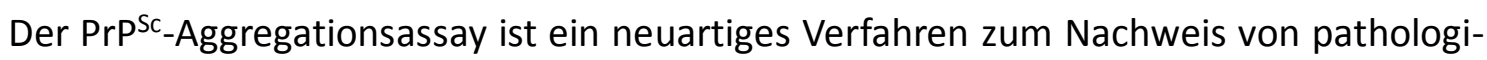
schem Prionprotein im Liquor von erkrankten Patienten. Unter Zugabe von rekombinantem Prionprotein $\left(\mathrm{PrP}^{\mathrm{c}}\right)$ zum Liquor wird die selbstreplizierende Eigenschaft des $\operatorname{PrP} \mathrm{P}^{\mathrm{Sc}}$ genutzt, um in mehreren Amplifikationsschritten das pathologische Prionprotein über 
eine bestimmte Nachweisgrenze anzureichern (Atarashi et al. 2011a; Cramm et al. 2015). In Studien wurde für diesen Test eine variierende Sensitivität von 80\% (Atarashi et al. 2011b) über $85 \%$ (Cramm et. al 2015) bis $89 \%$ (McGuire et al. 2012) sowie eine Spezifität von 99\% (McGuire et al. 2012; Cramm et al. 2015) bzw. 100\% (Atarashi et al. 2011b) ermittelt. In einer aktuellen Untersuchung zur Validierung und Reproduzierbarkeit von Testergebnissen zeigten sich eine Sensitivität von $85 \%$ und eine Spezifität von 99\%. Auch bei langen Lagerungszeiten bis zu neun Jahren und unterschiedlichen Lagerungsbedingungen (Raumtemperatur, $4^{\circ} \mathrm{C},-80^{\circ} \mathrm{C}$ ) sowie bei wiederholtem Einfrieren und Auftauen der Liquorproben konnte keine Verfälschung der Testergebnisse nachgewiesen werden. Die relevante Kontamination des Liquors mit Erythrozyten hingegen führt zu falsch negativen Ergebnissen (Cramm et al. 2016). Eine internationale Studie mit zwei Ringversuchen zur Verlässlichkeit und Reproduzierbarkeit des RT-QuIC erreichte eine Gesamtsensitivität von $85 \%-100 \%$ bei einer 100\% Gesamtspezifität (McGuire et al. 2016).

In mehreren Studien der letzten Jahre konnte die hohe Sensitivität und Spezifität des RTQuIC durch retrospektive Untersuchungen nochmals bestätigt werden. So berichten insbesondere Foutz et al. (2017) eine Sensitivität von 92\% und eine Spezifität vom 98,5\% und Rudge et al. (2018) eine Sensitivität von $87 \%$ und eine Spezifität von $100 \%$ für die RT-QulC-Untersuchung.

\subsection{Neuropathologische Diagnostik der Creutzfeldt-Jakob-Erkrankung}

Die endgültige und sichere Diagnosestellung kann nur nach Versterben des Patienten im Rahmen einer neuropathologischen und histochemischen Untersuchung und Diagnostik von Hirngewebe erfolgen. Neben der bereits makroskopisch sichtbaren deutlichen Atrophie des Gehirns sind die histopathologischen und immunhistochemischen Untersuchungen ausschlaggebend. In der histopathologischen Untersuchung gilt die Trias aus Neuronenverlust, Gliose, v.a. astrozytär und mikroglial, sowie spongiformen Veränderungen als typischer Befund (Budka 2003).

\subsection{Molekulare Subtypen der Creutzfeldt-Jakob-Erkrankung}

In Bezug auf die am häufigsten verwendete Einteilung nach P. Parchi werden - abhängig vom Polymorphismus der Aminosäuren Methionin und Valin am Codon 129 
(MM/MV/VV) sowie den beiden durch die molekularen Masse definierten Prionproteintypen (PrPSc Typ 1/Typ2) - sechs Subtypen der CJK unterschieden. Diese zeichnen sich durch unterschiedliche klinische Verläufe bezüglich Erkrankungsdauer, Symptomatik und Befunden in der apparativen Diagnostik aus (Parchi et al. 1999).

Neben dieser Einteilung gibt es weitere Unterscheidungen, die hier nicht berücksichtig werden.

Im Folgenden soll ein kurzer Überblick über die häufigsten Subtypen anhand ihrer Besonderheiten im klinischen Verlauf und in der Diagnostik gegeben werden.

\subsubsection{Klinischer Verlauf}

In Europa werden am häufigsten der MM1- und MV1-Subtyp beobachtet (Parchi et al. 1999). Zusammen machen sie $70 \%$ der sporadischen Fälle aus und zeigen den klassischen Verlauf einer CJK mit rasch progredienter Demenz zu Beginn der Erkrankung sowie Myoklonien und kortikalen Sehstörungen. Die Patienten versterben nach kurzem Krankheitsverlauf (vier Monate) im akinetischen Mutismus (Zerr und Poser 2001; Parchi und Saverioni 2012).

Beim zweithäufigsten Subtyp VV2 (14\%) manifestiert sich mit der Ataxie in der Regel zunächst eine zerebellare Symptomatik. Die dementielle Entwicklung tritt erst im Verlauf der Erkrankung hinzu. Die Erkrankungsdauer liegt hier mit sieben Monaten etwas über dem Durchschnittswert von sechs Monaten (Zerr und Poser 2001; Parchi und Saverioni 2012).

Der MV2-Subtyp ist ebenfalls durch ein ataxiebetontes Symptombild zu Beginn der Erkrankung gekennzeichnet. Häufig wird auch eine Symptomkombination aus Demenz und Ataxie als initiale Symptomatik beobachtet. Im Verlauf treten psychiatrische Symptome, extrapyramidale Symptomatik und Myoklonien hinzu (Krasnianski et al. 2006). Die Patienten leben doppelt so lange (zwölf Monate) wie der Durchschnitt der Patienten (Parchi et al. 1999; Krasnianski et al. 2006; Parchi und Saverioni 2012).

Der VV2- und MV2-Subtyp werden auf Grund des beschriebenen Verlaufs und im Gegensatz zur klassischen CJK auch als ataktischer Subtyp bezeichnet. 
VV1-und MM2-Subtypen sind mit jeweils zwei bis drei Patienten pro Jahr sehr selten und unterscheiden sich insbesondere durch ihre langen Krankheitsverläufe von 14 Monaten (MM2) und 18 Monaten (VV1) von der klassischen CJK. Patienten mit dem VV1-Subtyp erkranken in der Regel sehr früh mit durchschnittlich 44 Jahren (Krasnianski et al. 2006). Klinisch manifestieren sich beide Subtypen zunächst mit einer Demenz, der VV1-Subtyp entwickelt, ähnlich wie der MV2-Subtyp zusätzlich eine Ataxie und extrapyramidale Störungen (Parchi et al. 1999; Schelzke und Zerr 2010). Der MM2-Subtyp lässt sich nochmals in eine kortikale und eine thalamische Verlaufsform unterteilen. Die thalamische Form wird auch als sporadische tödliche Insomnie bezeichnet, da sie dem Verlauf der FFI stark ähnelt, ohne dass molekulargenetisch eine bekannte Mutation nachgewiesen werden kann (Puoti et al. 2012).

\subsubsection{Apparative Diagnostik}

Der folgende Abschnitt beschäftigt sich mit den subtypenspezifischen Unterschieden, unter anderem in Bezug auf Sensitivität der relevanten Diagnostik.

\subsubsection{Proteine 14-3-3}

Generell konnte bei Analysen der Sensitivität der Proteine 14-3-3 in den unterschiedlichen Subtypen eine höhere Sensitivität für homozygote Merkmalsträger am Codon 129 (MM, VV) beobachtet werden (Krasnianski et al. 2004). So konnte in der Untersuchung von K. Gmitterová (2009) eine Sensitivität von 100\% der Proteine 14-3-3 mittels ELISA für die MM1-, VV1- und VV2-Subtypen ermittelt werden. MV1- und MV2-Subtypen zeigten eine Sensitivität von jeweils $89 \%$. Die Sensitivität für den kortikalen MM2-Typ (MM2c) fiel mit 75\% am niedrigsten unter allen Subtypen aus (Gmitterová et al. 2009; Heinemann et al. 2007).

\subsubsection{2 $\mathrm{CMRT}$}

Die Befundmuster im cMRT variieren zwischen den verschiedenen Subtypen und werden im Folgenden beschrieben. 
Beim MM1- und MV1-Subtyp sind in der DWI-Wichtung häufig kortikale Hyperintensitäten sowie Hyperintensitäten der Basalganglien auffällig. Die betroffenen kortikalen Regionen sind ebenfalls abhängig vom Subtyp. Der MM1-Subtyp zeigt hier vorrangig frontale und parietale Hyperintensitäten, beim MV1-Typ sind die Hippocampusregion sowie der insuläre Cortex betroffen. Thalamische Hyperintensitäten werden in diesen beiden Subtypen in der Regel nicht beobachtet (Meissner et al. 2009; Puoti et al. 2012).

Die beiden ataktischen Subtypen VV2 und MV2 ähneln sich auch in den cMRT-Befunden. Diese zeigen in der Regel Hyperintensitäten der Basalganglien und des Thalamus. Falls kortikale Diffusionsrestriktionen auffällig sind, sind diese häufig im Gyrus cinguli zu finden.

Der seltene VV1-Subtyp zeichnet sich durch vorwiegend kortikale Befunde aus. Am häufigsten finden sich Hyperintensitäten im Gyrus cinguli, gefolgt vom insulären Cortex und der Temporalregion. Hyperintensitäten in den Basalganglien oder Thalamus finden sich in der Regel nicht.

Der thalamische MM2-Subtyp zeigt typischerweise keine cMRT Auffälligkeiten. Der kortikale Subtyp zeigt kortikale Hyperintensitäten in der Temporalregion. Basalganglienhyperintensitäten sind in diesem Subtyp eher selten zu finden (Meissner et al. 2009; Puoti et al. 2012).

\subsubsection{EEG}

Zur Sensitivität und Spezifität des EEG der verschiedenen Subtypen gibt es wenige Untersuchungen. Im Review von G. Puoti variiert die Sensitivität zwischen den Subtypen von 8\% (MV2) bis 73\% (MM1/MV1). Die Sensitivität für alle Subtypen liegt hier bei 44\% und ist auch abhängig vom Krankheitsstadium (Puoti et al. 2012).

\subsection{Diagnosekriterien für die sporadische Creutzfeldt-Jakob-Erkrankung}

Die Leitlinien der DGN von 2012 für die Diagnosestellung einer wahrscheinlichen oder möglichen Creutzfeldt-Jakob-Erkrankung gehen auf ein epidemiologisches Paper von Collin L. Masters zum weltweiten Vorkommen der sporadischen und familiären CJK aus dem Jahre 1979 zurück. Hier wird rückblickend eine Symptomkombination aus einer 
rasch fortschreitenden Demenz mit wenigstens einer weiteren Auffälligkeiten wie Myoklonien, pyramidale Störung, typisches EEG, zerebellare oder extrapyramidale Störung als wahrscheinliche Creutzfeldt-Jakob-Erkrankung definiert (Masters et al. 1979). Die Kriterien wurden, dem aktuellen Stand der Wissenschaft entsprechend, mehrfach angepasst. So wurden der akinetische Mutismus als zusätzliche klinische Symptomatik sowie der Nachweis des Proteins 14-3-3 im Liquor als Kriterien aufgenommen. 2009 wurden typische cMRT Befunde der CJK (Meissner et al. 2009) ergänzt.

Während der Anfertigung der Dissertation wurden die Diagnosekriterien der DGN überarbeitet und der RT-QuIC mit in die Kriterien aufgenommen. Die Themenstellung der vorliegenden Arbeit bezieht sich jedoch noch auf die alten Kriterien von 2012, wie oben beschrieben, daher werden im Text nur die alten Kriterien dargestellt. Die aktuellen Kriterien von 2018 sind im Anhang angefügt (s. A.1 DGN 2018).

Tabelle 2: Klinische Diagnosekriterien der CJK in Deutschland gemäß DGN 2012

Kriterien für eine sporadische CJK:

Progressive Demenz +

Zwei der folgenden klinischen Erscheinungen

- Moyklonus

- Visuelle oder zerebellare Symptome

- Pyramidale oder extrapyramidale Störung

- Akinetischer Mutismus

Mindestens ein positiver Befund der technischen Zusatzuntersuchungen

- Periodische sharp wave Komplexe im EEG

- Nachweis der Proteine 14-3-3 im Liquor bei Krankheitsdauer < 2 Jahre

- Hyperintense Basalganglien bzw. mindestens zwei kortikale Regionen (temporal-parietal-okzipital) im MRT in FLAIR und/oder DWI

\subsection{Relevanz der Fragestellung}

Die Creutzfeldt-Jakob-Erkrankung ist eine stets tödlich verlaufende Erkrankung mit kurzer Erkrankungsdauer, für die es derzeit keine kausale Behandlungsmöglichkeit gibt Die Anwendung der Diagnosekriterien soll daher zu einem möglichst verlässlichen Ergebnis führen. Eine verlässliche Diagnosestellung ist für die Arbeit der klinisch tätigen Ärzte, insbesondere bei der differenzialdiagnostischen Abgrenzung gegenüber anderen, potentiell behandelbaren neurologischen Erkrankungen, wichtig. 
Überdies kann eine verlässliche Diagnosestellung auch Angehörigen betroffener Patienten helfen, die Diagnose zu akzeptieren und schnellstmöglich eine umfassende palliativmedizinische Versorgung einzuleiten.

Die Diagnosekriterien von 2012 (DGN) stützen sich, wie bereits erwähnt, auf eine epidemiologische Studie aus dem Jahr 1979. Seither wurden die Kriterien mehrfach durch weitere Untersuchungsmethoden (cMRT im Jahr 2009) ergänzt. Diese Erweiterung der Diagnosekriterien wurde durch neue medizinische Erkenntnisse erforderlich. Hierbei wurde lediglich der zusätzliche Nutzen der jeweils einzelnen Untersuchung analysiert. Eine umfassende Prüfung der bestehenden Kriterien in ihrer Gesamtheit wurde in Deutschland bisher nicht durchgeführt.

Die folgende Untersuchung soll die Diagnosekriterien hinsichtlich des Auftretens relevanter Symptomatik im Krankheitsverlauf, Effizienz der erforderlichen Diagnostik sowie der Effizienz der Diagnosekriterien analysieren.

Weiterhin gibt es mit der $\mathrm{PrP}^{\mathrm{Sc}}$-Aggregationsassay neuere diagnostische Möglichkeiten, deren Nutzen in mehreren Studien belegt werden konnte (Atarashi et al. 2011b; Cramm et al. 2015; Hermann et al. 2018). Auf Grund dieser Möglichkeiten soll weiterhin der potentielle Nutzen des PrPSc-Aggregationsassay im Rahmen der Diagnosekriterien geprüft und aufgezeigt werden. 


\section{Material Und Methoden}

\subsection{Studiendesign}

Da es sich bei der bei der CJK um eine seltene Erkrankung handelt, wird in der vorliegenden Dissertation ein retrospektives Studiendesign gewählt, um auf einen möglichst großen Datensatz zurückgreifen zu können. Weiterhin spielt auch die Tatsache, dass eine Sicherung der CJK-Diagnose nicht zu Lebzeiten möglich ist, sondern nur post mortem bestätigt bzw. ausgeschlossen werden kann, eine Rolle bei der Gestaltung des Studiendesigns.

Hier ist der Grundgedanke, auf bereits abgeschlossene Fälle, bei denen eine eindeutige Diagnose vorliegt, sowohl im Fall- als auch im Kontrollkollektiv zurückzugreifen. Anhand bereits vorliegender, zu Lebzeiten erhobener Befunde sowie nachträglich im Rahmen der Studie auf der Basis vorhandenen Liquors durchgeführter Tests (RT-QuIC) soll die Qualität der Diagnoseinstrumente beurteilt und ein Vorschlag zur Verbesserung der Diagnosekriterien entwickelt werden.

Da es klinisch einige Differenzialdiagnosen gibt, die mit einer deutlich höheren Inzidenz als die CJK auftreten, und die klinische Abgrenzung zu diesen Erkrankungen häufig nicht eindeutig möglich ist, wurden lediglich sicher diagnostizierte CJK-Fälle bzw. sicher ausgeschlossene CJK-Fälle in die Studie aufgenommen. So soll eine Beeinflussung durch diesbezügliche Unsicherheiten und durch eventuell falsche Kollektivzuordnung (Fall vs. Kontrolle) vermieden werden.

Um das Vorliegen aller notwendigen Daten sicherzustellen und einen bestmöglichen Vergleich der Gruppen zu ermöglichen, wurden die Patienten für das Fall- und das KontrollKollektiv aus derselben Datenbank des NRZ für TSE akquiriert wurden. Daraus ergibt sich, dass die Patienten des Kontrollkollektivs ähnliche Symptome wie bei einer CJK, mit in der Regel schwerem enzephalopathischem Verlauf, aufweisen. Auf eine breitere Fächerung des Kontroll-Kollektivs wurde zu Gunsten der Vollständigkeit des Datensatzes verzichtet. Die Nachteile dieses Vorgehens werden im Abschnitt 4.2. diskutiert. 
Wie bereits erwähnt wurde für die ausgewählten Patienten, jeweils an eingelagertem Liquor, eine RT-QulC-Untersuchung durchgeführt. Die Klärung des Nutzens der RT-QulCUntersuchung bei der Diagnosestellung einer CJK ist zentraler Bestandteil der Studie.

\subsection{Erhebung der Daten}

Die erhobenen Daten stammen aus der Datenbank des nationalen Referenzzentrums für transmissible spongiforme Enzephalopathien. Das nationale Referenzzentrum akquiriert die Daten unter anderem im Rahmen einer konsiliarischen Mitbeurteilung von Patienten mit Verdacht auf eine Prionerkrankung. Neben einer telefonischen Beratung der behandelnden Ärzte kann mit dem Einverständnis der Patienten oder ihrer gesetzlichen Betreuer nach Übersendung einer Epikrise sowie der Ergebnisse der apparativen Diagnostik (EEG, cMRT, weitere Liquordiagnostik) eine umfassende differenzialdiagnostische Mitbeurteilung erfolgen.

Wird die Diagnose einer wahrscheinlichen oder möglichen CJK gestellt, bietet die Arbeitsgruppe einen persönlichen Besuch vor Ort an, um im Gespräch mit den Angehörigen über die Erkrankung und deren Verlauf sowie über die Möglichkeit einer genetischen Testung zu informieren. In den meisten Fällen wird bei den Patienten die häufigste Form einer Prionerkrankung, eine sporadische Creutzfeldt-Jakob-Erkrankung, vermutet. Die weit selteneren genetischen Erkrankungen sind meist durch eine positive Familienanamnese bezüglich einer Demenzerkrankung sowie einen prologierten Verlauf der Erkrankung gekennzeichnet. Eine Diagnose kann nur bei Nachweis einer Mutation im Prionproteingen mit passender Klinik gestellt werden.

Über einen Fragebogen zur „Epidemiologie und Frühdiagnostik der humanen spongiformen Enzephalopathien“ werden weitere Daten zum Patienten erhoben. Im Rahmen dieser Erhebung werden auch anamnestische Daten zum Krankheitsverlauf erfragt und es erfolgt eine klinisch-neurologische Untersuchung des Patienten. Die Erfassung der klinisch relevanten Daten erfolgt ebenfalls nach Einwilligung des Patienten der des gesetzlichen Betreuers. Weiterhin werden Einwilligungen zur wissenschaftlichen Nutzung des Bildmaterials sowie zur Überlassung der vorhandenen Bioproben für Forschungszwecke eingeholt. Falls zur Diagnosesicherung gewünscht übernimmt das Referenzzentrum die Organisation sowie die Kosten für eine Obduktion. 
Da die klinische Diagnosestellung der CJK nicht immer eindeutig möglich ist, wurden auch die Daten zahlreich Patienten erhoben, bei denen in der Obduktion eine CJK ausgeschlossen werden konnte. Diese Patienten dienen in dieser Studie als Kontroll-Kollektiv.

Alle erhobenen Daten werden anhand einer vom Referenzlabor in Göttingen vergebenen Nummer anonymisiert und archiviert.

\subsubsection{Das Patientenkollektiv}

Das Patientenkollektiv wurde aus der Datenbank des NRZ für TSE in Göttingen nach verschiedenen, für die Fragestellung relevanten Kriterien ausgewählt. Die Erkrankungsdauer bezieht sich auf das Auftreten der ersten erkrankungsrelevanten Symptomatik bis zum Versterben der Patienten. Für die Erfassung der klinischen Symptomatik im Verlauf wird die Erkrankungsdauer in jeweils in etwa gleich lange Drittel unterteilt. 


\subsubsection{Das Fallkollektiv}

Für das Fallkollektiv wurden 107 Patienten aus den Jahren 2001 bis 2014 nach folgenden Kriterien ausgewählt:

Tabelle 3: Einschlusskriterien Fallkollektiv

\begin{tabular}{|l|c|}
\hline Einschlusskriterien Fallkollektiv & $\begin{array}{l}\text { Anzahl der Pati- } \\
\text { enten die das } \\
\text { Kriterium erfül- } \\
\text { len }\end{array}$ \\
\hline $\begin{array}{l}\text { Neuropathologische Diagnose aus dem Referenzzentrum für spon- } \\
\text { giforme Enzephalopathien München oder Göttingen: sichere CJK }\end{array}$ & $107 / 107$ \\
\hline $\begin{array}{l}\text { Ausschluss einer genetischen Ursache für die CJK anhand einer } \\
\text { PRNP-Analyse }\end{array}$ & $107 / 107$ \\
\hline $\begin{array}{l}\text { Vorliegen relevanter klinischer Daten sowie Befunde der folgenden } \\
\text { apparativen Zusatzdiagnostik: } \\
\text { Klinische Daten: Geburtsdatum, Zeitpunkt des ersten Symptoms so- } \\
\text { wie Sterbedatum zur Berechnung der Erkrankungsdauer, Alter bei } \\
\text { Erkrankungsbeginn, klinische Daten zum Krankheitsverlauf (Symp- } \\
\text { tomatik; weiter relevante Befunde) }\end{array}$ & $107 / 107$ \\
\hline $\begin{array}{l}\text { cMRT: aus dem relevanten Erkrankungszeitraum mit DWI und } \\
\text { FLAR-Wichtung in ausreichender Qualität }\end{array}$ & $106 / 107$ \\
\hline $\begin{array}{l}\text { EEG: } \\
\text { Vorliegen repräsentativer Ausschnitte des EEG oder EEG-Be } \\
\text { funde aus dem relevanten Erkrankungszeitraum }\end{array}$ & $107 / 107$ \\
\hline $\begin{array}{l}\text { Liquordiagnostik: } \begin{array}{l}\text { Proteine 14-3-3 } \\
\text { Resamt-tau }\end{array} \\
\text { RulC/ PrPSc-Aggregationsassay }\end{array}$ & $107 / 107$ \\
\hline
\end{tabular}




\subsubsection{Das Kontrollkollektiv}

Für das Kontrollkollektiv wurde 68 Patienten aus den Jahre 2001 bis 2014 nach folgenden Kriterien ausgewählt:

Tabelle 4: Einschlusskriterien Kontrollkollektiv

\begin{tabular}{|c|c|c|}
\hline \multicolumn{2}{|c|}{ Einschlusskriterien Kontrollkollektiv } & $\begin{array}{l}\text { Anzahl der Pati- } \\
\text { enten, die das } \\
\text { Kriterium erfül- } \\
\text { len }\end{array}$ \\
\hline \multicolumn{2}{|c|}{$\begin{array}{l}\text { Neuropathologische Diagnose aus dem Referenzzentrum für spon- } \\
\text { giforme Enzephalopathien München oder Göttingen: keine CJK }\end{array}$} & $68 / 68$ \\
\hline \multicolumn{2}{|c|}{$\begin{array}{l}\text { Vorliegen relevanter klinischer Daten sowie Befunde der folgen- } \\
\text { den apparativen Zusatzdiagnostik: } \\
\text { Klinische Daten: Geburtsdatum, Zeitpunkt erstes Symp- } \\
\text { tom, Sterbedatum zur Berechnung der Erkrankungsdauer, } \\
\text { Alter bei Erkrankungsbeginn, klinische Daten zum Krank- } \\
\text { heitsverlauf (Symptomatik; weiter relevante Befunde) }\end{array}$} & $68 / 68$ \\
\hline \multicolumn{2}{|c|}{$\begin{array}{l}\text { cMRT: aus dem relevanten Erkrankungszeitraum mit DWI und } \\
\text { FLAR-Wichtung in ausreichender Qualität }\end{array}$} & $57 / 68$ \\
\hline \multicolumn{2}{|c|}{$\begin{aligned} \text { EEG: } & \text { Vorliegen repräsentativer Ausschnitte des EEG oder EEG- } \\
& \text { Befunde aus dem relevanten Erkrankungszeitraum }\end{aligned}$} & $66 / 68$ \\
\hline Liquordiagnostik & $\begin{array}{l}\text { Proteine } 14-3-3 \\
\text { Gesamt-tau } \\
\text { RT-QuIC/PrPSc-Aggregationsassay }\end{array}$ & $68 / 68$ \\
\hline \multicolumn{2}{|c|}{$\begin{array}{l}\text { PRNP-Analyse zum Ausschluss einer relevanten Mutation durchge- } \\
\text { führt }\end{array}$} & $16 / 68$ \\
\hline
\end{tabular}

\subsection{Die Diagnosekriterien}

In der folgenden Analyse der erhobenen Daten wurden die Kriterien der DGN von 2012 angewendet.

\subsubsection{Klinische Symptomatik}

Die klinische Symptomatik des Erkrankungszeitraums wurde anhand der vorliegenden Arztbriefe, Epikrisen und Studieninterviews der Studie zur „Epidemiologie und Frühdiagnostik humaner spongiformer Enzephalopathien“ entnommen. Zur besseren Beurteilung bezüglich des Auftretens der Symptomatik (Frühsymptomatik vs. Spätsymptomatik) 
wurde die Erkrankungsdauer in Drittel unterteilt. Hierbei definiert der Zeitpunkt des erstmaligen Auftretens eines Symptoms die Zugehörigkeit zum jeweiligen Drittel.

\subsubsection{Diagnostik}

Im Folgenden werden die Kriterien erläutert nach denen die vorliegende Diagnostik des eingeschlossenen Patientenkollektivs als „typisch“ oder „nicht typisch“ für eine CJK gewertet wurden.

\subsubsection{EEG}

Die vorliegenden EEGs wurden anhand der in Kapitel 1.5.1 beschrieben Kriterien nach Steinhoff 1998 als „typisch“ oder „nicht typisch“ für eine CJK bewertet. EEGs, die als nicht typisch bewertet wurden, können entweder unauffällig sein oder aber Allgemeinveränderungen sowie einzelne Sharp-Wave-Komplexe zeigen, die die Kriterien nicht erfüllen.

\subsubsection{2 cMRT}

Die vorliegenden cMRTs wurden gemäß der in den Diagnosekriterien aufgeführten charakteristischen Befunde nach Zerr et al. (2009), wie sie in Kapitel 1.5.2 beschrieben wurden, beurteilt und bei Erfüllung der Kriterien als positiv bewertet. cMRT-Befunde, die Auffälligkeiten zeigen, die jedoch nicht mit den Kriterien übereinstimmen oder die Kriterien nicht vollständig erfüllen, wurden als „nicht typisch“ bewertet.

\subsubsection{Proteine 14-3-3}

Die Bestimmung der Proteine 14-3-3 mittels Western Blot erfolgte für alle Patienten des Fall- und des Kontrollkollektivs. Der Western Blot dient als Methode zum Nachweis von Proteinen. Hierbei werden die Proteine zunächst mittels Elektrophorese aufgetrennt und in einem zweiten Schritt mittels eines spezifischen Antikörpers nachgewiesen. Die Untersuchung erfolgt standardisiert anhand des Göttinger Protokolls für das Immunoblotting der Proteine 14-3-3 im Liquor und wurde ausschließlich im Referenzlabor für diese Diagnostik am Universitätsklinikum Göttingen durchgeführt. 


\subsubsection{Gesamt-tau-Protein}

Die ermittelten Gesamt-tau-Werte wurden zum Teil im Fremdlabor in den behandelnden Kliniken bestimmt und zu Zwecken der konsiliarischen Mitbeurteilung an das NRZ für TSE übermittelt. Ein Teil der Gesamt-tau-Werte wurde durch das neurochemische Labor der Universitätsmedizin Göttingen (UMG) im Rahmen der durch die behandeInde Klinik angeforderten Diagnostik bestimmt. Hierfür wurde jeweils ein ELISA-Test zur quantitativen Bestimmung des absoluten Zahlenwertes des Gesamt-tau in pg/ml durchgeführt. Der Referenzbereich für das Gesamt-tau liegt bei Werten von kleiner oder gleich $450 \mathrm{pg} / \mathrm{ml}$. Bei den Prionerkrankungen gelten allerdings erst Werte ab 1300 pg/ml als relevant erhöhte Werte. (Otto et al. 1997). Für zwölf Patienten beider Kollektive wurde zur Vervollständigung der Werte das Gesamt-tau im neurochemischen Labor der UMG nachgemessen.

\subsubsection{PrPSc-Aggregationsassay}

Der PrP ${ }^{\mathrm{Sc}}$-Aggregationsassay ist ein neues Verfahren, das erst seit Kurzem in der Diagnostik der CJK genutzt wird; daher wird auf die labortechnische Durchführung im Weiteren genauer eingegangen.

Der PrPSc-Aggregationsassay oder RT-QuIC nutzt ein künstlich hergestelltes, also rekombinantes Prionprotein, um das im Liquor in geringen Mengen vorkommende pathologische Prionprotein über eine Nachweisgrenze zu vermehren. Das rekombinante Prionprotein wird durch das pathologische Prionprotein, indem dessen Neigung zur Aggregation ausgenutzt wird, in die krankhafte Form umgewandelt. Im aggregierten Zustand kann es in Echtzeit durch einen Thioflavin-T-haltigen Fluoreszenzfarbstoff angefärbt und so der Anstieg des pathologischen Prionproteins in Echtzeit gemessen werden. Der benutzte Reaktionspuffer besteht aus 162 mM Phosphatpuffer (pH 6,9), 70 mM Sodiumchloride, $1 \mathrm{mM}$ Ethylenediaminetetraaceticacid, $10 \mu \mathrm{M}$ Thioflavin-T und 0,1 mg/ml rekombinanten PrP. Zu $85 \mu$ l dieses Reaktionspuffers werden $15 \mu$ l des frisch aufgetauten Patientenliquors hinzugegeben, so dass sich ein Endvolumen von $100 \mu$ l ergibt. Die Reaktion wird auf optischen Bodenplatten vorbereitet. Die Platten werden versiegelt und in einem Plattenlesegerät bei $42^{\circ} \mathrm{C}$ für 80 Stunden inkubiert. Während dieser Zeit werden die Proben 
abwechselnd für eine Minute bei maximaler Geschwindigkeit (600 rpm) doppelt kreisförmig geschüttelt, gefolgt von einer einminütigen Pause.

Die Neigung zur Umformung in die Beta-Faltblatt-Formation wird durch die Messung des Thioflavin-T(ThT)-fluorescent-Signals (450 nm Stimulus und $480 \mathrm{~nm}$ Emissionen) alle 30 Minuten in relative fluorescence units ( $\mathrm{rfu}$ ) ermittelt. Das Ergebnis der Testung wird als positiv bewertet, wenn der maximale Wert der Probe über 10.000 rfu innerhalb von 80 Stunden ansteigt. Bleibt der maximale Wert während der Messzeit unter 10.000 rfu wird das Ergebnis als negativ bewertet (Cramm et al. 2015).

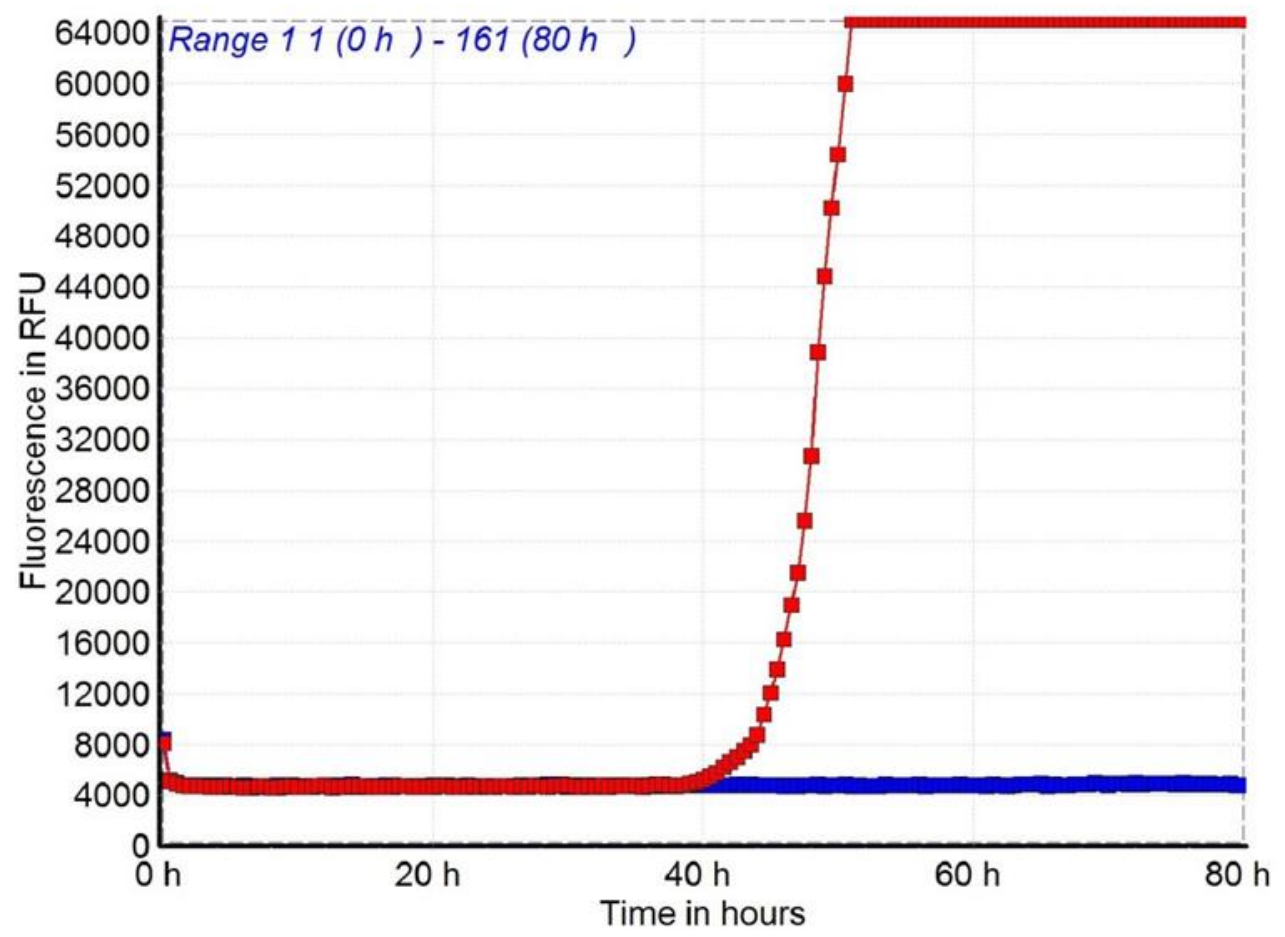

Abbildung 2: Graphische Darstellung Auswertung RT-QuIC

rot: CJK-Probe, blau: Kontrolle; Time in hours = Zeit in Stunden; Range = Spannweiter; rfu = relative fluorescence units

\subsection{Genetische Testung}

Zur Durchführung einer genetischen Analyse des Prionproteingens im Hinblick auf krankheitsrelevante Mutationen im Sinne einer diagnostischen Testung muss die schriftliche Einwilligung des Patienten oder des gesetzlichen Betreuers vorliegen.

Für die genetische Analyse wird zunächst die DNA aus dem vorliegenden Gewebe isoliert und dann eine PCR durchgeführt. Nach Aufreinigung des PCR-Produktes erfolgt die Sequenzierung. 
Für das vorliegende Fallkollektiv wurde eine Mutation am Prionproteingen ausgeschlossen. Im Kontrollkollektiv wurde eine genetische Prionerkrankung bei 16 Patienten mittels genetischer Analyse ausgeschlossen. Bei 52 Patienten wurde keine genetische Diagnostik durchgeführt, da hierzu keine Einwilligung vorlag.

Die Diagnostik wurde bei allen Patienten anhand von Vollblut oder Hirngewebe im Referenzzentrum für spongiforme Enzephalopathien München durchgeführt.

\subsection{Neuropathologische Diagnosesicherung}

Wie bereits in der Einleitung erwähnt wurde, kann die sichere Diagnose einer CJK nur neuropathologisch gestellt werden. Hierzu ist die feingewebliche Untersuchung von Hirngewebe im Rahmen einer Obduktion oder einer Biopsie nötig. Zur Durchführung einer Gehirnobduktion post mortem muss eine Einwilligung des Patienten oder des gesetzlich bestimmen Betreuer vorliegen. In der vorliegenden Untersuchung wurde bei allen 108 Patienten des Fallkollektives eine pathologische Diagnosesicherung durch Obduktion durchgeführt. Bei den 68 Patienten im Kontrollkollektiv wurde bei einer Obduktion post mortem eine andere Diagnose gestellt und somit eine CJK ausgeschlossen.

Ein Teil des entnommenen Hirngewebes wird für die Prionproteintypisierung bei Temperaturen zwischen -20 und $-80^{\circ} \mathrm{C}$ tiefgefroren. Der größte Teil wird in Formalin fixiert. Danach wird das Hirngewebe seziert; $5 \mathrm{~mm}$ dicke Blöcke werden für eine Stunde in konzentrierter Ameisensäure (96-98\%) dekontaminiert. Anschließend wird die Ameisensäure ausgespült und eine Nachfixierung der dekontaminierten Blöcke in frischem Formalin durchgeführt. Die feingewebliche Beurteilung anhand der typischen histologischen Merkmale einer CJK (spongiforme Vakuolisierung, Nervenzellverlust, astrozytäre Gliose) erfolgt in 5 verschiedenen Hirnregionen: Neokortex, limbischer Kortex, subkortikale Kerngebiete, Kleinhirn, Hirnstamm (Matschke und Hagel 2015). Die spongiformen Veränderungen werden als diffuse oder fokal gebündelte, ovale oder runde Vakuolen beschrieben. Diese finden sich in den tiefen kortikalen Schichten der grauer Substanz sowie zerebellar ebenfalls in der grauen Substanz (Budka 2003).

Zur Sicherung der histopathologischen Diagnostik erfolgt ein immunhistochemischer Nachweis des pathologischen Prionproteins mittels Westernblot, ELISA oder Immuno- 
blot an parafin- oder formalinfixiertem Gewebe. Da, wie bereits erwähnt, die neuropathologischen Veränderungen auch fokal auftreten können, sollte die immunhistochemische Untersuchung aus mehreren Blöcken aus unterschiedlichen Gehirnregionen erfolgen (Budka 2003).

Tabelle 5: Neuropathologische Kriterien für die CJK und andere Prionerkrankungen (nach Budka 2003)

\section{Neuropathologische Diagnosekriterien}

1. Spongiforme Enzephalopathie im ze-

Sporadisch CJK

latrogen CJK

familiär/genetisch auftretende CJK

(ein Verwandter 1. Grades erkrankt oder bekannte PrP-assoziierte Gen-Mutation in der Familie) rebralen und/oder zerebellaren und/oder in der subkortikalen grauen Substanz; und/oder

2. Enzephalopathie mit immunhistologischen Ansammlungen des pathologischen Prionproteins (Plaques und/oder diffus synaptischer und/oder perivakulärer Typ)

\subsection{Statistische Auswertung der Daten}

Liegt die Irrtumswahrscheinlichkeit einer Aussage bei oder unter fünf Prozent $(p<0,05)$ wird sie als statistisch signifikant bezeichnet. Das Konfidenzintervall ist also mit 95\% festgelegt.

Für die statistische Auswertung der Daten wurden zur deskriptiven Statistik sowohl Excel als auch das statistische Auswertungsprogramm Statistica benutzt. Hierbei wurden mittels Häufigkeitstabellen und gestapelten Vier-Felder-Tafeln die Auftretenswahrscheinlichkeit sowie Sensitivität und Spezifität der apparativen Diagnostik und der etablierten Diagnosekriterien berechnet. Häufigkeiten wurden für das Fall- und Kontrollkollektiv gesondert erhoben.

Die weitergehende statistische Analyse der relevanten Parameter wurde mittels einer logistischen Regressionsanalyse in „ $\mathrm{R}^{\prime \prime}$ durchgeführt. Für die Auswertung in R gelten folgende Signifikanzkodierungen: 


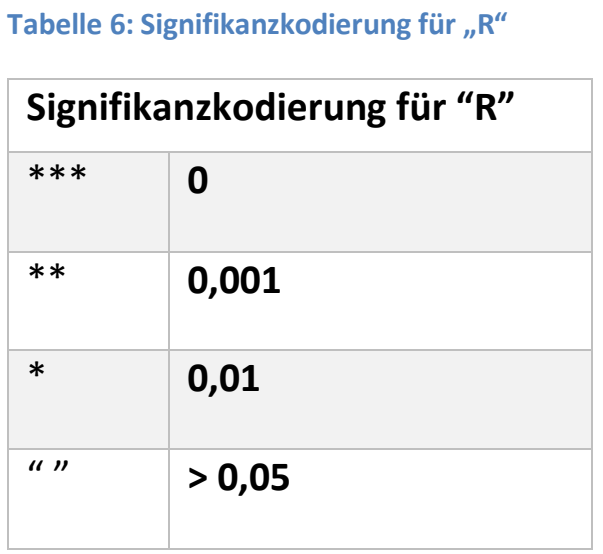

Des Weiteren wurde eine binominale logistische Regressionsanalyse durchgeführt, um den Einfluss der klinischen Symptomatik und apparativen Diagnostik auf die korrekte Vorhersage über das Vorliegen einer Prionerkrankung zu überprüfen. Das „endgültige Modell“ wurde durch Screening aller erhobenen klinischen Symptomatik und apparativen Diagnostik auf Reduzierung aller signifikanten Parameter entwickelt. Als Informationskriterium für das erarbeitete Modell wurde das AIC (Akaike information criterion) herangezogen. Dieses lässt eine Aussage über die Anpassungsgüte des genutzten Modells an die vorhandene Stichprobe zu. Nach Etablierung eines geeigneten Modells für die relevanten Parameter wurden die errechneten $\mathrm{p}$-Werte mittels Wald-Test als interferenzstatistisches Verfahren überprüft. Zur besseren Interpretation der Regressionskoeffizienten wurden diese zunächst durch Exponenzieren in Effektkoeffizienten umgewandelt; nach einer weiteren mathematischen Umformung wurde die Wahrscheinlichkeit des Vorliegens einer CJK bei Positivität der ermittelten Parameter berechnet.

Zur internen Validierung der berechneten Ergebnisse wurde ein Training-Data-Set genutzt. Diese Validierung ist notwendig, um ein Überschätzung der errechneten Werte für Sensitivität und Spezifität bezogen auf das gesamte Patientenkollektiv auszuschließen. Zur Validierung der Daten aus dem Training-Data-Set wurde eine Kreuzvalidierung (= cross-validation) mit zehn Durchläufen bei zufälligen Teilung der Daten im Verhältnis 0.7 durchgeführt. 


\section{ERGEBNISSE}

\subsection{Deskriptive Statistik der untersuchten Patientenkollektive}

Insgesamt wurden die Fälle von n=175 Patienten betrachtet und ausgewertet. Das untersuchte Kollektiv besteht aus 78 männlichen Patienten und 97 weiblichen Patientinnen.

Das Fallkollektiv besteht aus $n=107$ Patienten, hiervon sind 45 männlich und 62 weiblich. Das Geschlechterverhältnis männlich : weiblich im Fallkollektiv liegt bei 1:1,38.

Das mediane Erkrankungsalter liegt hier bei 65,83 Jahren. Der jüngste Patient erkrankte im Alter von 19,25 Jahre, der älteste im Alter von 82,04 Jahre. Die mediane Erkrankungsdauer beträgt 5,43 Monaten (Maximum 96,5 Monate, Minimum 1,2 Monate).

Im Kontrollkollektiv sind 33 der $n=68$ Patienten männlich und 35 weiblich. Das Geschlechterverhältnis männlich : weiblich im Kontrollkollektiv beträgt somit 1:1,06.

Das mediane Erkrankungsalter liegt bei 73 Jahre. Der jüngste Patient erkrankte im Alter von 34,95 Jahren, der älteste im Alter von 91,45 Jahren. Die mediane Erkrankungsdauer beträgt 5,3 Monaten (Maximum 226,73 Monate; Minimum 0,33 Monate). 


\subsection{Molekulare Subtypen des Patientenkollektivs}

Durch den Polymorphismus am Codon 129 ergibt sich folgende Genotypverteilung im Fall- und Kontrollkollektiv:

Tabelle 7: Verteilung des Genotyps im Fall- und Kontrollkollektiv

\begin{tabular}{|l|c|c|}
\hline Genotyp & Fallkollektiv (\%) & Kontrollkollektiv (\%) \\
\hline MV & $19(18)$ & $6(9)$ \\
\hline MM & $70(65)$ & $12(18)$ \\
\hline VV & $17(16)$ & $3(4)$ \\
\hline Nicht bestimmt & $1(1)$ & $47(69)$ \\
\hline
\end{tabular}

Eine weitere Unterteilung nach molekularem Subtyp und histologischem Prionproteintyp wurde für 59 der 107 Patienten (55\%) im Fallkollektiv durchgeführt, hieraus ergibt sich folgende Subtypenverteilung:

Tabelle 8: Verteilung molekularer Subtypen im Fallkollektiv

\begin{tabular}{|l|c|}
\hline Subtyp & Anzahl (\%) \\
\hline MM 1 & $36(33)$ \\
\hline MV 1 & $4(4)$ \\
\hline MM 2 & $3(3)$ \\
\hline MV 2 & $2(2)$ \\
\hline VV 1 & $1(1)$ \\
\hline VV 2 & $10(9)$ \\
\hline MM $1 / 2$ & $1(1)$ \\
\hline MV $1 / 2$ & $1(1)$ \\
\hline VV $1 / 2$ & $1(1)$ \\
\hline nicht bestimmt & $48(45)$ \\
\hline
\end{tabular}




\subsection{Neuropathologische Diagnosen im Kontrollkollektiv}

Für die Patienten im Kontrollkollektiv konnte neuropathologische eine CJK ausgeschlossen werden. Für 59 Patienten wurde eine weitergehende neuropathologische Diagnostik durchgeführt, um möglich Ursachen für die klinisch-neurologische Symptomatik zu eruieren. Eine Gehirnobduktion ergab demnach folgende Diagnosen:

Tabelle 9: Neuropathologische Diagnosen im Kontrollkollektiv

\begin{tabular}{|c|l|}
\hline $\begin{array}{c}\text { Anzahl } \\
\text { (n) }\end{array}$ & \multicolumn{1}{|c|}{ Neuropathologische Diagnose } \\
\hline $\mathbf{9}$ & Keine CJK (keine weitergehende neuropathologische Diagnose bekannt) \\
\hline $\mathbf{4}$ & Lewy-Körperchen-Erkrankung \\
\hline $\mathbf{1 1}$ & (Meningo-)Encephalitis viral \\
\hline $\mathbf{5}$ & Encephalitis autoimmun \\
\hline $\mathbf{1}$ & Zerebrales Tumorgeschehen \\
\hline $\mathbf{1}$ & Pontine Myelinolyse \\
\hline $\mathbf{2}$ & Fronto-temporale Demenz \\
\hline $\mathbf{3}$ & Hypoxische Enzephalopathie \\
\hline $\mathbf{4}$ & Metabolische Enzephalopathie \\
\hline $\mathbf{1}$ & Vaskuläre Enzephalopathie \\
\hline $\mathbf{4}$ & Hirninfarkt(e) \\
\hline $\mathbf{2}$ & Hirnblutung \\
\hline $\mathbf{1}$ & Progressiv multifokale Leukenzephalopathie \\
\hline $\mathbf{1}$ & Zerebellare Ataxie (Purkinjezellverlust) \\
\hline $\mathbf{1}$ & Subkorticale arteriosklerotische Enzephalopathie (M.Binswanger) \\
\hline $\mathbf{8}$ & Braak Stadium V-VI (M. Alzheimer) \\
\hline $\mathbf{6}$ & Braak Stadium III-IV (M. Alzheimer) \\
\hline $\mathbf{1}$ & Braak II (M. Alzheimer) + Leukaraiose \\
\hline $\mathbf{1}$ & Neurodegenerative Veränderung andere als CJK oder M. Alzheimer \\
\hline $\mathbf{1}$ & Status cribrosus + Synucleinopathie \\
\hline $\mathbf{1}$ & Globale zerebrale Minderperfusion \\
\hline & \\
\hline
\end{tabular}

\subsection{Die Diagnosekriterien}

Wie bereits in der Einleitung beschrieben werden die Diagnosekriterien der DGN von 2012 zur Untersuchung herangezogen. Die Erkrankungsdauer wurde als Zeitraum zwischen dem ersten aufgetretenen Symptom und dem Sterbedatum berechnet. Die Krankheitsdauer wurde in Krankheitsdrittel aufgeteilt. Die Daten bezüglich der klinischen 
Symptomatik wurden zum einen im Hinblick auf die Gesamthäufigkeit über den gesamten Erkrankungszeitraum als auch im Hinblick auf den Zeitpunkt des Auftretens im Krankheitsverlauf erhoben.

Dasselbe gilt für die Daten bzw. Befunde der apparativen Diagnostik. Hierbei wurden ausschließlich Befunde als positiv gewertet, die die Diagnosekriterien gänzlich erfüllen. (s. Kapitel 1.7)

Somit kann nicht nur eine Aussage darüber getroffen werden, ob retrospektiv die Kriterien überhaupt erfüllt werden, sondern auch der Zeitpunkt näher eingegrenzt werden, zu dem die Patienten die Kriterien erfüllen.

\subsection{Häufigkeiten der klinischen Symptomatik}

Aus der Pathophysiologie der Prionerkrankungen (vergleiche Abschnitt 1.1) ergibt sich, dass Symptome, die einmal aufgetreten sind, sich nicht mehr zurückbilden; daher wurde die klinische Symptomatik nach dem Zeitpunkt des erstmaligen Auftretens im Krankheitsverlauf erhoben. Um eine Abgrenzung von Symptomen, die sich früh im Krankheitsverlauf manifestieren, zu solchen, die erst später hinzukommen, zu ermöglichen wurde die Erkrankungsdauer in Drittel unterteilt.

Die Demenz trat als obligatorisches Symptom zur Diagnosestellung einer CJK beim größten Teil (94\%) des gesamten Patientenkollektivs auf. Im Fallkollektiv lag die Prävalenz der Demenz bei $96 \%$. Auch im Kontrollkollektiv wurde ein hohes Auftreten (90\%) einer Demenz beobachtet.

Insgesamt zeigte sich bei 61\% der Patienten eine Demenz im ersten Drittel der Erkrankung auf. Im Fallkollektiv trat bei 55\% der Patienten die Demenz im ersten Drittel auf, 35\% entwickelten während des zweiten Erkrankungsdrittels eine Demenz und 10\% erst im letzten Drittel. Bei 83\% der Patienten des Kontrollkollektivs wurde eine Demenz schon im ersten Erkrankungsdrittel, bei 93\% während der ersten beiden Erkrankungsdrittel zusammen und bei $7 \%$ im letzten Drittel diagnostiziert.

83\% aller Patienten entwickelten eine zerebellare Symptomatik. Für das Fallkollektiv ergab sich eine Häufigkeit von insgesamt 93\%. Die Auftretenswahrscheinlichkeit verteilt sich mit $47 \%$ auf das erste Drittel, mit 92\% auf die ersten beiden Drittel sowie mit $8 \%$ auf 
das letzte Drittel. Im Kontrollkollektiv liegt der Anteil der Patienten, die eine zerebellare Symptomatik entwickelten, bei insgesamt 68\%; hierbei manifestierte sich die Symptomatik bei $48 \%$ im ersten Drittel und bei $17 \%$ im zweiten Dritteln 35\% der Patienten entwickelten die Symptomatik erst im letzten Drittel.

Die kortikale Symptomatik trat im gesamten Patientenkollektiv bei $14 \%$ der Patienten auf. Im Fallkollektiv beträgt der Anteil der Patienten mit kortikaler Sehstörung 20\%. Das Auftreten wurde bei $62 \%$ der betroffenen Patienten im ersten Krankheitsdrittel, bei 33 \% im zweiten und bei 5\% im dritten Drittel dokumentiert. Für das Kontrollkollektiv, in dem 4\% der Patienten kortikale Sehstörungen entwickelten fiel diese bei $67 \%$ im ersten Drittel und bei 33\% im letzten Drittel der Erkrankung auf. Bei keinem der Patienten im Kontrollkollektiv wurde erstmals im zweiten Drittel über kortikale Sehstörungen berichtet.

Die pyramidale Symptomatik kam insgesamt weniger häufig als eine Demenz oder zerebellare Symptomatik vor. Die Gesamthäufigkeit liegt bei 53\%. Für das Fallkollektiv ergibt sich folgende Verteilung auf die Erkrankungsdrittel: insgesamt 58\% der Patienten im Fallkollektiv zeigten eine pyramidale Symptomatik. Diese trat bei $14 \%$ im ersten Drittel, bei 34\% im zweiten Dritteln und bei 52\% im letzten Drittel auf. Im Kontrollkollektiv wurde bei insgesamt $47 \%$ der Patienten eine pyramidale Symptomatik beschrieben; diese fiel bei $34 \%$ im ersten Erkrankungsdrittel, bei 16\% im zweiten Erkrankungsdritteln und bei $50 \%$ im letzten Erkrankungsdrittel auf.

Eine extrapyramidale Symptomatik wurde bei insgesamt 74\% der Patienten auf. Im Fallkollektiv beschrieben. Die Symptome bei Patienten mit extrapyramidaler Symptomatik (insgesamt $80 \%$ ) bei 21\% zum ersten Mal im ersten Drittel, und bei jeweils 39,5\% im zweiten und dritten Drittel auf. Im Kontrollkollektiv entwickelten 63\% der Patienten eine extrapyramidale Symptomatik. Hier manifestierte sich die Symptomatik am häufigsten im letzten Drittel auf (51\%). In den ersten beiden Dritteln zusammen waren $49 \%$ der Patienten betroffen.

Myoklonien traten mit einer Gesamthäufigkeit von 70\% im Verlauf der Erkrankung auf. Im Fallkollektiv entwickelten 83\% der Patienten im Verlauf Myoklonien. Bei 14\% der Patienten kamen diese zum ersten Mal im ersten Drittel, bei $60 \%$ in den ersten beiden Dritteln und bei $40 \%$ der Patienten im letzten Drittel der Erkrankung vor. Im Kontrollkollektiv 
verteilt sich die Gesamthäufigkeit von $49 \%$ mit $27 \%$ auf das erste Drittel, mit $24 \%$ auf das zweite Drittel und mit 49\% auf das letzte Drittel.

Insgesamt wurde bei 44\% der Patienten der Zustand eines akinetischen Mutismus beschrieben. Ein akinetisch-mutistischer Zustand zeigte sich im Fallkollektiv bei 57\% der Patienten. Hierbei wurde dieser Zustand für 3\% der Patienten im ersten Drittel beschrieben, $18 \%$ der Patienten befanden sich nach den ersten beiden Dritteln im akinetischen Mutismus und bei $82 \%$ wurde dieser Zustand im letzten Drittel erreicht. Im Kontrollkollektiv wurde bei insgesamt 24\% der Patienten ein akinetischer Mutismus beobachtet. Dieser trat bei $6 \%$ der Patienten im ersten Drittel und bei $94 \%$ im letzten Drittel ein. Für das zweite Erkrankungsdrittel wurde das Auftreten eines akinetischen Mutismus nicht beschrieben.

Eine psychiatrische Symptomatik ließ sich bei insgesamt 35\% des Patientenkollektivs eruieren. Für das Fallkollektiv ergibt sich eine Häufigkeit von 41\% für das Auftreten psychiatrischer Symptome. Diese verteilt sich mit 43\% auf das erste Drittel, mit 73\% auf die ersten beiden Drittel und mit 27\% auf das letzte Drittel. Im Kontrollkollektiv traten bei 25\% der Patienten psychiatrische Symptome auf. Diese begannen bei 59\% im ersten Drittel, bei $23 \%$ im zweiten Drittel und bei $18 \%$ im dritten Drittel. 
Tabelle 10: Auftreten klinischer Symptomatik im Krankheitsverlauf nach Dritteln

\begin{tabular}{|c|c|c|c|c|c|c|}
\hline Symptom & $\begin{array}{l}\text { Gesamt- } \\
\text { kollektiv }\end{array}$ & & Gesamt & $\begin{array}{l}\text { 1. Drit- } \\
\text { tel }\end{array}$ & $\begin{array}{l}\text { 2. Drit- } \\
\text { tel }\end{array}$ & $\begin{array}{l}\text { 3. Drit- } \\
\text { tel }\end{array}$ \\
\hline \multirow[t]{2}{*}{ Demenz } & \multirow[t]{2}{*}{$94 \%$} & $\mathrm{~F}$ & $96 \%$ & $55 \%$ & $35 \%$ & $10 \%$ \\
\hline & & $\mathrm{K}$ & $90 \%$ & $83 \%$ & $10 \%$ & $7 \%$ \\
\hline \multirow{2}{*}{$\begin{array}{c}\text { zerebellare } \\
\text { Symptomatik }\end{array}$} & \multirow[t]{2}{*}{$83 \%$} & $\mathrm{~F}$ & $93 \%$ & $47 \%$ & $45 \%$ & $8 \%$ \\
\hline & & K & $68 \%$ & $48 \%$ & $17 \%$ & $35 \%$ \\
\hline \multirow{2}{*}{$\begin{array}{c}\text { kortikale } \\
\text { Sehstörung }\end{array}$} & \multirow[t]{2}{*}{$14 \%$} & $\mathrm{~F}$ & $20 \%$ & $62 \%$ & $33 \%$ & $5 \%$ \\
\hline & & K & $4 \%$ & $67 \%$ & $0 \%$ & $33 \%$ \\
\hline \multirow{2}{*}{$\begin{array}{c}\text { pyramidale } \\
\text { Symptomatik }\end{array}$} & \multirow[t]{2}{*}{$53 \%$} & $\mathrm{~F}$ & $58 \%$ & $14 \%$ & $34 \%$ & $52 \%$ \\
\hline & & $\mathrm{K}$ & $47 \%$ & $34 \%$ & $16 \%$ & $50 \%$ \\
\hline \multirow{2}{*}{ 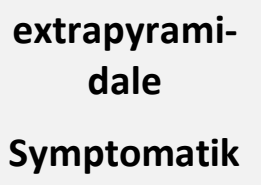 } & \multirow[t]{2}{*}{$74 \%$} & $\mathrm{~F}$ & $80 \%$ & $21 \%$ & $39,5 \%$ & $39,5 \%$ \\
\hline & & $\mathrm{K}$ & $63 \%$ & $16 \%$ & $33 \%$ & $51 \%$ \\
\hline \multirow[t]{2}{*}{ Myoklonien } & \multirow[t]{2}{*}{$70 \%$} & $\mathrm{~F}$ & $83 \%$ & $14 \%$ & $46 \%$ & $40 \%$ \\
\hline & & $\mathrm{K}$ & $49 \%$ & $27 \%$ & $24 \%$ & $49 \%$ \\
\hline \multirow{2}{*}{$\begin{array}{c}\text { akinetischer } \\
\text { Mutismus }\end{array}$} & \multirow[t]{2}{*}{$44 \%$} & $\mathrm{~F}$ & $57 \%$ & $3 \%$ & $15 \%$ & $82 \%$ \\
\hline & & $\mathrm{K}$ & $24 \%$ & $6 \%$ & $0 \%$ & $94 \%$ \\
\hline \multirow{2}{*}{$\begin{array}{l}\text { psychiatrische } \\
\text { Symptomatik }\end{array}$} & \multirow[t]{2}{*}{$35 \%$} & $\mathrm{~F}$ & $41 \%$ & $43 \%$ & $30 \%$ & $27 \%$ \\
\hline & & $\mathrm{K}$ & $25 \%$ & $59 \%$ & $23 \%$ & $18 \%$ \\
\hline
\end{tabular}

$\mathrm{F}=$ Fallkollektiv, $\mathrm{K}=$ Kontrollkollektiv

\subsection{Analyse der apparativen Diagnostik}

Im Folgenden werden die Ergebnisse der Analyse der apparativen Diagnostik dargestellt.

\subsubsection{Das EEG}

Das EEG als apparative Diagnostik fiel bei 42 der 107 Patienten im Fallkollektiv positiv aus. Dies entspricht einem Anteil von 39\%. Im Kontrollkollektiv erfüllte das EEG bei sieben Patienten (11\%) die Vorgaben als Diagnosekriterium einer CJK. Für zwei der Patienten der Kontrollgruppe lag kein EEG zur Auswertung vor. 
Hieraus ergeben sich eine Sensitivität von 39\% und eine Spezifität von $89 \%$ für das EEG als Diagnosekriterium einer CJK.

Tabelle 11: Sensitivität und Spezifität EEG

\begin{tabular}{|c|c|c|c|c|}
\hline & Fall/Kontrolle & EEG negativ & EEG positiv & Zeile gesamt \\
\hline Anzahl & \multirow{2}{*}{ Fall } & 65 & 42 & 107 \\
\hline Prozent & & $60,75 \%$ & $39,25 \%$ & \\
\hline Anzahl & \multirow{2}{*}{ Kontrolle } & 59 & 7 & 66 \\
\hline Prozent & Alle & $89,39 \%$ & $10,61 \%$ & \\
\hline Anzahl & & 124 & 49 & 173 \\
\hline
\end{tabular}

\subsubsection{Das CMRT}

Im cMRT erfüllten 75 der 106 zu statistischen Analysen herangezogenen Fälle die vorgegebenen Kriterien. Dies entspricht einem prozentualen Anteil von 71\% der Patienten. In der Kontrollgruppe konnte das cMRT von 57 bewertet werden. Hierbei erfüllten zwölf CMRT und somit 21\% der Patienten die Kriterien.

Hieraus ergibt sich eine Sensitivität von $71 \%$ und eine Spezifität von $82 \%$ für das CMRT als Diagnosekriterium für eine CJK.

Tabelle 12: Sensitivität und Spezifität cMRT

\begin{tabular}{|c|c|c|c|c|}
\hline & Fall/Kontrolle & cMRT negativ & cMRT positiv & Zeile gesamt \\
\hline Anzahl & \multirow{2}{*}{ Fall } & 31 & 75 & 106 \\
\hline Prozent & & $29,25 \%$ & $70,75 \%$ & \\
\hline Anzahl & Kontrolle & 47 & 10 & 57 \\
\hline Prozent & & $82,46 \%$ & $17,54 \%$ & \\
\hline Anzahl & Alle & 78 & 85 & 163 \\
\hline
\end{tabular}

\subsubsection{Die Liquordiagnostik}

Der folgende Abschnitt gibt die Ergebnisse der Analyse der Liquorparameter wieder.

\subsubsection{Proteine 14-3-3}

Für die Liquordiagnostik ergeben sich im Hinblick auf die Proteine 14-3-3 folgende relevanten Ergebnisse:

Insgesamt wurden im gesamten Patientenkollektiv bei 141 Patienten pathologisch erhöhte Werte für die Proteine 14-3-3 gemessen. 90 der 107 Patienten im Fallkollektiv fielen im Verlauf der Erkrankung mit positiven Proteinen 14-3-3 auf. Bei 17 Patienten fiel 
die Bestimmung der Proteine 14-3-3 falsch negativ aus. Dies entspricht prozentual $84 \%$ der Patienten und gibt auch die Sensitivität dieser Untersuchung wieder. Im Kontrollkollektiv wurden 51 falsch positive Werte für die 68 Patienten gemessen. Hieraus berechnet sich eine Spezifität von 25\%. 17 Patienten hatten einen richtig negativen Befund der Proteine 14-3-3.

Tabelle 13: Sensitivität und Spezifität Proteine 14-3-3

\begin{tabular}{|c|c|c|c|c|}
\hline & Fall/Kontrolle & $\begin{array}{c}\text { Protein 14-3-3 } \\
\text { negativ }\end{array}$ & $\begin{array}{c}\text { Protein 14-3-3 } \\
\text { positiv }\end{array}$ & Zeile gesamt \\
\hline Anzahl & \multirow{2}{*}{ Fall } & 17 & 90 & 107 \\
\hline Prozent & & $15,89 \%$ & $84,11 \%$ & \\
\hline Anzahl & \multirow{2}{*}{ Kontrolle } & 17 & 51 & 68 \\
\hline Prozent & Alle & $25,00 \%$ & $75,00 \%$ & \\
\hline Anzahl & & 34 & 141 & 175 \\
\hline
\end{tabular}

\subsubsection{Gesamt-tau}

Bei der Messung des Gesamt-tau wurden insgesamt bei 123 Patienten erhöhte Werte - im Sinne einer Prionerkrankung ( $\geq 1300$ pg/ml) - gemessen. Hiervon stammen 92 Patienten aus dem Fallkollektiv (Anteil im Fallkollektiv: 86\%) und 31 aus dem Kontrollkollektiv (Anteil im Kontrollkollektiv: 46\%). Im Fallkollektiv ließen sich relevant erhöhte Gesamt-tau Werte bei 92 Patienten (86\%) feststellen. Im Kontrollkollektiv wurden bei 31 der Patienten (46\%) relevant erhöhte Werte gemessen. Hieraus ergeben sich eine Sensitivität von $86 \%$ und eine Spezifität von 54\%. Der höchste gemessene Wert lag bei lag bei $107300 \mathrm{pg} / \mathrm{ml}$.

Tabelle 14: Sensitivität und Spezifität Gesamt-tau

\begin{tabular}{|c|c|c|c|c|}
\hline & Fall/Kontrolle & $\begin{array}{c}\text { Gesamt-tau (<1300 } \\
\text { pg/ml) negativ }\end{array}$ & $\begin{array}{c}\text { Gesamt-tau (> 1300 } \\
\text { pg/ml) positiv }\end{array}$ & Zeile gesamt \\
\hline Anzahl & Fall & 15 & 92 & 107 \\
\hline Prozent & Kontrolle & $14,02 \%$ & $85,98 \%$ & 68 \\
\hline Anzahl & & 37 & 31 & \\
\hline Prozent & Alle & $54,41 \%$ & $45,59 \%$ & 175 \\
\hline Anzahl & & 52 & 123 & \\
\hline
\end{tabular}




\subsubsection{PrPSc-Aggregationsassay}

Für den PrPSc-Aggregationsassay ergeben sich bei 61 richtig positiven Befunde im Fallkollektiv und vier falsch positiven Befunden im Kontrollkollektiv sowie 46 falsch negativen und 64 richtig negativen Ergebnissen eine Sensitivität von 57\% und eine Spezifität von $94 \%$.

Tabelle 15: Sensitivität und Spezifität RT-QuIC

\begin{tabular}{|c|c|c|c|c|}
\hline & Fall/Kontrolle & RT-QuIC negativ & RT-QuIC positiv & Zeile gesamt \\
\hline Anzahl & \multirow{2}{*}{ Fall } & 46 & 61 & 107 \\
\hline Prozent & & $42,99 \%$ & $57,01 \%$ & \\
\hline Anzahl & \multirow{2}{*}{ Kontrolle } & 64 & 4 & 68 \\
\hline Prozent & Alle & $94,12 \%$ & $5,88 \%$ & \\
\hline Anzahl & 110 & 65 & 175 \\
\hline
\end{tabular}

\subsection{Zeitliche Aspekte bei der Diagnosestellung einer Creutzfeldt-Jakob-Erkrankung}

Dieser Unterpunkt beschäftigt sich mit den zeitlichen Aspekten bei der Diagnosestellung der CJK. Hier sind insbesondere der Zeitpunkt der Liquorpunktion (LP) im Krankheitsverlauf sowie der Zeitpunkt, an dem die Diagnosekriterien im Krankheitsverlauf erfüllt werden, von Interesse.

Bei beiden Betrachtungen werden Krankheitsbilder, die die Kriterien für eine „mögliche“ oder “wahrscheinliche“ CJK erfüllten, als „positiv“ gewertet.

\subsubsection{Zeitpunkt der Liquorpunktion}

Die Liquorpunktion im Fallkollektiv wurde in 19 Fällen (18\%) im ersten Drittel, bei 45 Patienten (42\%) im zweiten Drittel, und bei 43 Patienten (40\%) im dritten Drittel durchgeführt.

Im Kontrollkollektiv wurde die Liquorpunktion bei vier Patienten (6\%) im ersten Drittel durchgeführt. Bei 19 Patienten (28\%) wurde die Liquorpunktion im zweiten Drittel und bei 45 (66\%) im dritten Drittel durchgeführt. 


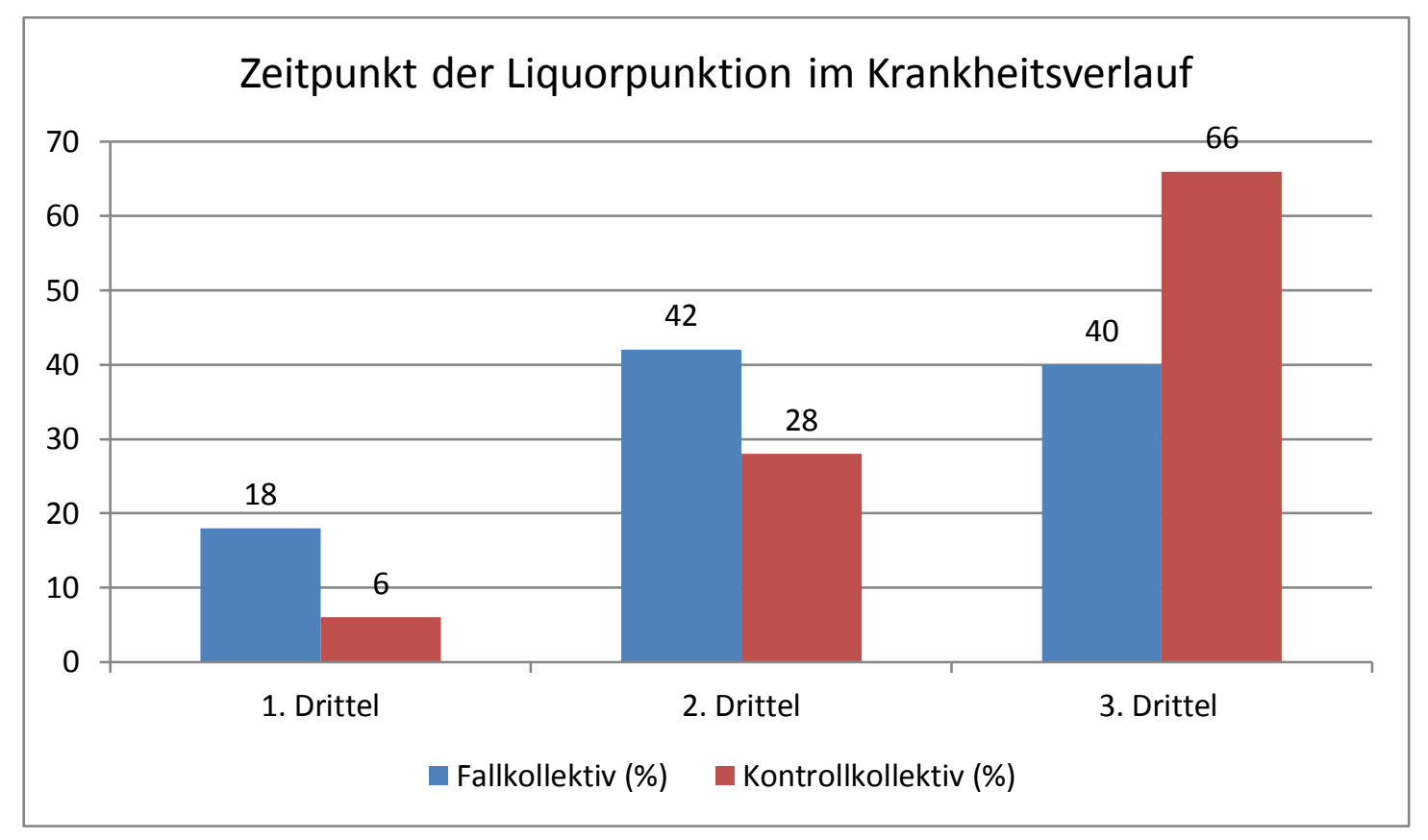

Abbildung 3: Zeitpunkt der Liquorpunktion im Krankheitsverlauf

\subsubsection{Zeitpunkt der Diagnosestellung}

Der Zeitpunkt der Diagnosestellung soll im Folgenden zum einem rückblickend, also post mortem, betrachtet werden. Zum anderen wird analysiert, wie viele Patienten bereits zum Zeitpunkt der Liquorpunktion anhand der Diagnosekriterien als CJK-Fall klassifiziert werden können; es wird also die Sensitivität und Spezifität der Diagnosekriterien zum Zeitpunkt der Liquorpunktion ermittelt.

\subsubsection{Diagnosestellung rückblickend}

Teilt man die erhobenen Daten nach Erkrankungsdrittel auf, zeigt sich rückblickend - also nach Versterben der Patienten -, dass 15 Patienten (14\%) im Fallkollektiv die Diagnosekriterien (DGN 2012) nicht erfüllten, obwohl sie an einer Creutzfeldt-Jakob-Erkrankung litten. Bei neun Patienten (8\%) konnte die Diagnose einer wahrscheinlichen CJK im ersten Drittel gestellt werden. 33 Patienten (31\%) erfüllten die Diagnosekriterien im zweiten Drittel und 46 Patienten (43\%) erfüllten die Kriterien im dritten Drittel. Bei vier der diagnostizierten Patienten wurde eine mögliche CJK klassifiziert; dies entspricht $4 \%$ aller diagnostizierten Fälle. 


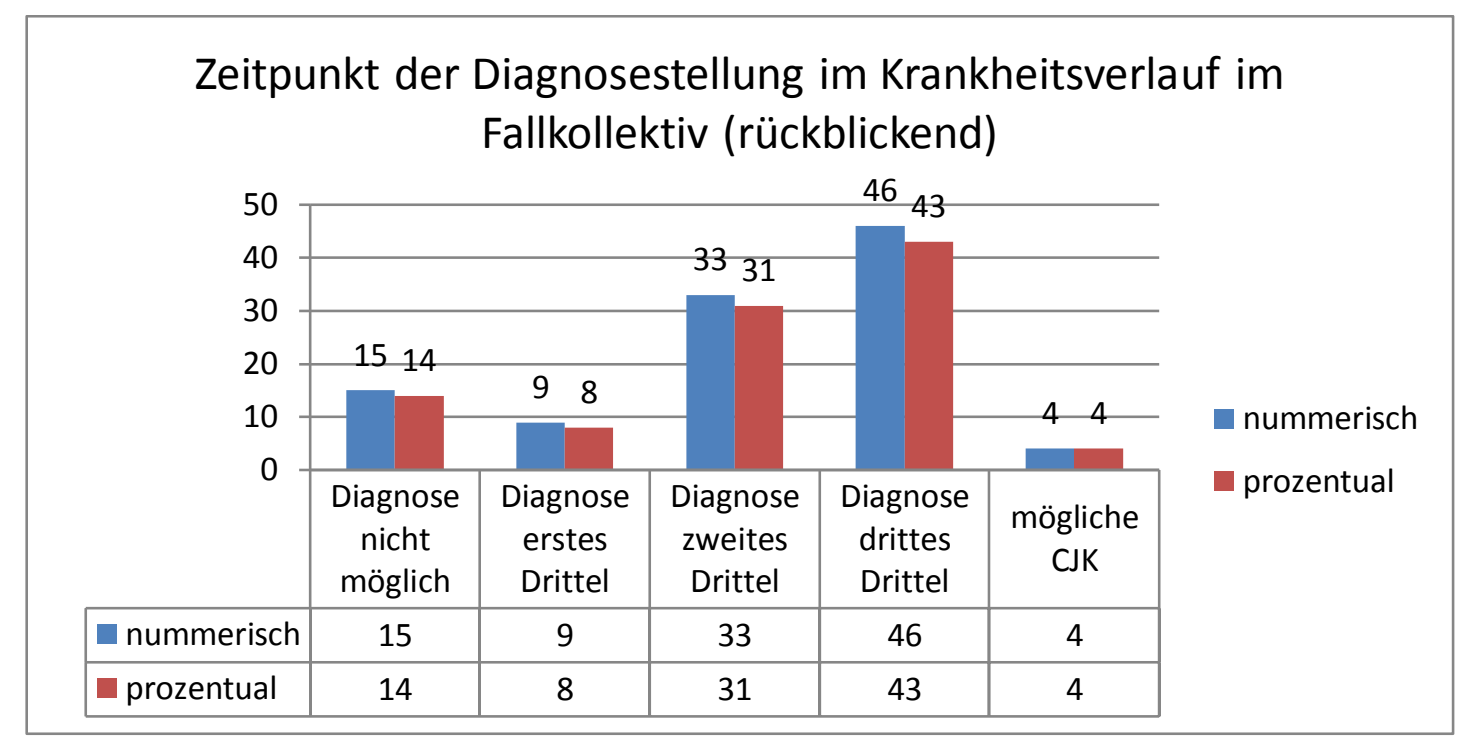

Abbildung 4: Zeitpunkt der Diagnosestellung im Krankheitsverlauf im Fallkollektiv (rückblickend) nach DGN Leitlinie 2012

Auch im Kontrollkollektiv erfüllten einige Patienten die Diagnosekriterien für die CJK. Für diese falsch positiven Fälle verteilt sich der Zeitpunkt, an dem die Kriterien erfüllt wurden, wie folgt auf die Krankheitsdrittel: bei 47 der 68 Patienten (69\%) im Kontrollkollektiv ließen sich die Diagnosekriterien nicht anwenden; sie wurden als „,anderer Fall“ klassifiziert. Bei einem Patienten (1\%) ließen sich die Diagnosekriterien im ersten Erkrankungsdrittel anwenden, zwei Patienten (3\%) erfüllten die Diagnosekriterien im zweiten Erkrankungsdrittel und zwölf Patienten (18\%) im dritten. Acht der diagnostizierten Patienten wurden als mögliche CJK klassifiziert (12\%). 


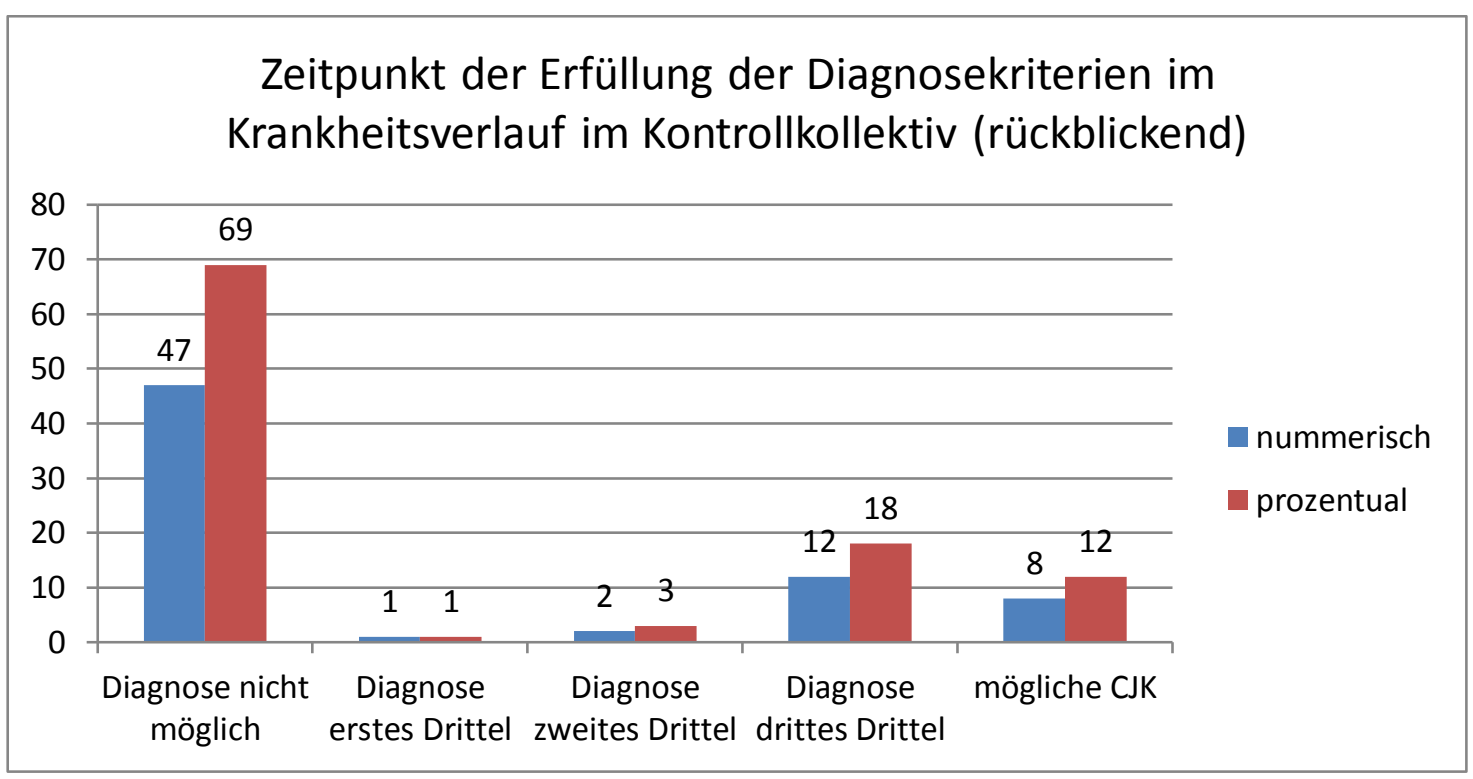

Abbildung 5: Zeitpunkt der Diagnosestellung im Krankheitsverlauf im Kontrollkollektiv (rückblickend) nach DGN Leitlinie 2012

Für die offiziellen Diagnosekriterien einer möglichen oder wahrscheinlichen CJK errechnen sich aus den erhobenen Daten im Rückblick eine Sensitivität von $84 \%$ und eine Spezifität von $69 \%$.

Tabelle 16: Sensitivität und Spezifität der Diagnosekriterien (DGN 2012) rückblickend betrachtet

\begin{tabular}{|c|c|c|c|c|}
\hline & Fall/Kontrolle & $\begin{array}{c}\text { Diagnosekriterien } \\
\text { nicht erfüllt }\end{array}$ & $\begin{array}{c}\text { Diagnosekriterien } \\
\text { erfüllt }\end{array}$ & Zeile gesamt \\
\hline Anzahl & Fall & 17 & 90 & 107 \\
\hline Prozent & & $16 \%$ & $84 \%$ & \\
\hline Anzahl & Kontrolle & 47 & 21 & 68 \\
\hline Prozent & Alle & $69 \%$ & $31 \%$ & \\
\hline Anzahl & 64 & 111 & 175 \\
\hline
\end{tabular}

\subsubsection{Diagnosestellung zum Zeitpunkt der Liquorpunktion}

Betrachtet man Sensitivität und Spezifität der Diagnosekriterien zum Zeitpunkt der Liquorpunktion so ergeben sich folgende Werte: Sensitivität 75\% und Spezifität 69\%.

Tabelle 17: Sensitivität und Spezifität der Diagnosekriterien (DGN 2012) zum Zeitpunkt der Liquorpunktion

\begin{tabular}{|c|c|c|c|c|}
\hline & Fall/Kontrolle & $\begin{array}{c}\text { Diagnosekrite- } \\
\text { rien zum Zeit- } \\
\text { punkt LP nega- } \\
\text { tiv }\end{array}$ & $\begin{array}{c}\text { Diagnosekrite- } \\
\text { rien zum Zeit- } \\
\text { punkt LP positiv }\end{array}$ & Zeile gesamt \\
\hline Anzahl & Fall & 27 & 80 & 107 \\
\hline
\end{tabular}




\begin{tabular}{|c|c|c|c|c|}
\hline Prozent & & $25,23 \%$ & $74,77 \%$ & \\
\hline Anzahl & Kontrolle & 47 & 21 & 68 \\
\hline Prozent & Alle & $69,12 \%$ & $30,88 \%$ & \\
\hline Anzahl & & 74 & 101 & 175 \\
\hline
\end{tabular}

In Hinblick auf eine mögliche Integration des RT-QulC in die bestehenden Diagnosekriterien wurde eine erneute Berechnung der Sensitivität und Spezifität der Diagnosekriterien zum Zeitpunkt der Liquorpunktion unter gleichzeitiger Berücksichtigung des RT-QuIC durchgeführt. Als positiv gewertet wurden bei dieser Berechnung sowohl die Fälle, welche die offiziellen Diagnosekriterien erfüllen, als auch diejenigen, die die Diagnosekriterien nicht erfüllen, aber ein positives Ergebnis im RT-QuIC aufweisen. Diese Annahme beruht auf der hohen Spezifität des RT-QulC.

Bereits frühere Studien zum diagnostischen Wert des RT-QuIC zeigen immer wieder vereinzelt falsch positive Ergebnisse (z. B. McGuire et al. (2012) und Cramm et al. (2015)). Daher wurde bei positivem Ergebnis des RT-QuIC, wenn zugleich Hinweise auf eine Alternativdiagnose vorlagen, das Krankheitsbild als „,kein Fall“ bewertet.

In zwei der vier Fälle mit falsch positiven Befunden im RT-QulC ergaben sich auf Grund der durchgeführten Diagnostik Hinweise auf eine andere Diagnose. In einem Fall zeigten sich klinisch Hinweise auf ein Tumorgeschehen; die neuropathologische Diagnose bestätigte ein Glioblastoma multiforme. Im zweiten Fall wurden bei untypischer Klinik und falsch positiver Bestimmung der Proteine 14-3-3 nach epileptischen Geschehen die Diagnosekriterien als nicht erfüllt beurteilt.

In den beiden weiteren Fällen ergab sich aus den vorliegenden klinischen Befunden kein Hinweis auf eine Alternativdiagnose. Die neuropathologische Beurteilung ergab in einem Fall alzheimerassoziierte Veränderungen Braak Stadium V (Braak und Braak 1991) sowie eine Amyloidangiopathie. Hier wurde klinisch bei positiven Proteinen 14-3-3 und passender Klinik eine wahrscheinliche CJK diagnostiziert. Im zweiten Fall wurde bei typischer Klinik ohne typische Befunde in der etablierten Diagnostik eine CJK für möglich gehalten. Neuropathologisch zeigten sich senile Veränderungen mit geringgradiger Amyloidangiopathie sowie kleine ischämische Infarkte im zerebellaren Cortex sowie im Hippocampus rechts. Ein cMRT wurde bei diesem Patienten nicht durchgeführt. 
Für die Diagnosekriterien zusammen mit dem RT-QulC berechnen sich eine Spezifität von $87 \%$ sowie eine Spezifität von $67 \%$.

Tabelle 18: Sensitivität und Spezifität der Diagnosekriterien zum Zeitpunkt der LP mit RT-QuIC

\begin{tabular}{|c|c|c|c|c|}
\hline & Fall/Kontrolle & $\begin{array}{c}\text { Diagnosekrite- } \\
\text { rien mit RT- } \\
\text { QuIC negativ }\end{array}$ & $\begin{array}{c}\text { Diagnosekrite- } \\
\text { rien mit RT- } \\
\text { QulC positiv }\end{array}$ & Zeile gesamt \\
\hline Anzahl & Fall & 14 & 93 & 107 \\
\hline Prozent & Kontrolle & $13,08 \%$ & 86,92 & \\
\hline Anzahl & Alle & 46 & 22 & 68 \\
\hline Prozent & & $67,65 \%$ & 32,35 & 175 \\
\hline Anzahl & & & 115 & \\
\hline
\end{tabular}

\subsection{Logistische Regressionsanalyse}

Mittels logistischer Regressionsanalyse wird im Folgenden ein Modell entwickelt, welches die Parameter berücksichtigt, die statistisch signifikant für die Diagnosestellung einer CJK sind.

In einem ersten Schritt wurden zunächst anhand eines Ausgangsmodells, das alle klinischen und diagnostischen Parameter der Diagnosekriterien von 2012 sowie zusätzlich den RT-QuIC umfasst, mittels logistischer Regressionsanalyse, die statistisch signifikanten Werte dieses Modells herausgefiltert. Diese sind die zerebellare Symptomatik, der RT-QulC, Myoklonien, der akinetische Mutismus und das CMRT.

In einem weiteren Schritt wird ein „endgültiges Modell“ entwickelt. In dessen Entwicklung fließen - mit Ausnahme der Überlegungen zur Beibehaltung der Demenz als Kriterium (s. u.) - keine klinische Expertise, sondern rein statistische Überlegungen ein. Diese Erwägungen schließen die Parameter aus dem Ausgangsmodell aus, die keinen statistisch signifikanten Wert erreichen. Das „endgültige Modell“ berücksichtigt auf Grund der errechneten statistischen Signifikanz die zerebellare Symptomatik, den RT-QulC, das cMRT, die beiden klinischen Symptome akinetischer Mutismus und Myoklonien sowie die zerebellare Symptomatik. Diese Parameter haben aus statistischer Sicht also einen hohen Einfluss auf die Diagnosestellung einer CJK. Die Proteine 14-3-3, das Gesamt-tau, das EEG, die kortikale Sehstörung, die extrapyramidale und die pyramidale Symptomatik erreichen kein statistisch signifikantes Niveau und gehen somit nicht in das „endgültige 
Modell" ein. Obwohl auch die Demenz unter einem statistisch signifikanten Wert bleibt, wird diese auf Grund der klinischen Relevanz für die Diagnosestellung in das „endgültige Modell“ übernommen.

Mittels AIC wird zusätzlich beurteilt, ob Veränderungen des Modells zu einer statistisch signifikanten Verbesserung führen.

Das AIC kann u. a. als absoluter Zahlenwert bei der Entwicklung von Modellen mittels logistischer Regressionsanalyse als Gütekriterium herangezogen werden. Es zeigt bei Abnahme des Wertes um größer fünf nach Veränderungen des Modells in der logistischen Regressionsanalyse eine statistisch signifikante Verbesserung an. Abnahmen des AIC kleiner fünf oder Zunahmen des AIC nach Veränderungen werden als statistisch nicht signifikant und somit als nicht sinnvoll bewertet. Das AIC dient also als Indikator für eine relevante Verbesserung in der Entwicklung von Modellen mittels logistischer Regressionsanalyse.

Der AIC für ein Modell, in das die gesamte Symptomatik und Diagnostik der aktuellen Diagnosekriterien eingehen, beträgt 122,68. Der AIC-Wert für das Modell, in dem neben der klinischen Symptomatik und Diagnostik der Diagnosekriterien auch der RT-QuIC mitberücksichtigt wird, beträgt 97,91. Dieser Wert fällt durch den Ausschluss der statistisch nicht signifikanten Werte auf 92,32 für das „endgültige Modell“. Somit verbessert sich der AIC durch Hinzunahme des RT-QuIC um den Wert 24,77 und durch die Beschränkung auf die statistisch signifikanten Parameter nochmals um 5,59. Diese Abnahme spricht jeweils für eine statistisch signifikante Verbesserung der Modelle.

Tabelle 19: Werte des Akaike Informationskriteriums für verschiedene Modelle der logistischen Regressionsanalyse

\begin{tabular}{|c|c|}
\hline Modell & AIC \\
\hline Diagnosekriterien $\mathbf{2 0 1 2}$ & 122,68 \\
\hline $\begin{array}{c}\text { Diagnosekriterien + RT-QuIC } \\
\text { (Ausgangsmodell) }\end{array}$ \\
\hline “Endgültiges Modell" & 97,91 \\
\hline
\end{tabular}


Das „endgültige Modell“ beinhaltet, wie bereits beschrieben, neben dem RT-QuIC, das cMRT, Demenz, zerebellare Diagnostik, Myoklonien und den akinetischen Mutismus.

\begin{tabular}{|c|c|c|c|c|}
\hline Koeffizient & $\begin{array}{l}\text { Schät- } \\
\text { zung }\end{array}$ & $\begin{array}{l}\text { Standard- } \\
\text { abweichung }\end{array}$ & z-Wert & $\operatorname{Pr}(>|z|)$ \\
\hline Faktor (RT-QuIC) & 4,6754 & 1,0460 & 4,470 & $7,83 \mathrm{e}-06 * * *$ \\
\hline Faktor (cMRT) & 3,0410 & 0,6984 & 4,354 & $1,34 \mathrm{e}-05 * * *$ \\
\hline Faktor (Demenz) & 2,3350 & 1,6978 & 1,375 & 0,169028 \\
\hline Faktor (Zerebellar) & 2,5480 & 0,9205 & 2,768 & $0,005640 * *$ \\
\hline Faktor (Myoklonien) & 2,7831 & 0,7083 & 3,929 & $8,52 \mathrm{e}-05 * * *$ \\
\hline $\begin{array}{l}\text { Faktor (Akinetischer Mutis- } \\
\text { mus) }\end{array}$ & 1,8267 & 0,6246 & 2,924 & $0,003450 * *$ \\
\hline
\end{tabular}

Die $p$-Werte für die integrierten Parameter variieren zwischen 0,00000783 für den RTQuIC und 0,005640 für die zerebellare Symptomatik. Der $p$-Wert für die Demenz beträgt 0,169028 und liegt somit über dem Signifikanzniveau von $p$ kleiner als 0,05 . Auf Grund des hohen klinischen Stellenwerts der Demenz für die Diagnosekriterien wurde der Parameter trotzdem in das Modell integriert.

Die Schätzungs-Werte liegen alle im Konfidenzintervall zwischen 2,5\% und 97,5\%. Der Wald-Test für das „endgültige Modell“ berechnet folgende Werte: 
Tabelle 21: Ergebnisse des Wald-Tests

\begin{tabular}{|l|c|c|}
\hline \multicolumn{1}{|c|}{ Faktor } & $\mathbf{\chi}^{\mathbf{2}}$ & $\mathbf{P}\left(\mathbf{\mathbf { \chi } ^ { 2 }} \mathbf{}\right)$ \\
\hline Faktor (Zerebellar) & 7,5 & 0,0061 \\
\hline Faktor (Demenz) & 1,6 & 0,2 \\
\hline Faktor (Myoklonien) & 15,9 & $6,8 \mathrm{e}-05$ \\
\hline Faktor (Akinetischer Mutismus) & 8,8 & 0,003 \\
\hline Faktor (cMRT) & 19,2 & $1,2 \mathrm{e}-05$ \\
\hline Faktor (RT-QuIC) & 18,6 & $1,6 \mathrm{e}-05$ \\
\hline
\end{tabular}

Somit wird die Signifikanz der Parameter, die in das Modell eingehen, bis auf die Demenz durch den Wald-Test bestätigt.

\subsection{Odds Ratio}

Die höchste Odds-Ratio berechnet sich mit 107,4 für den RT-QuIC. Daraus ergibt sich, dass bei positivem Ergebnis im RT-QulC die Wahrscheinlichkeit für das Vorliegen einer CJK 107-fach höher ist als bei einem negativen Ergebnis. Die Odds-Ration des RT-QuIC ist mehr als fünfmal höher als die für das cMRT und die weiteren Parameter und unterstreicht nochmals die Bedeutung des RT-QulC für die Diagnosestellung einer CJK. Die niedrigste Odds-Ration wird mit 6,21 für den akinetischen Mutismus berechnet. Die Odds-Ratio für Demenz liegt bei 10,25 und somit höher als bei der statistisch signifikanten Symptomatik des akinetischen Mutismus. Dies bekräftigt nochmals die Entscheidung zur Beibehaltung der Demenz im „endgültigen Modell“. 


\begin{tabular}{|l|l|}
\hline RT-QuIC & Odds Ratio \\
\hline CMRT & 107,4 \\
\hline Demenz & 20,92 \\
\hline Zerebellar & 10,25 \\
\hline Myoklonien & 12,78 \\
\hline Akinetischer Mutismus & 16,17 \\
\hline
\end{tabular}

\subsection{Training-Data-Set}

Für das Training-Data-Set wird das gesamte Patientenkollektiv im Verhältnis 0,7 geteilt, demnach werden 70\% der Daten als Trainingsdatensatz für das neue Modell verwendet. Anschließend wird das trainierte Modell auf die restlichen $30 \%$ des Datensatzes angewandt, und es werden Werte für Sensitivität, Spezifität sowie die Genauigkeit ermittelt. Da der Datensatz willkürlich aufgeteilt wird, erfolgt die Berechnung der endgültigen Werte anhand einer Kreuzvalidierung mit zehn Durchläufen.

Zunächst wird eine Reciever-Operating-Characteristics-Kurve (ROC-Kurve) erstellt, welche zur Abschätzung der Vorhersagegenauigkeit des getesteten Modells genutzt wird. Anhand dieser wird die Schwelle (= thresholde) für die weitere Berechnung gewählt, um ein möglichst optimales Gleichgewicht zwischen falsch positiven und falsch negativen Ergebnissen zu halten. 


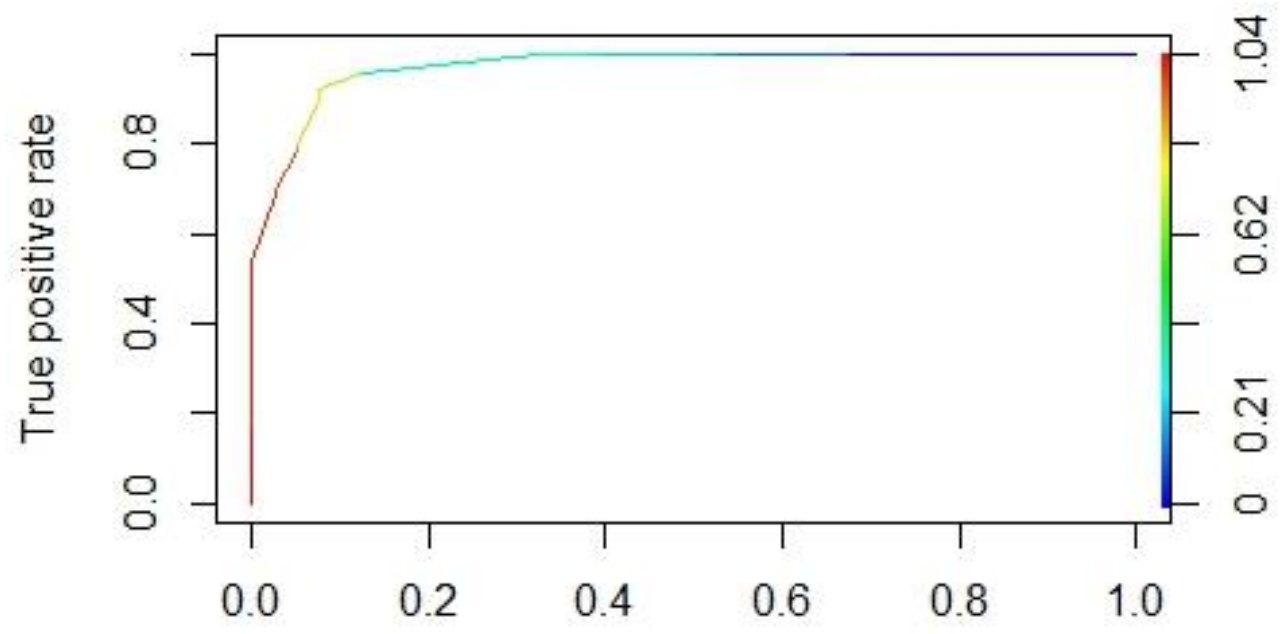

\section{False positive rate}

Abbildung 6: ROC-Kurve für das „endgültige Modell“

False positive rate $=$ Rate falsch positiver Ergebnisse; True positive rate $=$ Rate richtig positiver Ergebnisse

Auf Grund der ROC-Kurve wird die Schwelle für die folgende Kreuzvalidierung anhand des Training-Data-Sets mit 0,45 festgelegt.

Tabelle 23: Kreuzvalidierung Training-Data-Set für das „endgültige Modell“

\begin{tabular}{|r|c|c|c|}
\hline Durchlauf & Sensitivität & Spezifität & Genauigkeit \\
\hline 1. Durchlauf & $87,1 \%$ & $94,1 \%$ & $89,6 \%$ \\
\hline 2. Durchlauf & $87,1 \%$ & $88,2 \%$ & $87,5 \%$ \\
\hline 3. Durchlauf & $90,3 \%$ & $88,2 \%$ & $89,6 \%$ \\
\hline 4. Durchlauf & $87,1 \%$ & $88,2 \%$ & $87,5 \%$ \\
\hline 5. Durchlauf & $93,5 \%$ & $76,5 \%$ & $87,5 \%$ \\
\hline 6. Durchlauf & $87,5 \%$ & $76,5 \%$ & $87,5 \%$ \\
\hline 7. Durchlauf & $87,5 \%$ & $76,5 \%$ & $87,5 \%$ \\
\hline 8. Durchlauf & $87,5 \%$ & $76,5 \%$ & $87,5 \%$ \\
\hline 9. Durchlauf & $87,5 \%$ & $76,5 \%$ & $87,5 \%$ \\
\hline 10. Durchlauf & $87,5 \%$ & $76,5 \%$ & $87,5 \%$ \\
\hline
\end{tabular}


Als endgültige Werte für Sensitivität, Spezifität und Genauigkeit des ermittelten Modells wurden folgende Werte berechnet:

Tabelle 24: Sensitivität, Spezifität und Genauigkeit „endgültiges Modell“

\begin{tabular}{|l|c|c|c|}
\hline \multicolumn{1}{|c|}{ Modell } & Sensitivität & Spezifität & Genauigkeit \\
\hline $\begin{array}{l}\text { RT-QuIC/cMRT/De- } \\
\text { menz/Zerebellare }\end{array}$ & $88,26 \%$ & $81,77 \%$ & $87,92 \%$ \\
Symptomatik/My- & & \\
oklonien/Akin. Mu- \\
tismus
\end{tabular}

\subsection{1 „Expertenmodell“}

Das „Expertenmodell“ soll als Weiterentwicklung des „endgültigen Modells“ neben statistischen Überlegungen auch die klinische Expertise aus meiner Arbeit im Referenzzentrum für TSE einbeziehen. Hierbei steht als Zielsetzung eine möglichst frühe und sichere Diagnosestellung im Mittelpunkt (s. Relevanz der Fragestellung).

Aus der Analyse des Auftretens der Symptomatik im Verlauf der Erkrankung (Abschnitt 3.5, Tabelle sechs) geht hervor, dass insbesondere der akinetische Mutismus, aber auch die Myoklonien erst im späteren Stadien der Erkrankung auftreten. Im Hinblick auf eine frühere Diagnosestellung erscheinen Myoklonien und der akinetische Mutismus demnach nicht hilfreich. Trotz ihrer statistischen Signifikanz werden sie daher im „Expertenmodell“ nicht berücksichtigt. Das CMRT und der RT-QuIC werden als wichtige wegweisende und sehr spezifische sowie statistisch signifikante Parameter beibehalten.

Die Erfahrung aus meiner Tätigkeit im NRZ für TSE zeigt, dass die Analyse der Proteine 14-3-3 derzeit in der klinischen Arbeit von ärztlichen Kolleginnen und Kollegen als Screening-Parameter für die Möglichkeit des Vorliegens einer CJK genutzt wird. Daher werden die Proteine 14-3-3 trotz fehlender statistischer Signifikanz in der vorangegangenen logistischen Regressionsanalyse und im „Expertenmodel“I mit aufgenommen werden.

Das „Expertenmodel“ berücksichtigt also: Demenz, zerebellare Symptomatik, RT-QulC, cMRT und die Proteine 14-3-3. 
Tabelle 25: Ergebnisse logistische Regressionsanalyse „Expertenmodell“

\begin{tabular}{|l|c|c|c|c|}
\hline \multicolumn{1}{|c|}{ Faktor } & Schätzung & $\begin{array}{c}\text { Standard- } \\
\text { abweichung }\end{array}$ & z Wert & $\operatorname{Pr}(>|\mathbf{z}|)$ \\
\hline factor(RT.QuIC) & 3,8989 & 0,8429 & 4,626 & $3,73 \mathrm{e}-06^{* * *}$ \\
\hline factor(cMRT) & 2,7519 & 0,5499 & 5,004 & $5,60 \mathrm{e}-07^{* * *}$ \\
\hline factor(Zerebellar) & 1,8913 & 0,7089 & 2,668 & $0,00764^{* *}$ \\
\hline factor(Demenz) & 2,3788 & 1,2250 & 1,942 & 0,05215 \\
\hline factor(Protein 14-3-3) & $-0,5964$ & 0,6104 & $-0,977$ & 0,32853 \\
\hline
\end{tabular}

Signifikanzkodierung: $0^{(* * * \prime} 0,001^{(* * \prime} 0,01^{* \prime}>0,05^{\prime \prime}$

Da in das „Expertenmodell“ vor allem klinische Expertise einfließt, ist eine Überprüfung der statistischen Signifikanz mittels AIC und Wald-Test nicht sinnvoll.

Zur Ermittlung der Sensitivität und Spezifität des „Expertenmodells“ wurde wiederum ein Training-Data-Set durchgeführt.

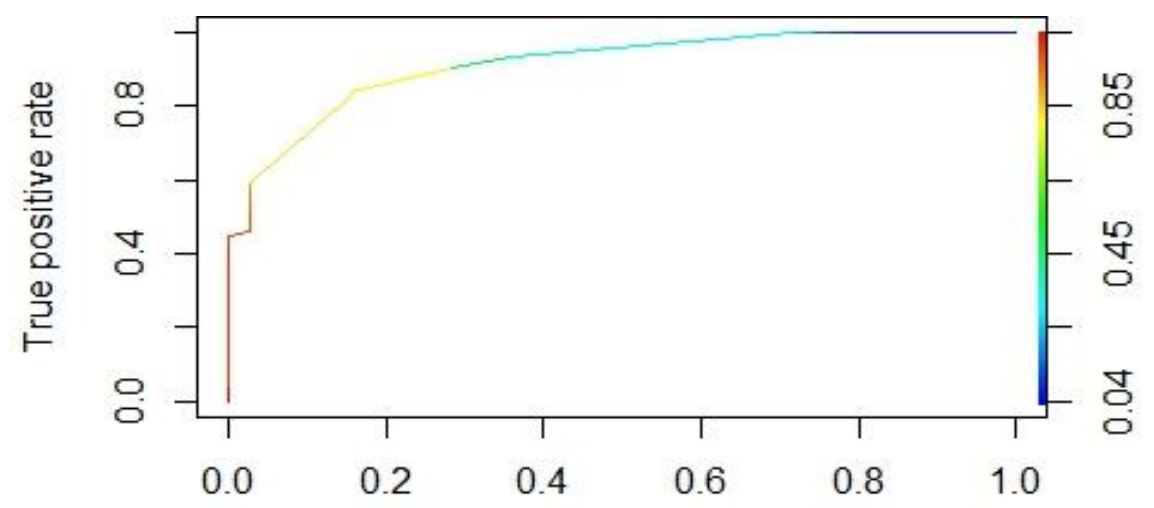

False positive rate

Abbildung 7: ROC-Kurve für das „Expertenmodell“

False positive rate $=$ Rate falsch positiver Ergebnisse; True positive rate $=$ Rate richtige positiver Ergebnisse

Der Teilung der Daten in Trainings- und Daten-Set erfolgt im Verhältnis 0,7. Die Schwelle wird anhand der ermittelten ROC-Kurve mit 0,45 festgelegt.

Zur Berechnung der Sensitivität und Spezifität für das „Expertenmodell“ wurde ebenfalls eine zehnfache Kreuzvalidierung durchgeführt; die Werte wurden gemittelt. 
Tabelle 26: Kreuzvalidierung Training-Data-Set für das „Expertenmodell“

\begin{tabular}{|c|c|c|c|}
\hline Druchlauf & Sensitivität & Spezifität & Genauigkeit \\
\hline 1. Durchlauf & $93,5 \%$ & $82,4 \%$ & $89,6 \%$ \\
\hline 2. Durchlauf & $93,5 \%$ & $82,4 \%$ & $89,6 \%$ \\
\hline 3. Durchlauf & $93,5 \%$ & $82,4 \%$ & $89,6 \%$ \\
\hline 4. Durchlauf & $93,5 \%$ & $82,4 \%$ & $89,6 \%$ \\
\hline 5. Durchlauf & $93,5 \%$ & $82,4 \%$ & $89,6 \%$ \\
\hline 6. Durchlauf & $93,5 \%$ & $82,4 \%$ & $89,6 \%$ \\
\hline 7. Durchlauf & $93,5 \%$ & $82,4 \%$ & $89,6 \%$ \\
\hline 8. Durchlauf & $93,5 \%$ & $82,4 \%$ & $89,6 \%$ \\
\hline 9. Durchlauf & $87,1 \%$ & $82,4 \%$ & $85,4 \%$ \\
\hline 10. Durchlauf & $93,5 \%$ & $82,4 \%$ & $89,6 \%$ \\
\hline
\end{tabular}

Aus den gemittelten Werten der Kreuzvalidierung berechnen sich folgender Wert für Sensitivität, Spezifität und Genauigkeit des „Expertenmodells“:

Tabelle 27: Sensitivität, Spezifität und Genauigkeit „Expertenmodell“

\begin{tabular}{|l|c|c|c|}
\hline \multicolumn{1}{|c|}{ Modell } & Sensitivität & Spezifität & Genauigkeit \\
\hline $\begin{array}{l}\text { Demenz/Zerebel- } \\
\text { lar/RT- } \\
\text { QuIC/cMRT/14-3-3 }\end{array}$ & $92,86 \%$ & $82,4 \%$ & $89,19 \%$ \\
\hline
\end{tabular}

3.12 Neu entwickelte Diagnosekriterien für die sporadische Creutzfeldt-Jakob-Erkrankung

Als Weiterentwicklung des „Expertenmodells“ wurden nun neue klinisch anwendbare Diagnosekriterien für die sCJK aufgestellt. Diese bestehen aus zwei Teilkriterien.

Das erste Teilkriterium wird erfüllt, wenn neben einer Demenz oder einer zerebellaren Symptomatik auch ein positives Testergebnis des RT-QulC vorliegt.

Das zweite Teilkriterium wird erfüllt, wenn eine Demenz und oder eine zerebellare Symptomatik auftreten und zusätzlich das EEG oder cMRT einen eindeutig CJK-typischen Befund aufweisen und die Proteine 14-3-3 im Liquor nachgewiesen werden.

Wird mindestens eines der beiden Teilkriterien erfüllt und liegt kein Hinweis auf eine Alternativdiagnose vor, kann klinisch eine wahrscheinliche CJK diagnostiziert werden. 
Da die Sensitivität des RT-QuIC in vorangegangenen Studien bei ca. 85\% (Cramm et al 2015) und in dieser Untersuchung nur bei 57\% lag, können über das erste Kriterium nicht alle CJK-Patienten diagnostiziert werden. Hier greift das zweite Teilkriterium; es diagnostiziert Patienten mit einer Demenz oder einer zerebellaren Symptomatik sowie einem negativen RT-QuIC, aber positiven Befunden für die Proteine 14-3-3 sowie typischen Veränderungen im cMRT oder EEG ohne Hinweis auf eine Alternativdiagnose.

Für die entwickelten Kriterien berechnen sich im Vergleich zu den aktuell gültigen Kriterien folgende relevante Werte:

Tabelle 28: Sensitivität und Spezifität der“ neu entwickelten“ Kriterien im Vergleich zu den Kriterien der DGN 2012

\begin{tabular}{|l|c|c|}
\hline & Neue Kriterien & Aktuelle Kriterien \\
\hline Sensitivität* (\%) & 91,5 & 84 \\
\hline Spezifität** (\%) & 84 & 69 \\
\hline PPW (\%) & 91,5 & 73 \\
\hline * Sensitivität errechnet aus verkleinertem Patientenkollektiv $(n=106)$ & \\
** Spezifität errechnet aus verkleinertem Kontrollkollektiv $(n=56)$
\end{tabular}

Hierbei ist zu beachten, dass die Werte für die Sensitivität aus einem verkleinerten Patientenkollektiv und die Spezifität aus einem verkleinerten Kontrollkollektiv berechnet wurden. Grund hierfür ist, dass für das zweite Teilkriterium ein cMRT bzw. EEG zwingend vorliegen muss; diese Bedingung wurde jedoch nur von 106 der 107 Patienten im Patientenkollektiv und von 56 der 68 Patienten im Kontrollkollektiv erfüllt.

\subsubsection{Zeitpunkt der Diagnosestellung anhand der „neu entwickelten Diagnosekrite- rien"}

Betrachtet man den Zeitpunkt der Diagnosestellung mittels der „neu entwickelten Kriterien", so zeigte sich, dass nun 15\% der Fälle bereits im ersten Drittel und die meisten Fälle im zweiten Drittel diagnostiziert werden (46\%). Im dritten Drittel werden 32\% der Fälle diagnostiziert, und 7\% der Fälle können auch anhand der neuen Kriterien nicht sicher klassifiziert werden. 
"neu entwickelte Diagnosekriterien": Diagnosestellung nach Dritteln

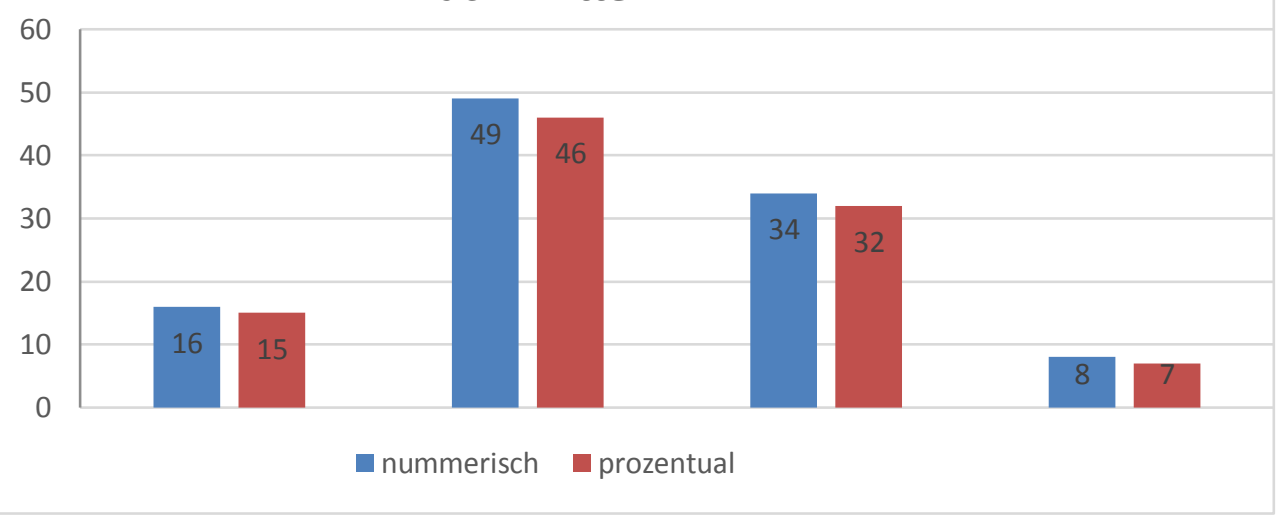

Abbildung 8: Neue Diagnosekriterien Diagnosestellung nach Dritteln

Sieht man die Zahlen der Diagnosestellung nach Drittel der DGN 2012 und der „neu entwickelten Kriterien" im Vergleich, zeigt sich zum einen, dass insgesamt mehr Fälle als wahrscheinliche CJK klassifiziert werden können (DGN Kriterien 2012 82\%, „neu entwickelte Kriterien" 93\%) und zum anderen, dass sich der Zeitpunkt der Diagnose nach vorne verschiebt. Anhand der alten Kriterien wurden die meisten Fälle (43\%) erst im letzten Drittel als wahrscheinliche CJK diagnostiziert, mittel der neuen Kriterien verschiebt sich der Zeitpunkt der wahrscheinlichsten Diagnosestellung in das zweite Drittel (46\%). Weiterhin werden im Vergleich zu den DGN Kriterien 2012 durch die „neu entwickelten Kriterien" fast doppelt so viele Fälle im ersten Drittel diagnostiziert. 


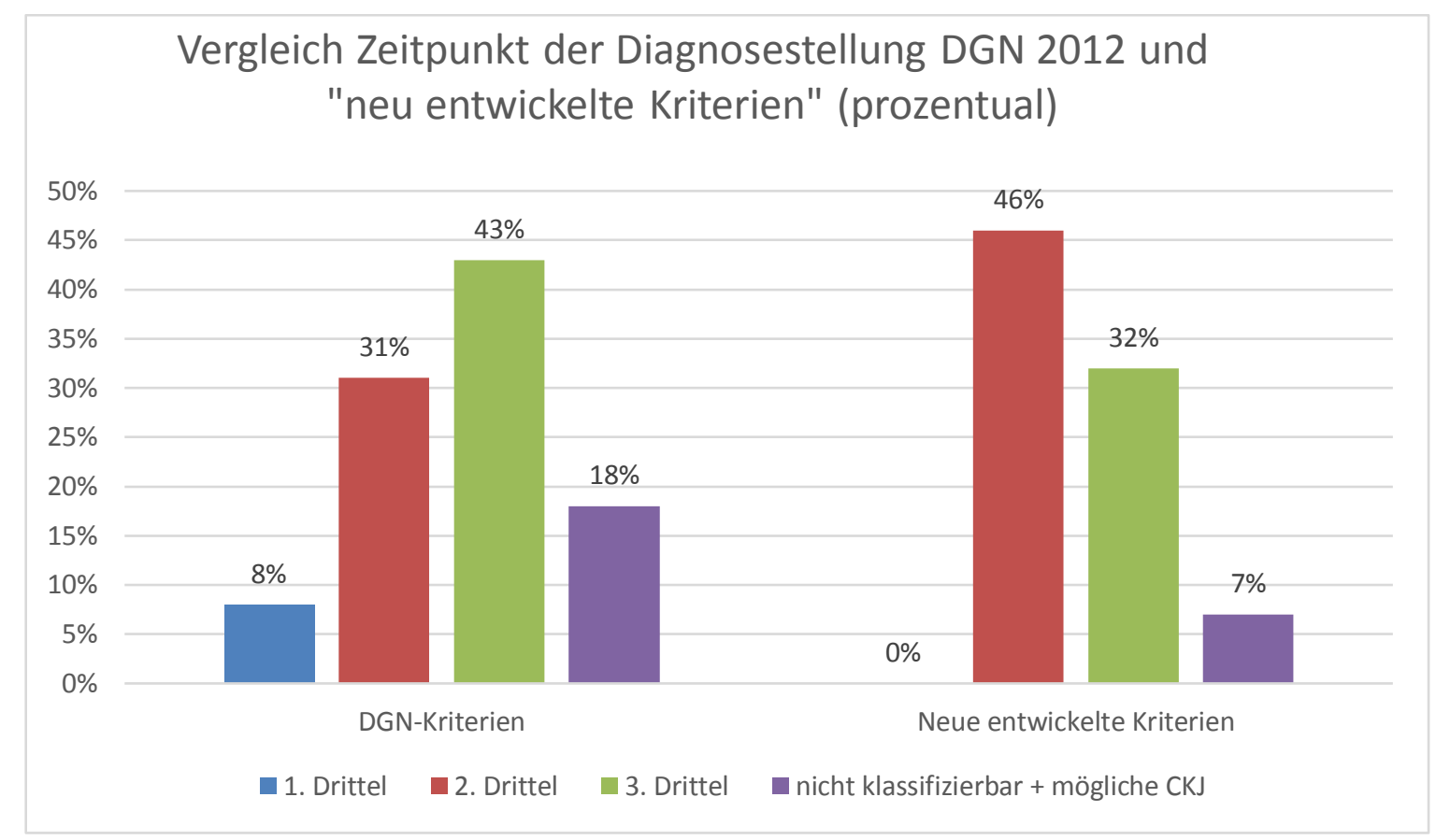

Abbildung 9: Vergleich Zeitpunkt der Diagnosestellung DGN 2012 und neu entwickelte Kriterien (prozentual)

3.12.2 Diagnosestellung des VV2-Subtyps anhand der neu entwickelten Diagnosekriterien

Betrachtet man zusätzlich die Subtypenklassifizierung, zeigt sich, dass vor allem der VV2Subtyp früher diagnostiziert werden kann.

Anhand der neu entwickelten Kriterien können im Fallkollektiv alle subklassifizierten VV2-Fälle diagnostiziert werden. Hierbei ist zu beachten, dass nur bei $55 \%$ der Fälle im Fallkollektiv eine Subtypisierung anhand des Prionproteintyps durchgeführt wurde (Vergleiche Abschnitt 3.2).

Im Weiteren können mittels der neu entwickelten Kriterien 62,5\% der VV2-Fälle in den ersten beiden Dritteln diagnostiziert werden. Im Vergleich konnten durch die DGN Kriterien 2012 nur ein Viertel der VV2-Fälle in einem frühen Stadium (erstes und zweites Drittel) diagnostiziert werden. 


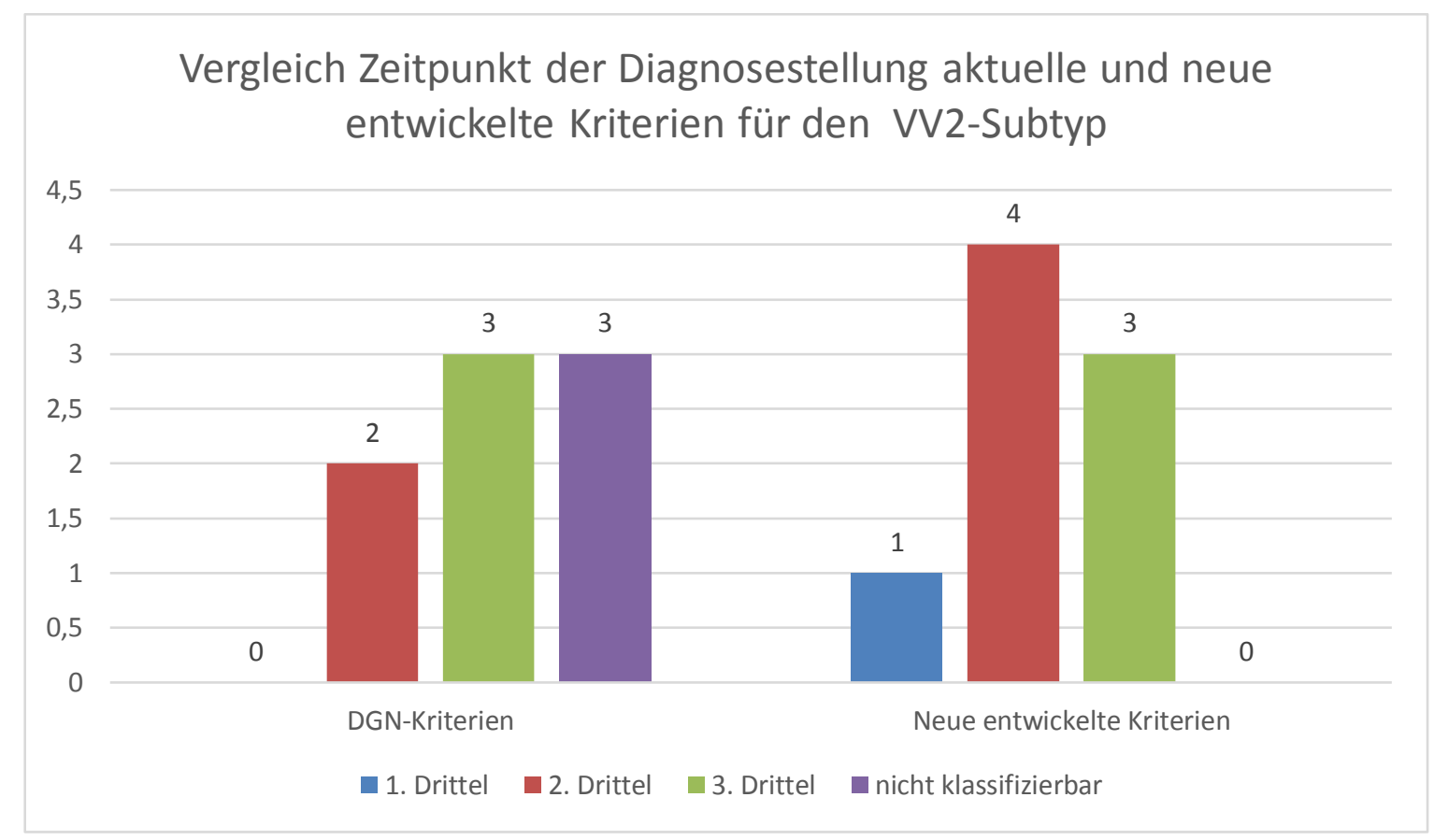

Abbildung 10: Vergleich Zeitpunkt der Diagnosestellung aktuelle und neu entwickelte Kriterien für den VV2-Subtyp

Auch in den weiteren Subtypen konnten Effekte, wie sie in Abschnitt 3.12.1 beschrieben werden, beobachtet werden; diese sind jedoch nicht so stark ausgeprägt wie beim Subtyp VV2 und werden daher nicht im Einzelnen aufgelistet. 


\section{DISKUSSION}

Die vorangegangene Die vorangegangene Analyse beschäftigte sich zunächst mit den Diagnosekriterien der DGN von 2012 sowie ihrer klinischen Anwendung. Damit war die Zielsetzung verbunden, Stärken und Schwächen der Kriterien zu erkennen und im weiteren Schritt zu versuchen, die Diagnosestellung im Hinblick auf eine frühere, aber auch eine verlässlichere Diagnose zu optimieren. Für diesen zweiten Schritt wurde die Methode der logistischen Regressionsanalyse gewählt; diese entspricht derzeit dem Goldstandard in der Entwicklung neuer Prognose- und Diagnosemodelle gemäß dem Statement zum „transparent reporting of a multivariable prediction model for individual prognosis or diagnosis" (TRIPOD-Statement) (Collins et al. 2015). Bereits in der Vergangenheit wurden immer wieder Analysen einzelner diagnostischer Test bezüglich ihres möglichen Nutzens für die verbesserte Diagnosestellung einer CJK durchgeführt (z. B. Weber et al. 1997a; Skillbäck et al. 2014). Hieran zeigt sich zum einen, dass die Diagnosestellung einer CJK auf Grund der Heterogenität sowohl des klinischen Verlaufs als auch der Befunde in den technischen Zusatzuntersuchungen nicht immer einfach ist. Zum anderen weisen die Bemühungen darauf hin, dass eine Verbesserung der Diagnosekriterien für möglich gehalten wird.

Eine vergleichbare Analyse der diagnostischen Kriterien der DGN 2012 für die Creutzfeldt-Jakob-Erkrankung in Deutschland in ihrer Gesamtheit ist bisher noch nicht durchgeführt worden. Somit schließt diese Analyse eine wissenschaftliche „Lücke“ und kann als Grundlage für weitere Analysen zur Verbesserung der Diagnosekriterien für die CJK dienen.

Wie bereits in der Einleitung der Arbeit erwähnt (s. Abschnitt 1.8), wurden während er Anfertigung der Arbeit die Diagnosekriterien der DGN überarbeitet und der RT-QuIC in die Kriterien aufgenommen. Eine Einordnung dieser Aktualisierung in Bezug auf die vorliegende Arbeit erfolgt im Kapitel 5.

\subsection{Das Studienmodell}

Für die Analyse wurde eine retrospektive Fall-Kontroll-Studie durchgeführt. Diese erlaubt nicht nur die Bestimmung der Sensitivität der diagnostischen Tests in Bezug auf 
eine CJK und der Diagnosekriterien in ihrer Gesamtheit, sondern auch die Bestimmung der Spezifität und der Genauigkeit. In der Studie wurden die Diagnosekriterien der DGN von 2012 der Analyse zu Grunde gelegt.

\subsection{Limitationen der Studie}

Die ausgewählten Patientendaten sind der Datenbank des NRZ für TSE entnommen. Dies bedeutet, dass bei allen Patienten zu einem Zeitpunkt im Krankheitsverlauf der Verdacht auf eine Prionerkrankung bzw. eine Creutzfeldt-Jakob-Erkrankung bestanden hat. Da es sich bei der CJK um eine Enzephalopathie, also eine Erkrankung handelt, die in der Regel das gesamte Gehirn und nicht nur einzelne Teilbereiche mit isolierter Symptomatik betrifft, kann man davon ausgehen, dass bei allen Patienten im Kontrollkollektiv ebenfalls eine erhebliche neurologische/enzephalopathische Symptomatik bestanden hat, die an die Diagnose einer CJK hat denken lassen. Insofern waren alle Patienten im Kontrollkollektiv schwer erkrankt (vergleiche Tabelle acht), so dass im Kontrollkollektiv nicht die gesamte Breite an neurologischen Patienten repräsentiert wird. Diese Vorselektierung kann unter anderem zu verfälschten - in diesem Fall unterschätzten - Werten bei der Berechnung der Spezifitäten der einzelnen diagnostischen Tests, aber auch der Diagnosekriterien in ihrer Gesamtheit führen. Im Weiteren wurde Werte für Sensitivität und Spezifität der einzelnen diagnostischen Tests sowie der aktuellen Diagnosekriterien ermittelt; Bezugsgröße bildeten die vorliegenden neuropathologischen Befunde. Dies führt häufig zu einer verification bias, welche - gemäß einem Paper A. Karchs - zwar zu validen Werten für die Sensitivität, verursacht jedoch massiv unterschätzen Werten für die Spezifität (Karch et al. 2016). Dieser Effekt wurde in der vorliegenden Untersuchung bei der Auswahl des Patientenkollektivs diskutiert, auf Grund der Schwierigkeit, ein Kontrollkollektiv mit vollständigem Datensatz zu rekrutieren, jedoch in Kauf genommen. 


\subsection{Deskriptive Analyse des Patientenkollektivs}

\subsubsection{Fallkollektiv}

Das mediane Erkrankungsalter liegt im Fallkollektiv bei 65 Jahren und entspricht dem medianen Erkrankungsalter vorangegangener Untersuchungen von CJK-Patientenkollektiven (z. B. Pocchiari et al. 2004). Die mediane Erkrankungsdauer beträgt 5,1 Monate und liegt im Mittel der in der Literatur beschriebenen Erkrankungsdauer von vier bis sechs Monaten (Pocchiari et al. 2004). Der gemittelte Wert für die Erkrankungsdauer liegt bei neun Monaten. Das Geschlechterverhältnis beträgt bei 45 männlichen und 62 weiblichen Patienten 1:1,38 zu Ungunsten der Frauen. Somit sind Frauen etwas häufiger betroffen als Männer; auch diese Verteilung entspricht vorangegangenen epidemiologischen Untersuchungen von Patientenkollektiven mit CJK-Patienten (z. B. Will et al. 1998). Da die CJK eine sehr seltene Erkrankung darstellt, ist das Datenkollektiv für diese Patienten in der Regel klein. Bei dieser Untersuchung wurde auf Patientendaten aus einem Zeitraum von 14 Jahren zurückgegriffen; dies ermöglicht die große Fallzahl im Fallkollektiv. Allerdings muss berücksichtigt werden, dass in diesem langen Zeitraum von 14 Jahren auf dem Gebiet der Prionerkrankungen und insbesondere der sporadischen CreutzfeldtJakob-Erkrankung einige neue Forschungsergebnisse erzielt wurden, die die Sichtweise im Hinblick auf die Diagnosestellung verschoben haben. Dies ist unter anderem im Hinblick auf die Integration der Proteine 14-3-3 und der cMRT in die Diagnosekriterien zu berücksichtigen. Diese Erkenntnisse können den Zeitpunkt der Äußerung des Verdachts auf eine CJK und somit beispielsweise auch den Zeitpunkt der Lumbalpunktion verändert haben und dadurch wiederum zu verzerrten Werten beispielsweise bei der Ermittlung des Diagnosezeitpunkts führen.

\subsubsection{Das Kontrollkollektiv}

Das mediane Erkrankungsalter liegt im Kontrollkollektiv bei 73 Jahren und somit sechs Jahre über dem Erkrankungsalter im Patientenkollektiv. Die mediane Erkrankungsdauer im Kontrollkollektiv beträgt 5,3 Monate, gemittelt beträgt die Überlebensdauer 15 Monate. Auch die Erkrankungsdauer unterscheidet sich somit signifikant ( $p=5,874 \mathrm{e}-11$ ) 
von der Erkrankungsdauer im Patientenkollektiv. Das Geschlechterverhältnis ist im Kontrollkollektiv mit einem Verhältnis von 1:1,06 nahezu ausgeglichen.

\subsection{Molekulare Subtypen der Creutzfeldt-Jakob-Erkrankung}

Die Normalverteilung des Polymorphismus der europäischen Bevölkerung zeigt bei $37 \%$ den MM-Subtyp, bei 51\% den MV-Subtyp und bei 12\% den VV-Subtyp (Head 2013). Die Verteilung des Polymorphismus am Codon 129 im Patientenkollektiv entfällt mit 65\% auf Patienten mit dem Genotyp MM, mit $18 \%$ auf den Genotyp MV und mit 16\% auf den Genotyp VV. Dies entspricht in etwa der Verteilung, wie sie auch in anderen Studien in Patientenkollektiven von CJK-Patienten ermittelt wurde (Parchi et al. 1999; Krasnianski et al. 2004). Die weitere Subtypenspezifizierung bezüglich des Prionproteintyps ließ sich nur für etwas mehr als die Hälfte der Patienten (55 \%) nachvollziehen. Hierbei zeigt sich eine Verteilung von 68\% auf den MM1-/MV1-Subtyp, 16\% auf den VV2-Subtyp, 5\% auf MM2-Subtyp - eine weitere Unterteilung in den kortikalen MM2-Subtyp und den thalamischen MM2-Subtyp wurde nicht durchgeführt - sowie 3\% auf den MV2-Subtyp. Jeweils $2 \%$ der bezüglich des Subtyps untersuchten Patienten hatten einen MM1/2-, MV1/2- und VV1/2-Subtyp. Auch dies entspricht in etwa dem Verteilungsmuster früherer Untersuchungen (Parchi et al. 1999).

Wie bereits in der Einleitung (siehe Abschnitt 1.7) dieser Arbeit beschrieben, unterscheiden sich die verschiedenen Subtypen im klinischen Verlauf, in der Erkrankungsdauer und in den Befunden der apparativen Zusatzdiagnostik. Damit rückt ein wichtiger Aspekt ins Blickfeld: Aufgrund der Varietät der Erkrankung, insbesondere in ihrem frühen Stadium, können weder die etablierten, noch die in dieser Studie entwickelten Diagnosekriterien alle Patienten bzw. Krankheitsverläufe abdecken bzw. aufdecken. Somit ist es nicht Ziel der weitergehenden Untersuchung, für Sensitivität und Spezifität Werte von $100 \%$ zu erreichen, sondern bei hohen Werten der Sensitivität eine Kombination an Parametern zu ermitteln, die in einem frühen Stadium der Erkrankung so spezifisch wie möglich die tatsächlichen CJK-Patienten identifizieren kann. Hierbei soll der Focus auf einer möglichst hohen Spezifität liegen, um so wenig wie möglich falsch positive Ergebnisse zu erhalten, und somit Patienten mit einer potentiell behandelbaren Erkrankung einer Therapie zuführen zu können. 


\subsection{Die Diagnosekriterien der DGN von 2012}

Im Folgenden werden die Ergebnisse der Analyse der Diagnosekriterien der DGN 2012 für die CJK diskutiert. Zunächst wird die klinische Symptomatik betrachtet, im Anschluss werden die Ergebnisse für die apparative Diagnostik analysiert. Da es thematische sinnvoll erscheint, werden hier auch Ergebnisse des RT-QuIC in einem separaten Unterpunkt mit einbezogen, auch wenn diese kein Bestandteil der Diagnosekriterien der DGN von 2012 sind.

\subsubsection{Klinische Symptomatik}

Bei der Erhebung der klinischen Symptomatik muss berücksichtigt werden, dass diese aus Anamneseerhebungen, Arztbriefen, Untersuchungsbefunden sowie epidemiologischen Erfassungsbögen der jeweiligen Patientenakten der Datenbank des NRZ für TSE entnommen wurde. Dies bedeutet, dass die klinischen Befunde bezüglich der Symptomatik durch verschiedene, jedoch stets ärztliche Untersucher erhoben wurden. Interindividuelle Unterschiede bei der Erhebung der klinischen Befunde können daher nicht ausgeschlossen werden.

In Verbindung damit ist auch der Anspruch auf Vollständigkeit hinfällig. Zum einen werden die Informationen nach Diagnosestellung und Verlegung in andere Pflegeeinrichtungen oder das häusliche Umfeld meist spärlich. Zum anderen ist es, insbesondere zu Beginn der Erkrankung, häufig schwierig, den exakten Zeitpunkt des Auftretens von Symptomen zu definieren, da hier meist nur auf Berichte von Angehörigen zurückgegriffen werden kann.

Als Schlüsselsymptom der CJK ist die Demenz zu sehen. Sie tritt sowohl im Fallkollektiv mit $96 \%$ als auch im Kontrollkollektiv mit 90\% wie erwartet sehr häufig auf. Bei den 4\% der Patienten im Fallkollektiv, bei denen über keine Demenz berichtet wird, ist, wie bereits beschrieben, davon auszugehen, dass ein Problem der Datenerhebung vorliegt und dass auch diese Patienten im Verlauf der Erkrankung eine dementielle Entwicklung gezeigt haben. Über die Hälfte (55\%) der CJK-Patienten zeigen eine dementielle Entwicklung bereits im ersten Drittel der Erkrankung. 90\% der Patienten entwickeln eine Demenz in den ersten beiden Erkrankungsdritteln. 
Die zerebellare Symptomatik kann ebenfalls als unspezifische Symptomatik (83\% Auftretenswahrscheinlichkeit im gesamten Patientenkollektiv) bewertet werden. Hier fällt jedoch auf, dass sich eine zerebellare Symptomatik mit 93\% Auftretenswahrscheinlichkeit im Fallkollektiv wesentlich häufiger zeigt als bei Patienten im Kontrollkollektiv (68\% Auftretenswahrscheinlichkeit). Die zerebellare Symptomatik tritt bei über $90 \%$ der CJK-Patienten in den ersten beiden Erkrankungsdritteln auf.

Die kortikale Sehstörung kann im Vergleich zur Demenz und zur zerebellaren Symptomatik als eher spezifisches Symptom für die CJK gewertet werden. Sie tritt im Fallkollektiv bei einem Fünftel der Patienten auf. Bei Patienten im Kontrollkollektiv hingegen wird nur für 4\% der Patienten über eine kortikale Sehstörung berichtet. Tritt sie bei CJK-Patienten auf, so geschieht dies am häufigsten schon im ersten Erkrankungsdrittel (62\%).

Eine pyramidale Symptomatik tritt bei 58\% der CJK-Patienten auf. Selten präsentiert sie sich als frühe Symptomatik (14\% im ersten Drittel). Die meisten Patienten entwickeln eine pyramidale Symptomatik erst im letzten Drittel (52\%) der Erkrankung.

Extrapyramidale Symptomatik und Myoklonien treten bei ca. $80 \%$ der untersuchten CJKPatienten auf. Im Kontrollkollektiv wird über eine extrapyramidale Symptomatik bei 63\% der Patienten, über das Auftreten von Myoklonien sogar nur bei jedem zweiten Patienten (49\%) berichtet. Die Verteilung über die Erkrankungsdauer zeigt, dass weder die extrapyramidale Symptomatik noch Myoklonien früh (extrapyramidale Symptomatik 21\% im ersten Drittel, Myoklonien 14\% im ersten Drittel) im Krankheitsverlauf auftreten, sondern eher im weiteren Verlauf hinzukommen.

Als akinetischer Mutismus wird der Endzustand im Verlauf einer CJK bezeichnet, in dem keine Kommunikation und keine eigenständige Bewegung der Patienten mehr möglich ist. Dieser Zustand wird für 57\% der CJK-Patienten beschrieben. Im Kontrollkollektiv wird ein ähnlicher Zustand für 24\% der Patienten dokumentiert.

Der akinetische Mutismus als zumeist präfinaler Endzustand einer CJK tritt, wie erwartet, vor allem im letzten Erkrankungsdrittel auf. 18\% der Patienten erreichen diesen Zustand schon im zweiten bzw. sogar schon im ersten Erkrankungsdrittel; hier muss davon aus- 
gegangen werden, dass die Erkrankungsdauer dieser Patienten durch supportive Maßnahmen, wie z. B. eine PEG-Sonde, über die normale Erkrankungsdauer hinaus verlängert wurde.

Zusammenfassend lässt sich sagen, dass neben der Demenz auch die zerebellare Symptomatik und die kortikale Sehstörung in der Regel früh im Krankheitsverlauf auftreten und somit als Frühsymptome einer CJK gewertet werden können. Diese Beobachtung wird auch in einer Studie zu Früh- und Prodromalsymptomatik bei CJK-Patienten von Krasnianski et al. (2014) gemacht, in der Demenz mit 37\% als häufigstes erstes Symptom bei CJK in Deutschland berichtet wird. Danach folgt eine zerebellare Symptomatik (34\%) als zweithäufigstes erstes Symptom und die kortikale Sehstörung (15\%) als dritthäufigstes erstes Symptom bei CJK-Patienten (Krasnianski et al. 2014).

Zur eher späten Symptomatik oder Spätsymptomatik zählen demnach die extrapyramidale und pyramidale Symptomatik sowie Myoklonien und der akinetische Mutismus.

Außer der kortikalen Sehstörung, die im Fallkollektiv fünfmal so häufig auftritt wie im Kontrollkollektiv, und dem akinetischen Mutismus, der im Fallkollektiv mehr als doppelt so häufig wie im Kontrollkollektiv auftritt, ist die untersuchte Symptomatik nicht sehr spezifisch für eine Creutzfeldt-Jakob-Erkrankung, sondern tritt in ähnlicher Häufigkeit auch bei vielen anderen neurologischen Erkrankungen auf. Dies liegt zum einen daran, dass gesamte Symptomkomplexe (Demenz: Einschränkung höherer kortikaler Funktionen (Masuhr et al. 2013)) und nicht nur einzelne Symptome betrachtet werden. Zum anderen tritt die Demenz als Leitsymptom bei vielen neurokognitiven Krankheitsbildern auf (z. B. fronto-temporale Demenz, Lewy-body-Demenz, vaskuläre Demenz etc.). Auch für die Symptomkonstellation Demenz und Bewegungsstörung gibt es zahlreiche Differenzialdiagnosen (z. B. Huntigton-Krankheit, Demenz im Zusammenhang mit der Parkinson-Krankheit). Ähnlich verhält es sich bei Myoklonien; diese können durch die Schädigung verschiedener Gehirnareale verursacht werden und zur unterschiedlichen Ausprägung ein und desselben Symptoms führen.

Die breite Fächerung der in die Diagnosekriterien aufgenommenen Symptomatik ist, wie bereits im vorangegangen Abschnitt beschrieben, notwendig, um die Symptomvarianz 
in den verschiedenen Subtypen abzudecken. Es verdeutlicht nochmals, dass die klinischen Verläufe der CJK sehr variabel sind und sich vor allem im raschen Voranschreiten der Erkrankung als gemeinsamem Merkmal treffen.

\subsubsection{Liquordiagnostik}

Im nächsten Abschnitt werden die Ergebnisse der Analyse der Liquorparameter und Liquoruntersuchungen diskutiert.

\subsubsection{Proteine 14-3-3}

Die Sensitivität der Proteine 14-3-3 fiel in der durchgeführten Studie mit 84\% etwas niedriger aus als in anderen Untersuchungen wie z. B. bei Collins et al. (2000) mit einer Sensitivität von 91\% oder bei Schmitz et al. (2016) mit einer Sensitivität von 88\%. Die Spezifität hingegen fiel mit 25\% im Vergleich zu Collins et al. (2000) und Schmitz et al. (2016) mit jeweils einer Spezifität von 96\% unverhältnismäßig niedrig aus. Dieser Abweichung im Vergleich zu andern Untersuchungen liegen zwei Ursachen zu Grunde: Zum einen führt, wie schon beschrieben, das anhand der Protein 14-3-3 Diagnostik vorselektierte Kontrollkollektiv zu den niedrigen Werten für die Spezifität. Zum anderen kann die Ermittlung der Spezifität anhand eines autoptisch gesicherten Patientenkollektiv zu unterschätzen Werten für die Spezifität der Proteine 14-3-3 führen (Karch et al. 2016). Diese beiden Effekte zusammen können aus meiner Sicht die niedrigen Werte für die Spezifität der Proteine 14-3-3 im Liquor hinreichend erklären. Allerdings muss berücksichtigt werden, dass die niedrigen Werte auch Auswirkungen auf die Ergebnisse - insbesondere der statistischen Signifikanz für die Proteine 14-3-3 - der durchgeführten logistischen Regressionsanalyse haben. Hierauf soll später bei der Diskussion der Ergebnisse der logistischen Regressionsanalyse genauer eingegangen werden.

\subsubsection{Gesamt-tau im Liquor}

Für das Gesamt-tau berechnet sich die Sensitivität in dieser Untersuchung mit $86 \%$ und liegt somit etwas höher als die Sensitivität der Proteine 14-3-3. Die Spezifität beträgt 54\% und ist doppelt so hoch wie für die Proteine 14-3-3. Auch hier spielt das vorselektierte 
Kontrollkollektiv mit neurologisch schwer erkrankten Patienten, wie bereits beschrieben, eine Rolle und erklärt die niedrigen Werte für die Spezifität der beiden unspezifischen Destruktionsmarker Gesamt-tau und Protein 14-3-3.

\subsubsection{PrPSc-Aggregationsassay}

Im Rahmen dieser Untersuchung wurde für alle Patienten ein $\mathrm{PrPS}^{\mathrm{Sc}}$-Aggregationsassay durchgeführt. Die Sensitivität für den RT-QuIC liegt in dieser Untersuchung bei $57 \%$ und damit wesentlich unter den Werten vorangegangener Untersuchungen zur Sensitivität dieses Tests; die Spezifität liegt in der vorliegenden Untersuchung bei $94 \%$. Wie in der Einleitung (s. Abschnitt 1.5.3.4) dargelegt zeigt eine aktuelle Untersuchung zur Stabilität und Reproduzierbarkeit der Testergebnisse des RT-QuIC von M. Cramm (2015) eine Sensitivität von $85 \%$ und eine Spezifität von 99\% (McGuire et al. 2016). Eine internationale Studie mit zwei Ringversuchen aus dem Jahr 2016 konnte sogar eine Gesamtsensitivität des RT-QulC von 85\%-100\% sowie eine Spezifität von 100\% erreichen (McGuire et al. 2016).

Hauptursache für die Abweichungen bei Sensitivität und Spezifität in der vorliegenden Untersuchung im Vergleich zu anderen Studien ist die unterschiedliche Durchführung des RT-QuIC. Zu diagnostischen Zwecken - und so auch bei den oben genannten Studien - wurde der RT-QuIC dreimal angesetzt. Hierbei wurde ein RT-QuIC, der in zwei von drei dieser Durchläufe positiv ausgefallen war, im Endergebnis als positiv gewertet. Proben, die in keinem oder einem von drei Durchläufen positiv waren, wurden im endgültigen Ergebnis als negativ gewertet.

In der vorliegenden Untersuchung hingegen wurde zugunsten einer hohen Fallzahl nur ein Durchlauf pro Patient durchgeführt. Somit können Patienten, die in einer diagnostischen Testung mit zwei von drei positiven Durchläufen als endgültig positiv bewertet worden wären, in der vorliegenden Untersuchung unter Umständen fälschlicherweise als negativ diagnostiziert worden sein, wenn sie beim ersten - und in diesem Fall einzigen - Durchlauf ein negatives Ergebnis erbracht haben. Weiterhin wurden Patienten in der Kontrollgruppe, die einen positiven Durchlauf hatten, als positiv gewertet, obwohl sie in einer diagnostischen Testung mit drei Durchläufen möglicherweise nur in diesem 
einen Durchlauf positiv gewesen wären, und somit in diesem Fall fälschlicherweise positiv gewertet worden sind.

Weiterhin muss auch der Einfluss der zum Teil langen Lagerungszeit des Liquors von mehr als zehn Jahre auf die Ergebnisse des RT-QulC diskutiert werden. Ein Studie von Cramm et al. (2015), welche die Reproduzierbarkeit von RT-QulC-Ergebnissen unter verschieden Bedingungen getestet hat, konnte keine Verfälschung der getesteten Proben durch Langzeitlagerung bis zu neun Jahren sowie nach mehrfachen Auftau- und Einfriervorgängen (bis zu 16-mal) feststellen; jedoch liegen keine Daten für Lagerungen länger als neun Jahre und häufigere Ein- und Auftauvorgänge vor.

In der vorliegenden Untersuchung betrifft dieser Sachverhalt 59 Patienten (55\%) im Fallkollektiv, welche in den Jahren 2001-2005 erkrankten, so dass deren Liquor zum Zeitpunkt der Durchführung des RT-QuIC (2015) eine Lagerungszeit von mehr als neun Jahren aufwies. Im Fallkollektiv erkrankten 48 Patienten (45\%) in den Jahren 2006-2014, hier lag die Liquorlagerungszeit somit bei weniger oder gleich neun Jahren zum Zeitpunkt der durchgeführten RT-QuIC-Untersuchung. Die Anzahl der Einfrier- und Auftauvorgänge der einzelnen Liquorproben lässt sich aktuell nicht nachvollziehen.

Im Kontrollkollektiv erkrankten 21 Patienten (30\%) in den Jahren 2001 bis 2005. Somit bestand zum Zeitpunkt der RT-QuIC-Durchführung (2015) eine Liquorlagerungszeit von mehr als neun Jahren. 47 Patienten (70\%) erkrankten im Zeitraum von 2006-2014.

Auch für das Kontrollkollektiv lässt sich die Anzahl der Einfrier- und Auftauvorgänge nicht nachvollziehen.

Zusammenfassend kann die einmalige Durchführung des RT-QuIC die niedrigeren Werte in dieser Untersuchung sowohl hinsichtlich der Sensitivität als auch der Spezifität ausreichend erklären.

Weiterhin kann ein Einfluss der zum Teil langen Lagerungszeit von mehr als neun Jahren auf die Ergebnisse der RT-QulC-Untersuchung nicht ausgeschlossen werden.

Die Relevanz des RT-QulC wird nochmals bei der Diskussion der Ergebnisse der logistischen Regressionsanalyse aufgegriffen. 


\subsubsection{EEG}

Das EEG ist lange Zeit die wichtigste apparative Diagnostik zur Diagnosestellung der CJK gewesen (Masters et al. 1979), bevor es durch neue diagnostische Möglichkeiten wie Liquoruntersuchung und cMRT abgelöst wurde. Die Werte für das EEG in dieser Untersuchung liegen bei 39\% Sensitivität und $89 \%$ Spezifität. Auch andere Studien mit ähnlichem Fall- und Kontrollkollektiv (neuropathologisch gesicherte CJK-Fällen vs. neuropathologisch CJK ausgeschlossen) zeigen ähnliche Werte für Sensitivität und Spezifität (z. B. Zerr et al. 2009).

Andere Studien konnten deutlich höhere Werte für die Sensitivität und Spezifität ermitteln. Als Ursache für die niedrigere Sensitivität im Vergleich mit Studien von Steinhoff et al. (1998) und Zerr et al. (2000) mit Sensitivitäten von 66\% bzw. 67\% ist die nicht standardisierte Erhebung im Krankheitsverlauf anzuführen. Da in der Regel nur ein EEG im Krankheitsverlauf zur Beurteilung vorlag und es keine Verlaufsuntersuchung gab, wurde bei einigen Patienten ein EEG im frühen Krankheitsverlauf ausgewertet, welches keine typischen Befunde aufwies. Da sich Veränderungen im EEG aber vor allem im späten Krankheitsverlauf zeigen (Steinhoff et al. 1998), könnte sich diese im Verlauf der Erkrankung noch ausgebildet haben und sind bei der Untersuchung nicht erhoben worden. Dies führt zu den beschriebenen Abweichungen bei den Werten der Sensitivität.

Die Spezifität des EEG in dieser Studie wurde mit 89\% berechnet. Dies entspricht in etwa der Spezifität früherer Studien (Steinhoff et al. 1998). Auch hier muss bei nur punktueller Betrachtung des EEG eine Überschätzung der Spezifität berücksichtig werden, da auch im Kontrollkollektiv durch die Beurteilung von EEGs in früheren Erkrankungsphasen typische Pathologien nicht erfasst worden sein können, die als falsch positiv hätten gewertet werden können.

Insgesamt ist die Bedeutung des EEG für die Diagnosestellung nach Etablierung moderner Diagnoseverfahren (Liquor, cMRT) eher in den Hintergrund gerückt. Trotz einfacher und kostengünstiger Durchführung ist das EEG auf Grund der niedrigen Sensitivität als diagnostisches Instrumentarium kaum von Relevanz. Hinzu kommt, dass das Auftreten der typischen Pathologien im EEG in der Regel für späte Erkrankungsphasen beschrieben wird (Steinhoff et al. 1998). Diese Befunde können dann zur Festigung der Diagnose einer CJK beitragen, haben in der Regel aber wenig richtungsweisende Bedeutung. 


\subsection{4 $c M R T$}

Das CMRT als diagnostisches Hilfsmittel im Rahmen der Diagnosefindung einer CJK wurde 2009 als letzte Neuerung in die WHO-Diagnosekriterien mit aufgenommen. Allerdings war der Nutzen des CMRT bei der Diagnosestellung einer CJK auch schon vorher bekannt (u. a. Finkenstaedt et al. 1996; Schröter et al. 2000).

Young et al. (2005) berichten über eine Sensitivität des cMRT von 83\% und eine Spezifität von sogar 92\% bei Betrachtung der diffusionsgewichteten und der FLAIR-Aufnahmen bezüglich Hyperintensitäten des Neocortex und der Basalganglien. Ebenfalls hohe Werte für Sensitivität (83\%) und Spezifität (83\%) der cMRT als Diagnosekriterium konnten in der Untersuchung von Zerr et al. (2009) bei Vorliegen von Signalsteigerungen in der DWI und/oder der FLAIR-gewichteten MRT-Aufnahmen in mindestens zwei kortikalen Regionen (temporal-parietal-occipital) alleine oder zusammen mit Signalsteigerungen im Nucleus caudatus und Putamen als typische Befunde für eine CJK erhoben werden.

Dies entspricht den Erkenntnissen, wie sie in die Leitlinie der deutschen Gesellschaft für Neurologie zur Diagnosestellung einer CJK (DGN 2012) eingegangen sind.

Die Sensitivität für das cMRT wurde in der aktuellen Untersuchung mit 71\% berechnet, die Spezifität beträgt 79\%. Neben einer Interobserver-Variabilität, welche eine subjektiv unterschiedliche Bewertung verschiedener Pathologien durch verschiedene Untersucher widerspiegelt, konnte - wie bei der Erhebung der EEG-Daten - in dieser retrospektiven Untersuchung kein standardisiertes Erhebungsverfahren der vorliegenden CMRTDaten bezüglich Erhebungszeitpunkt und Verlaufsuntersuchungen vorgenommen werden. Somit sind auch bei der cMRT die abweichenden Werte insbesondere für die Sensitivität durch die Beurteilung früher Aufnahmen im Krankheitsverlauf, die noch keine typischen Pathologien zeigen, erklärbar.

\subsection{Zeitliche Aspekte bei der Diagnosestellung einer Creutzfeldt-Jakob-Erkrankung}

\subsubsection{Zeitpunkt der Liquorpunktion}

Der Zeitpunkt der Liquorpunktion hat bei der Diagnosestellung einer CJK eine große Bedeutung. Er markiert in der Regel den Zeitpunkt, an dem klinisch der Verdacht auf eine 
Prionerkrankung diskutiert wird. Seit Einführung der Proteine 14-3-3 als diagnostischer Marker bei Patienten mit Verdacht auf eine CJK und Aufnahme der Proteine 14-3-3 in die Diagnosekriterien, ist die Diagnosestellung einer CJK ohne Vorliegen eines 14-3-3 Befundes kaum noch denkbar. Besteht also klinisch der Verdacht auf eine Creutzfeldt-Jakob-Erkrankung, wird in der Regel eine Liquorpunktion als einfache, kostengünstige sowie - bei Beachtung der klinischen Einschränkungen bezüglich der Spezifität - aussagekräftige diagnostische Methode durchgeführt (Hsich et al. 1996; Zerr et al. 1998; Schmitz et al. 2016). Zur Analyse der Diagnosekriterien wurde daher zunächst der Zeitpunkt der Liquorpunktion im Verlauf der Erkrankung als wichtiger Eckpunkt zur Diagnosestellung betrachtet.

Für die untersuchten Patienten im Fallkollektiv zeigt sich, dass nur in 18\% der Fälle eine Liquorpunktion im ersten Erkrankungsdrittel, beim weit größeren Teil der Patienten jedoch erst im zweiten oder dritten Drittel durchgeführt wurde. Dies deutet daraufhin, dass die Möglichkeiten der Liquorpunktion im Hinblick auf die Bestimmung der Proteine 14-3-3 und auf ihren möglichen Nutzen als Screening-Marker für das Vorliegen einer CJK noch viel zu wenig bzw. erst zu spät im Krankheitsverlauf genutzt werden. Eine Erhebungen zum Zeitpunkt der Liquorpunktion von Boesenberg-Grosse et al. (2006) von Patienten aus den Jahren 1993-2003 zeigt ebenfalls, dass wenige Patienten im ersten Erkrankungsdrittel eine Liquorpunktion (11\%) erhielten. Bei 21\% der Patienten wurde im zweiten Drittel und bei ca. zwei Drittel der Patienten (68\%) erst im dritten Drittel überhaupt eine Liquorpunktion durchgeführt (Boesenberg-Grosse et al. 2006).

Im Kontrollkollektiv der aktuellen Untersuchung verschiebt sich der Zeitpunkt der Liquorpunktion im Vergleich zum Fallkollektiv noch stärker auf das letzte Erkrankungsdrittel. 4\% der Patienten erhielten eine Liquorpunktion im ersten Drittel, 28\% der Patienten im zweiten Drittel und 66\% im dritten Drittel.

Diese Beobachtung deutet darauf hin, dass klinisch erst bei Entwicklung einer komplexen neurologischen Symptomatik an das Vorliegen einer CJK gedacht wird. Ziel sollte hingegen sein, dass bei Patienten frühzeitig eine Bestätigung bzw. ein Ausschluss der Verdachtsdiagnose angestrebt wird. 


\subsubsection{Zeitpunkt der Diagnosestellung}

In Korrelation zum Zeitpunkt der Liquorpunktion kann die Diagnose einer wahrscheinlichen CJK im untersuchten Fallkollektiv bei nur $8 \%$ der Patienten im ersten Erkrankungsdrittel gestellt werden. Dies liegt im vorliegenden Patientenkollektiv sowohl an fehlender Diagnostik als auch an nicht ausreichender klinischen Symptomatik im frühen Stadium der Erkrankung.

19 (18\%) Patienten im Fallkollektiv haben zwar bereits im ersten Drittel eine Lumbalpunktion mit positiver Bestimmung der Proteine 14-3-3 erhalten, jedoch können auf Grund der fehlenden Symptomatik nur neun der Patienten (8\%) auch im ersten Drittel als wahrscheinliche CJK klassifiziert werden. Daraus lässt sich schließen, dass die Diagnosekriterien der DGN 2012 sich nur schlecht als Screening-Kriterien eignen, um Patienten im Anfangsstadium der Erkrankung zu identifizieren

31\% der Patienten lassen sich im zweiten Drittel, der größte Teil der CJK-Patienten (43\%) lässt sich leider erst im dritten Drittel der Erkrankung klassifizieren. 14\% der Fälle lassen sich über den gesamten Krankheitsverlauf hinweg bei fehlender Klinik nicht klassifizieren. Mögliche Gründe hierfür wurden bereits im vorangegangenen Kapitel Studienmodell erörtert (insbesondere: Vollständigkeit der erhobenen Daten s. Abschnitt 4.1). Weiterhin wurden $4 \%$ der Fälle bei negativen diagnostischen Tests über den Krankheitsverlauf hinweg als mögliche CJK eingestuft.

Aus den erhobenen Daten errechnet sich rückblickend betrachtet eine Sensitivität von 86\% für die Diagnosestellung einer möglichen oder wahrscheinlichen CJK.

Betrachtet man das Kontrollkollektiv wurden hier 69\% der Patienten richtigerweise als anderer Fall klassifiziert. Dies beschreibt auch die Spezifität der Diagnosekriterien DGN 2012 rückblickend, also nach Verstreben der Patienten, betrachtet.

Um der klinischen Realität näher zu kommen, wurde die Sensitivität und Spezifität der Diagnosekriterien zum Zeitpunkt der Liquorpunktion betrachtet. Hier zeigt sich im Vergleich zur rückblickenden Betrachtung ein niedrigerer Wert für die Sensitivität von 75\%. Diese Beobachtung ist zu erwarten und erklärt sich zum einem durch die zeitlich punktuelle Betrachtung sowie den häufig früheren Betrachtungszeitpunkt. 
Es zeigt sich hier nochmals, dass es Verbesserungspotential für die Diagnosekriterien der DGN von 2012 im Hinblick auf eine frühere Diagnosestellung gibt.

Neben der vorangegangen beschriebene Schwierigkeit einer frühen Diagnosestellung mittels der Diagnosekriterien von 2012, ist die Spezifität von 69\% bei Betrachtung zum Zeitpunkt der Liquorpunktion im Vergleich zur rückblickenden Analyse der Diagnosekriterien gleichbleibend, insgesamt aber nicht zufriedenstellend. Eine Spezifität von 69\% bedeutet, dass formal in 31\% der Fälle eine CJK bei den betroffenen Patienten diagnostiziert wurde, obwohl diese Patienten nicht an einer CJK erkrankt waren. Diese Fehlerquote ist bei einer tödlichen Erkrankung ohne wirkliche Therapieoptionen bzw. der Gefahr einer Unterlassung von möglichen Behandlungsoptionen bei eigentlichem Vorliegen einer potentiell behandelbaren Erkrankung ist nicht akzeptabel.

In diesem Zusammenhang muss auch hier berücksichtige werden, dass zum einen die niedrigen Spezifitäten der einzelnen diagnostischen Tests, aber auch die wenig spezifische Symptomatik, die in die Diagnosekriterien eingeht, für die niedrige Spezifität der gesamten Diagnosekriterien mitverantwortlich ist. Aufgrund der - aus den erläuterten Gründen - in der vorliegenden Untersuchung deutlich unterschätzen Werte für die Spezifität der einzelnen diagnostischen Tests muss auch bei der Gesamtspezifität für die Diagnosekriterien von unterschätzten Werten ausgegangen werden. Dennoch hängt die Spezifität der Diagnosekriterien bei vielen Ursachen für falsch positive Ergebnisse in den einzelnen Untersuchungen entscheidend von einer breiten und sorgfältigen differenzialdiagnostische Abklärung aller Verdachtsfälle ab (Poser et al. 1999). Dieser Tatsache wird in den Diagnosekriterien durch den Zusatz „ohne Hinweise auf eine andere Ursache in der Diagnostik“ Rechnung getragen und muss stets berücksichtigt werden.

\subsection{Ergebnisse der logistischen Regressionsanalyse}

Im Folgenden sollen die Ergebnisse der logistischen Regressionsanalyse dargestellt und diskutiert werden. Im Weiteren wird die Entwicklung des auf den Ergebnissen der logistischen Regressionsanalyse basierenden Modells erläutert, ebenso werden dessen Limitationen aufgezeigt. 


\subsubsection{Nachteile des in der logistischen Regressionsanalyse entwickelten Modells}

Die logistische Regressionsanalyse ist ein Verfahren, um statistisch signifikante Parameter für die Diagnose oder Prognose des Auftretens einer Erkrankung zu ermitteln. Diese rein statistische Modellentwicklung führt jedoch zu Abstrichen in der klinischen Anwendbarkeit des entwickelten Algorithmus, die im Folgenden diskutiert werden sollen.

Das in Kapitel 3.8 vorgestellte Modell diagnostiziert bei gleichzeitiger Erfüllung aller Kriterien mit einer hohen Sensitivität und Spezifität Patienten mit einer sCJK. Jedoch erlaubt das Modell nur eine starr eindimensionale Anwendung ohne die Möglichkeit der Berücksichtigung individuell unterschiedlicher Symptomkombinationen. Die Diagnosekriterien der DGN 2012 hingegen geben, so weit möglich, eine Auswahlmöglichkeit bei der geforderten Symptomatik und der apparativen Diagnostik, um die klinische Varianz der unterschiedlichen Verläufe der CJK mit einzubeziehen.

Die logistische Regressionsanalyse schätzt weiterhin vor allem jene Symptome/Symptomgruppen als statistisch signifikant ein, die den gemeinsamen Endpunkt aller CJK-Erkrankungen kennzeichnet, nämlich den akinetischen Mutismus sowie Myoklonien, die bei einem großen Teil der Patienten - über den gesamten Krankheitsverlauf gesehen auftreten. Befinden sich Patienten im akinetischen Mutismus haben sie in der Regel eine präfinale Phase der Erkrankung erreicht, in der eine ausschließlich palliative Therapie angezeigt ist. Die Einbeziehung der späten Symptomatik führt zwar zu einer sensitiven und sicheren Diagnosestellung anhand des neuen Modells, verschiebt den Diagnosezeitpunkt in jedem Fall aber weiter nach hinten, da Patienten nur dann als „positiv“ bzw. „krank“ klassifiziert werden, wenn sie alle Parameter des Modells erfüllen. Ziel der Diagnosekriterien sollte aber eine frühe Diagnosestellung sein, um in jedem Fall, also sowohl bei CJK-Patienten als auch bei Patienten mit einer potentiell behandelbaren Erkrankung, ein möglichst großes therapeutisches Fenster nutzen zu können.

Vor diesem Hintergrund liefert die logistische Regressionsanalyse zusammen mit der Analyse des erstmaligen Auftretens einer Symptomatik (vgl. Tabelle neun) einen Hinweis auf die Symptomatik, die statistisch signifikant für die Diagnosestellung einer CJK ist und zugleich im frühen Stadium der Erkrankung auftritt. Dies ist in der vorliegenden Analyse allerdings nur für die zerebellare Symptomatik der Fall. 
Die Demenz, als Schlüsselsymptom für die Diagnosestellung, konnte anhand der logistischen Regressionsanalyse nicht als statistisch signifikanter Parameter ermittelt werden. Ein Grund ist, dass die Demenz bei einer Vielzahl von Erkrankungen, besonders auch bei jenen differenzialdiagnostisch relevanten Erkrankungen, als Symptom auftritt. Die Entscheidung zur Beibehaltung der Demenz im „endgültigen Modell“ wurde vor allem auf Grund der klinischen Relevanz der Demenz bei der Diagnosestellung getroffen. Weiterhin tritt die Demenz ebenfalls im frühen Stadium der Erkrankung auf und kann daher bei der frühen Diagnosestellung hilfreich sein.

\subsubsection{Der RT-QuIC in der logistischen Regressionsanalyse}

Wie bereits diskutiert wurde (vergleiche Abschnitt 4.5.2.3), erreichen die Werte für Sensitivität und Spezifität des RT-QuIC in dieser Untersuchung nicht die Werte vorangegangener Studien. Dennoch beträgt die Odds-Ratio 107,4 für der RT-QulC. Dies bedeutet, dass bei Positivität des RT-QulC ein Patient 107mal wahrscheinlicher eine CJK hat als ein Patient mit einem negativen Ergebnis im RT-QulC. Weiterhin tendiert der ermittelte $p$ Wert in der logistischen Regressionsanalyse gegen Null und erreicht somit neben dem CMRT und den Myoklonien das höchstmögliche Signifikanzniveau. Vor diesem Hintergrund ist das diagnostische Potential des RT-QuIC höher einzuschätzen als die Werte der Einzelanalyse vermitteln mögen.

\subsubsection{Das „Expertenmodell“}

Auf Grund der beschriebenen Problematik des anhand der logistischen Regressionsanalyse ermittelten Modells wurde in einem zweiten Schritt ein weiteres Modell („Expertenmodell“) entwickelt, in welchem neben der statistischen Signifikanz auch klinische Aspekte Einfluss auf die Auswahl der relevanten Parameter hatten. Das „Expertenmodell“ wurde ebenfalls in einem Training-Data-Set validiert. Zielsetzung bei der Entwicklung des Modells war eine frühe und zugleich möglichst sichere Diagnosestellung. Steigende Analysezahlen für die Proteine 14-3-3 im Referenzlabor an der Universitätsmedizin Göttingen (s. Tabelle 31) deuten ebenso wie eine tendenziell steigende Inzidenz für die CJK seit Beginn der Surveillance (s. Tabelle 1) darauf hin, dass das Bewusstsein für Prionerkrankungen als möglich Ursache für rasch verlaufende Demenzen zunimmt. Daher sollte das 
entwickelte Modell idealerweise als eine Art Screening-Modell für Patienten mit dem Verdacht auf eine CJK funktionieren.

Das entwickelte „Expertenmodell“ berücksichtigt neben der Demenz als Schlüsselsymptom die als statistisch signifikant ermittelte zerebellare Symptomatik als früh auftretende Symptomatik sowie das cMRT und den RT-QuIC als ebenfalls statistisch signifikante diagnostische Parameter. Die Spätsymptome Myoklonien und akinetischer Mutismus sind im „Expertenmodel“ nicht vertreten.

Im „Expertenmodell“ verbessert sich die Sensitivität gegenüber dem „endgültigen Modell“ aus der logistischen Regressionsanalyse nochmals um vier Prozentpunkte auf 92\%. Hinsichtlich der Sensitivität der Diagnosekriterien - rückblickend betrachtet - lässt sich sogar eine Verbesserung um 6\% verzeichnen. Die Spezifität verbessert sich gegenüber der ermittelten Spezifität für die Diagnosekriterien ebenfalls deutlich von $69 \%$ auf $82 \%$ und muss vor dem Hintergrund des präselektierten Kontrollkollektivs als herausragend eingeschätzt werden. Das entwickelte Modell hat offenbar selbst unter Patienten mit enzephalopathischem Verlauf eine ausreichende Diskrimination, um Patienten mit einer tatsächlichen CJK zu identifizieren.

Die Proteine 14-3-3 konnten auf Grund der niedrigen Werte in der Einzeluntersuchung nicht zu einer Verbesserung des „Expertenmodells“ beitragen und sind daher auch nicht in das Modell eingegangen. Auf Grund der dargestellten Entwicklung mit deutlich steigenden Zahlen für Liquoruntersuchungen zur Analyse der Proteine 14-3-3 in den letzten Jahren im nationalen Referenzlabor Göttingen (s. Tabelle 31) und der guten Ergebnisse in anderen aktuellen Untersuchungen (Schmitz et al. 2016) sollten sie in ein praxisrelevantes Modell als Screeningparameter dennoch integriert werden.

\subsection{Die „neu entwickelten Diagnosekriterien“}

In einem letzten Schritt wurden die neuen Diagnosekriterien nach statistisch und klinisch relevanten Gesichtspunkten aus dem „Expertenmodell“ abgeleitet. Hierbei lag ein besonderes Augenmerk auf der klinischen Anwendbarkeit der Kriterien. Die Werte für die neuen Diagnosekriterien wurden in der Anwendung auf das Gesamtkollektiv unter Berücksichtigung der Vollständigkeit der Patientendatensätze ermittelt. 
Das „Expertenmodell“ liefert bereits gute Werte bezüglich seiner Sensitivität und Spezifität im kleinen Testkollektiv (30\% des Gesamtkollektivs im Training-Data-Set). Hierbei müssen zur Klassifizierung als CJK alle fünf geforderten klinischen Symptome bzw. apparativen Testbefunde erfüllt werden. Somit ist das entwickelte „Expertenmodell“ in seiner klinischen Anwendung weiterhin starr und wenig flexibel.

Wie bereits dargestellt ist die CJK aber eine klinisch sehr variable Erkrankung, weiterhin ist keine der gängigen apparativen Testungen in der Lage eine ausreichende Sensitivität zu erreichen, um alle Fälle zu erfassen. Diese mangelnde Sensitivität addiert sich bei der zwingenden Erfüllung der positiven Befunde in der Testdiagnostik auf. Bei gleichzeitig drei geforderten positiven diagnostischen Tests plus zwei weiteren klinischen Symptomen erscheint eine breite Anwendbarkeit des Modells daher schwierig. Die „neu entwickelten Kriterien“ greifen sowohl die klinische Symptomatik als auch die apparative Diagnostik auf und umgehen die beschriebene Problematik durch Aufteilung des einen Modells in zwei Teilkriterien. Hierbei ist die klinische Symptomatik aus Demenz und/oder zerebellarer Symptomatik in beiden Teilkriterien zwingend erforderlich; lediglich die geforderten apparativen Befunde variieren zur Diagnosestellung einer wahrscheinlichen CJK. So ist es bereits das Vorhandensein der typischen klinischen Symptomatik (Demenz und/oder zerebellare Symptomatik) und ein positives Ergebnis im RT-QuIC ausreichend, um eine wahrscheinliche CJK diagnostizieren zu können. Falls kein positives RT-QuIC-Ergebnis vorliegt kann weiterhin über typische Befunde im EEG, cMRT und Liquor in Zusammenschau mit der passenden Klinik (Demenz und/oder zerebellare Symptomatik) eine wahrscheinliche CJK diagnostiziert werden. Für beide Teilkriterien gilt, dass es in der weiteren Routinediagnostik keinen Hinweis auf eine Alternativdiagnose geben darf.

Für diese „neu entwickelten Kriterien“ berechnet sich eine Sensitivität von 91,5\%, eine Spezifität von $84 \%$ sowie eine positiv prädiktiver Wert (PPV) von ebenfalls $91,5 \%$. Hierbei ist zu beachten, dass diese Werte anhand des Patientenkollektivs errechnet wurden, für das ein vollständiger Datensatz mit EEG und cMRT vorlag. Somit verkleinert sich das Patientenkollektiv auf 106 Patienten und das Kontrollkollektiv auf 56 Patienten.

Im Vergleich zu den Kriterien von 2012 zeigt sich eine deutliche Verbesserung von Sensitivität von $84 \%$ auf $91,5 \%$ und dem PPW von $73 \%$ auf $91,5 \%$. Die Verbesserung der 
Spezifität von 69\% auf $84 \%$ fällt ebenfalls deutlich aus. Dennoch erscheint für die Diagnose einer CJK eine noch höhere Spezifität erstrebenswert. Hierbei möchte ich nochmals darauf hinweisen, dass das Kontrollkollektiv in dieser Untersuchung stark vorselektiert ist und es daher zu unterschätzen Werten für die Spezifität kommen kann.

In einer prospektiv, epidemiologischen Studie von Hermann et al. (2018) wurde ein angepasster bzw. erweiterter Diagnostikalgorithmus, ähnlich dem hier vorgestellten Model, unter Einbeziehung des RT-QuIC erarbeitet.

Dieser Diagnostikalgorithmus wurde als Zusatz zu den bestehenden WHO-Diagnosekriterien entwickelt und sieht vor, dass auch Patienten die eine typische klinischen Symptomatik (Demenz, visuelle oder zerebellare Symptomatik, Myoklonus, pyramidale oder extrapyramidale Symptomatik, akinetischer Mutismus) aufweisen und ein positives Ergebnis in der RT-QulC-Untersuchung haben, als wahrscheinlicher Fall klassifiziert werden. Dadurch konnte die Sensitivität bei der Diagnosestellung einer wahrscheinlichen CJK erhöht werden (WHO-Kriterien: Sensitivität 74\% versus angepasste Kriterien: Sensitivität 97\%). Auch die Spezifität der angepassten Kriterien ist mit 99\% sehr hoch. Die RTQuIC-Untersuchung wurde in dieser Studie bei einem kleineren Fallkollektiv in drei Durchläufen durchgeführt. (Hermann et al. 2018)

Die Untersuchung von Hermann et al. (2018) unterstreicht nochmals die in dieser Dissertation aufgestellte These, dass eine Verbesserung der Diagnostik durch Etablierung der RT-QuIC-Untersuchung möglich ist. Dies zeigte sich auch in der Tatsache, dass der RTQuIC während der Anfertigung dieser Arbeit in die Diagnosekriterien der DGN (s. Tabelle 29) Eingang gefunden hat. 


\section{ZUSAMMENFASSUNG}

Die Creutzfeldt-Jakob-Erkrankung ist nicht behandelbar. Eine sichere Diagnosestellung ist daher unabdingbar. Um das mögliche Verbesserungspotential der Diagnosekriterien von 2012 zu erschließen, wurden die Kriterien zunächst analysiert. In einem zweiten Schritt wurde auf der Grundlage dieser Analyse eine logistische Regressionsanalyse mit dem Ziel durchgeführt, einen Vorschlag für verbesserte Diagnosekriterien zu entwickeln. In der vorliegenden Arbeit erfolgte die Analyse der Kriterien insbesondere im Hinblick auf Sensitivität und Spezifität der verwendeten apparativen Diagnostik inklusive des RTQuIC. Zudem standen auch die Auftretenswahrscheinlichkeit und der Zeitpunkt der klinischen Symptomatik im Fokus der Aufmerksamkeit. Für die primäre Analyse der Diagnosekriterien der DGN von 2012 wurde eine Fall-Kontrollstudie gewählt. Für die Entwicklung der neuerarbeiteten Diagnosekriterien wurde mit der logistischen Regressionsanalyse gearbeitet

Die Analyse der relevanten klinischen Symptomatik der Diagnosekriterien von 2012 zeigte, dass die Demenz und zerebellare Symptomatik zwar unspezifisch für die CJK sind, jedoch die Früh- bzw. Schlüsselsymptomatik darstellen, wie auch andere Studien bereits gezeigt haben (Krasnianski et al. 2014).

In Bezug auf die apparative Diagnostik weichen die im Rahmen dieser Arbeit erhobenen Werte für Sensitivität und Spezifität von anderen nationalen und internationalen Studien teilweise ab. Die Gründe hierfür liegen unter anderem in einem stark vorselektierten Kontrollkollektiv, einer Interobserver-Variabilität, am Zeitpunkt der Erhebung der Befunde und der Durchführung der Untersuchungstechniken. Die beschriebenen Gründe für die vorliegenden Ergebnisse sowie deren Interpretation wurden ausführlich diskutiert.

Bei der Untersuchung des wichtigen zeitlichen Aspekts der Diagnosestellung zeigte sich, dass zum Zeitpunkt der Liquorpunktion die Diagnosekriterien von 2012 nur eine unzureichende Zahl an Krankheitsfällen als „wahrscheinlichen Fall“ bzw. „kein Fall“ klassifizieren konnten; auch hierfür wurden mögliche Gründe reflektiert.

Mittels der log. Regressionsanalyse wurden die zuvor dargestellten Ergebnisse genauer in den Blick genommen. In mehreren Schritten wurden die Ergebnisse der Analyse nach 
klinischen Gesichtspunkten optimiert, um sich der Idealvorstellung von möglichst sicheren bzw. spezifischen und zugleich zu einem frühen Zeitpunkt der Erkrankung sehr sensitiven Kriterien (siehe auch Kapitel 1.9) anzunähern. Die theoretischen und klinisch relevanten Überlegungen wurden dargelegt. Hierbei wurde die Demenz trotz fehlender statistischer Signifikanz in der logistischen Regressionsanalyse als klinische Hauptsymptomatik in die „neu entwickelten Diagnosekriterien“ übernommen. Es ließ sich zudem zeigen, dass der RT-QuIC trotz der im Vergleich zu anderen nationalen und internationalen Studien niedrigeren Werte für Sensitivität und Spezifität in der logistischen Regressionsanalyse eine hohe Relevanz für die Diagnosestellung einer CJK hat und Potenzial für die Verbesserung der Diagnosestellung/Diagnosekriterien mit sich führt. Die „neu entwickelten Diagnosekriterien“ bestehen aus zwei Teilkriterien. Das erste Teilkriterium wird erfüllt, wenn als klinische Symptomatik eine Demenz und/oder eine zerebellare Symptomatik besteht und der RT-QuIC positiv ausfällt. Falls der RT-QulC negativ ausfällt, jedoch weitere Diagnostik - wie das EEG oder cMRT - einen typischen Befund zeigt, kann ebenfalls eine „wahrscheinliche CJK" diagnostizierte werden. Ein positiver Befund der Proteine 14-3-3 kann hier die klinische Diagnosestellung unterstützen. Bei Anwendung der neu entwickelten Kriterien auf das ausgewählte Patientenkollektiv konnte eine Verbesserung der Sensitivität von $84 \%$ auf $91,5 \%$ und der Spezifität von $69 \%$ auf $84 \%$ gegenüber den Diagnosekriterien von 2012 erreicht werden. 


\section{ANHANG}

Tabelle 29: Klinische Klassifikationskriterien der sporadischen CJK 2018 (modifiziert nach DGN Leitlinie CJK 2018)

\begin{tabular}{|c|c|c|c|}
\hline CJK-Form & & $\begin{array}{l}\text { Klinische } \\
\text { Erscheinungen: } \\
\text { Myoklonus, visuelle o- } \\
\text { der zerebrale Sympto- } \\
\text { matik, pyramidale oder } \\
\text { extrapyramidale Symp- } \\
\text { tomatik, akinetischer } \\
\text { Mutismus }\end{array}$ & $\begin{array}{l}\frac{\text { Typische Befunde }}{\text { in technischen Un- }} \\
\text { tersuchungen: } \\
\text { EEG, cMRT, Liquor } \\
\text { (Proteine 14-3-3) }\end{array}$ \\
\hline \multirow[t]{2}{*}{$\begin{array}{l}\text { Wahrscheinliche } \\
\text { CJK }\end{array}$} & $\begin{array}{l}\text { Progressive } \\
\text { Demenz }\end{array}$ & $\begin{array}{l}+ \text { mindestens } \\
2 \text { Erscheinungen }\end{array}$ & $\begin{array}{l}\text { + mindestens } 1 \\
\text { technische Zusat- } \\
\text { zuntersuchung po- } \\
\text { sitiv }\end{array}$ \\
\hline & \multicolumn{3}{|c|}{$\begin{array}{l}\text { Oder progressiv neurologisches Syndrom mit positiven RT- } \\
\text { QulC-Test im Liquor oder anderen Geweben }\end{array}$} \\
\hline Mögliche CJK & $\begin{array}{l}\text { Progressive } \\
\text { Demenz } \\
\text { (<2 Jahre) }\end{array}$ & $\begin{array}{l}+ \text { mindestens } \\
2 \text { Erscheinungen }\end{array}$ & $\begin{array}{l}\text { fehlender wegwei- } \\
\text { sender Befund }\end{array}$ \\
\hline
\end{tabular}


Tabelle 30: WHO-Diagnosekriterien für die sporadische CJK 2018 (modifiziert nach Center of Disease Control and Prevention)

\begin{tabular}{|c|c|c|c|c|}
\hline CJK-Form & & $\begin{array}{l}\text { Klinische } \\
\text { Erscheinungen: } \\
\text { Myoklonus, visuelle } \\
\text { oder zerebrale Symp- } \\
\text { tomatik, pyramidale } \\
\text { oder extrapyrami- } \\
\text { dale Symptomatik, a- } \\
\text { kinetischer Mutis- } \\
\text { mus }\end{array}$ & $\begin{array}{l}\text { Typische Be- } \\
\text { funde in tech- } \\
\text { nischen Unter- } \\
\text { suchungen: } \\
\text { EEG, cMRT, Li- } \\
\text { quor (Proteine } \\
\text { 14-3-3) }\end{array}$ & \\
\hline \multirow[t]{2}{*}{$\begin{array}{l}\text { Wahr- } \\
\text { scheinliche } \\
\text { CJK }\end{array}$} & \multirow[t]{2}{*}{$\begin{array}{l}\text { Progressive } \\
\text { Demenz }\end{array}$} & $\begin{array}{l}+ \text { mindestens } \\
2 \text { Erscheinungen } \\
\text { Ohne Hinweis auf Al- } \\
\text { ternativdiagnose }\end{array}$ & $\begin{array}{l}+ \text { mindestens } \\
1 \text { technische } \\
\text { Zusatzuntersuc } \\
\text { hung positiv }\end{array}$ & $\begin{array}{l}\text { Oder: } \\
\text { Neuropsychi- } \\
\text { atrische } \\
\text { Symptoma- } \\
\text { tik und posi- } \\
\text { tiver RT-QulC }\end{array}$ \\
\hline & & \multicolumn{3}{|c|}{ Ohne Hinweis auf Alternativdiagnose } \\
\hline \multirow[t]{2}{*}{$\begin{array}{l}\text { Mögliche } \\
\text { CJK }\end{array}$} & \multirow[t]{2}{*}{$\begin{array}{l}\text { Progressive } \\
\text { Demenz } \\
\text { (<2 Jahre) }\end{array}$} & $\begin{array}{l}+ \text { mindestens } \\
2 \text { Erscheinungen }\end{array}$ & \multicolumn{2}{|c|}{$\begin{array}{l}\text { fehlender wegweisender Be- } \\
\text { fund }\end{array}$} \\
\hline & & Ohne Hinweis auf Alter & ativdiagnose & \\
\hline
\end{tabular}


Tabelle 31: Entwicklung der Probeneingänge und der positiven Befunde 1993-2019 tabellarisch

\begin{tabular}{|c|c|c|}
\hline Jahr & Liquoreingang & $14-3-3+$ \\
\hline 1993 & 17 & 11 \\
\hline 1994 & 95 & 52 \\
\hline 1995 & 99 & 60 \\
\hline 1996 & 141 & 80 \\
\hline 1997 & 305 & 75 \\
\hline 1998 & 729 & 146 \\
\hline 1999 & 806 & 150 \\
\hline 2000 & 1248 & 270 \\
\hline 2001 & 1724 & 306 \\
\hline 2002 & 1876 & 283 \\
\hline 2003 & 2164 & 466 \\
\hline 2004 & 2387 & 597 \\
\hline 2005 & 2408 & 274 \\
\hline 2006 & 2440 & 417 \\
\hline 2007 & 3113 & 406 \\
\hline 2008 & 3701 & 498 \\
\hline 2009 & 4434 & 415 \\
\hline 2010 & 4720 & 466 \\
\hline 2011 & 5206 & 628 \\
\hline 2012 & 6008 & 555 \\
\hline 2013 & 5658 & 450 \\
\hline 2014 & 6409 & 378 \\
\hline 2015 & 6654 & 442 \\
\hline 2016 & 6968 & 622 \\
\hline 2017 & 6920 & 613 \\
\hline 2018 & 7322 & 707 \\
\hline 2019 & 7317 & 742 \\
\hline
\end{tabular}

(Erstellt durch NZR für TSE, mit freundlicher Genehmigung NRZ für TSE) 


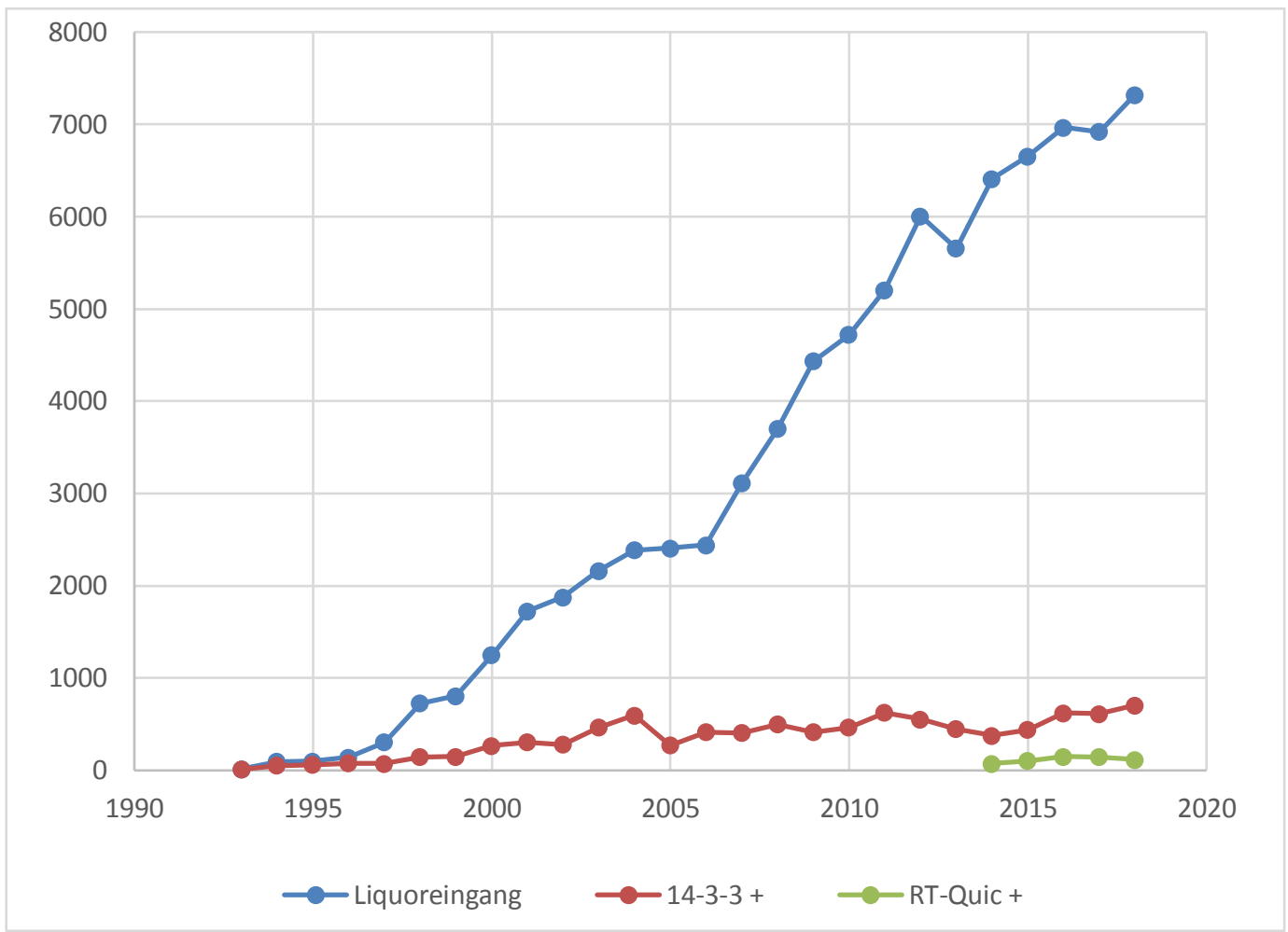

Abbildung 11: Entwicklung der Probeneingänge und der positiven Befunde 1993-2019, graphisch

(Erstellt durch NZR für TSE, mit freundlicher Genehmigung NRZ für TSE) 


\section{LITERATURVERZEICHNIS}

Atarashi R, Sano K, Satoh K, Nishida N (2011a): Real-time quaking-induced conversion: a highly sensitive assay for prion detection. Prion $\underline{5}, 150-153$

Atarashi R, Satoh K, Sano K, Fuse T, Yamaguchi N, Ishibashi D, Matsubara T, Nakagaki T, Yamanaka H, Shirabe S, et al. (2011b): Ultrasensitive human prion detection in cerebrospinal fluid by real-time quaking-induced conversion. Nat Med $\underline{17}, 175-$ 178

Boesenberg-Grosse C, Schulz-Schaeffer WJ, Bodemer M, Ciesielczyk B, Meissner B, Krasnianski A, Bartl M, Heinemann U, Varges D, Eigenbrod S, et al. (2006): Brainderived proteins in the CSF: do they correlate with brain pathology in CJD? BMC Neurol $\underline{6}, 35$

Boston PF, Jackson P, Thompson RJ (1982): Human 14-3-3 protein: radioimmunoassay, tissue distribution, and cerebrospinal fluid levels in patients with neurological disorders. J Neurochem $\underline{38}, 1475-1482$

Braak H, Braak E (1991): Neuropathological stageing of Alzheimer-related changes. Acta Neuropathol. 82, 239-259

Brown P, Gibbs CJ, Rodgers-Johnson P, Asher DM, Sulima MP, Bacote A, Goldfarb LG, Gajdusek DC (1994): Human spongiform encephalopathy: The national institutes of health series of 300 cases of experimentally transmitted disease. Ann Neurol $\underline{35}, 513-529$

Brown P, Preece M, Brandel J-P, Sato T, McShane L, Zerr I, Fletcher A, Will RG, Pocchiari M, Cashman NR, et al. (2000): latrogenic Creutzfeldt-Jakob disease at the millennium. Neurology $\underline{55}, 1075-1081$

Budka H (2003): Neuropathology of prion diseases. Br Med Bull 66, 121-130

Cohen FE, Prusiner SB (1998): Pathologic conformations of prion proteins. Annu Rev Biochem 67, 793-819

Colby DW, Prusiner SB (2011): Prions. Cold Spring Harb Perspect Biol $\underline{3}$, a006833

Collins GS, Reitsma JB, Altman DG, Moons KGM (2015): Transparent reporting of a multivariable prediction model for individual prognosis or diagnosis (TRIPOD): the TRIPOD statement. BMJ $\underline{350}$, g7594-g7594

Collins S, Boyd A, Fletcher A, Gonzales M, McLean CA, Byron K, Masters CL (2000): Creutzfeldt-Jakob disease: diagnostic utility of 14-3-3 protein immunodetection in cerebrospinal fluid. J Clin Neurosci 7 , 203-208

Cramm M, Schmitz M, Karch A, Zafar S, Varges D, Mitrova E, Schroeder B, Raeber A, Kuhn F, Zerr I (2015): Characteristic CSF prion seeding efficiency in humans with prion diseases. Mol Neurobiol 51, 396-405

Cramm M, Schmitz M, Karch A, Mitrova E, Kuhn F, Schroeder B, Raeber A, Varges D, Kim Y-S, Satoh K, et al. (2016): Stability and Reproducibility Underscore Utility of RT-QulC for Diagnosis of Creutzfeldt-Jakob Disease. Mol Neurobiol 53, 1896-1904 
Creutzfeldt HG (1920): On a particular focal disease of the central nervous system (preliminary communication), 1920. Alzheimer Dis Assoc Disord 3, 3-25

DGN (2012): Creutzfeldt-Jakob-Krankheit (Leitlinien für Diagnostik und Therapie in der Neurologie) S1-Leitlinie der deutschen Gesellschaft für Neurologie. https://www.dgn.org/images/red_leitlinien/LL_2012/pdf/II_43_2012_creutzfeldtjakob-krankheit.pdf; abgerufen am 10.03.2020

DGN 2018 Creutzfeldt-Jakob-Krankheit (Leitlinien für Diagnostik und Therapie in der Neurologie) S1-Leitlinie der deutschen Gesellschaft für Neurologie. https://www.dgn.org/leitlinien/3619-II-030-042-creutzfeldt-jakob-krankheit-2019; abgerufen am 17.05.2020

Dietz K, Raddatz G, Wallis J, Müller N, Zerr I, Duerr H-P, Lefèvre H, Seifried E, Löwer J (2007): Blood Transfusion and Spread of Variant Creutzfeldt-Jakob Disease. Emerg Infect Dis 13, 89-96

Ermann N, Lewczuk P, Schmitz M, Lange P, Knipper T, Goebel S, Kornhuber J, Zerr I, Llorens $F$ (2018): CSF nonphosphorylated Tau as a biomarker for the discrimination of AD from CJD. Ann Clin TransI Neurol $\underline{5}, 883-887$

Finkenstaedt M, Szudra A, Zerr I, Poser S, Hise JH, Stoebner JM, Weber T (1996): MR imaging of Creutzfeldt-Jakob disease. Radiology $\underline{199}$, 793-798

Foutz A, Appleby BS, Hamlin C, Liu X, Yang S, Cohen Y, Chen W, Blevins J, Fausett C, Wang $\mathrm{H}$, et al. (2017): Diagnostic and prognostic value of human prion detection in cerebrospinal fluid: CSF RT-QuIC Test. Ann Neurol 81, 79-92

Glatzel M, Linsenmeier L, Dohler F, Krasemann S, Puig B, Altmeppen HC (2015): Shedding light on prion disease. Prion $\underline{9}, 244-256$

Gmitterová K, Heinemann U, Bodemer M, Krasnianski A, Meissner B, Kretzschmar HA, Zerr I (2009): 14-3-3 CSF levels in sporadic Creutzfeldt-Jakob disease differ across molecular subtypes. Neurobiol Aging 30, 1842-1850

Hamlin C, Puoti G, Berri S, Sting E, Harris C, Cohen M, Spear C, Bizzi A, Debanne SM, Rowland DY (2012): A comparison of tau and 14-3-3 protein in the diagnosis of Creutzfeldt-Jakob disease. Neurology $\underline{79}, 547-552$

Head MW (2013): Human prion diseases: Molecular, cellular and population biology: Human prion diseases. Neuropathology 33, 221-236

Heinemann U, Krasnianski A, Meissner B, Varges D, Kallenberg K, Schulz-Schaeffer WJ, Steinhoff BJ, Grasbon-Frodl EM, Kretzschmar HA, Zerr I (2007): Creutzfeldt-Jakob disease in Germany: a prospective 12-year surveillance. Brain 130, 1350-1359

Hermann P, Laux M, Glatzel M, Matschke J, Knipper T, Goebel S, Treig J, SchulzSchaeffer W, Cramm M, Schmitz M, Zerr I (2018): Validation and utilization of amended diagnostic criteria in Creutzfeldt-Jakob disease surveillance. Neurology 91, e331-e338

Hsich G, Kenney K, Gibbs CJ, Lee KH, Harrington MG (1996): The 14-3-3 brain protein in cerebrospinal fluid as a marker for transmissible spongiform encephalopathies. $\mathrm{N}$ Engl J Med 335, 924-930 
Hu W, Kieseier B, Frohman E, Eagar TN, Rosenberg RN, Hartung H-P, Stüve O (2008): Prion proteins: physiological functions and role in neurological disorders. J Neurol Sci 264, 1-8

Jakob A (1921) Über eigenartige Erkrankungen des Zentralnervensystems mit bemerkenswerten anatomischen Befunden (spastische Pseudosklerose-Encephalo-Myelopathie mit disseminierten Degenerationsherden). Dtsch Z Nervenkeilkd 70: 132146

Karch A, Koch A, Zapf A, Zerr I, Karch A (2016): Partial verification bias and incorporation bias affected accuracy estimates of diagnostic studies for biomarkers that were part of an existing composite gold standard. J Clin Epidemiol 78, 73-82

Kittner C, Heinemann U, Zerr I (2009):Risikofaktoren für die sporadische CreutzfeldtJakob-Krankheit. Dtsch Med Wochenschr 134, 1429-1435

Kovács GG, Puopolo M, Ladogana A, Pocchiari M, Budka H, van Duijn C, Collins SJ, Boyd A, Giulivi A, Coulthart M, et al. (2005): Genetic prion disease: the EUROCJD experience. Hum Genet $\underline{118}$, 166-174

Krasnianski A, Meissner B, Heinemann U, Zerr I (2004): Clinical findings and diagnostic tests in Creutzfeldt-Jakob disease and variant Creutzfeldt-Jakob disease. Folia Neuropathol $\underline{42 \text { Suppl B }}$, 24-38

Krasnianski A, Meissner B, Schulz-Schaeffer W, Kallenberg K, Bartl M, Heinemann U, Varges D, Kretzschmar HA, Zerr I (2006): Clinical features and diagnosis of the MM2 cortical subtype of sporadic Creutzfeldt-Jakob disease. Arch Neurol $\underline{63}$, 876880

Krasnianski A, Kallenberg K, Collie DA, Meissner B, Schulz-Schaeffer WJ, Heinemann U, Varges D, Summers DM, Kretzschmar HA, Talbot T, et al. (2008): MRI in the classical MM1 and the atypical MV2 subtypes of sporadic CJD: an inter-observer agreement study. Eur J Neurol 15, 762-771

Krasnianski A, Kaune J, Jung K, Kretzschmar HA, Zerr I (2014): First symptom and initial diagnosis in sporadic CJD patients in Germany. J Neurol 261, 1811-1817

Ladogana A, Puopolo M, Croes EA, Budka H, Jarius C, Collins S, Klug GM, Sutcliffe T, Giulivi A, Alperovitch A, et al. (2005): Mortality from Creutzfeldt-Jakob disease and related disorders in Europe, Australia, and Canada. Neurology 64, 1586-1591

Leitlinie CJK siehe Deutsche Gesellschaft für Neurologie

Mackenzie G, Will R (2017): Creutzfeldt-Jakob disease: recent developments. F1000Research $\underline{6}, 2053$

Masters CL, Harris JO, Gajdusek DC, Gibbs CJ, Bernoulli C, Asher DM (1979): Creutzfeldt-Jakob disease: patterns of worldwide occurrence and the significance of familial and sporadic clustering. Ann Neurol $\underline{5}, 177-188$

Masuhr KF, Masuhr F, Neumann M: Neurologie, 7. vollständig überarbeitete und erweiterte Auflage; Thieme, Stuttgart 2013

Matschke J, Hagel C (2015): Sektion bei Verdacht auf CJK. Standard operating procedure (SOP), Neuropathologie Universitätsklinikum Hamburg-Eppendorf (UKE) ver- 
öffentlicht am 23.09.2015. https://www.uke.de/dateien/institute/neuropathologie/sektion-bei-verdacht-auf-jakob-creutzfeldt-krankheit.pdf (Zugriff am 17.05.2020)

McGuire LI, Peden AH, Orrú CD, Wilham JM, Appleford NE, Mallinson G, Andrews M, Head MW, Caughey B, Will RG, et al. (2012): Real time quaking-induced conversion analysis of cerebrospinal fluid in sporadic Creutzfeldt-Jakob disease. Ann Neurol $\underline{72}, 278-285$

McGuire LI, Poleggi A, Poggiolini I, Suardi S, Grznarova K, Shi S, de Vil B, Sarros S, Satoh $\mathrm{K}$, Cheng K, et al. (2016): Cerebrospinal fluid real-time quaking-induced conversion is a robust and reliable test for sporadic creutzfeldt-jakob disease: An international study. Ann Neurol 80, 160-165

Mead S, Poulter M, Beck J, Webb TEF, Campbell TA, Linehan JM, Desbruslais M, Joiner S, Wadsworth JDF, King A, et al. (2006): Inherited prion disease with six octapeptide repeat insertional mutation--molecular analysis of phenotypic heterogeneity. Brain 129, 2297-2317

Meissner B, Kallenberg K, Sanchez-Juan P, Collie D, Summers DM, Almonti S, Collins SJ, Smith P, Cras P, Jansen GH, et al. (2009): MRI lesion profiles in sporadic Creutzfeldt-Jakob disease. Neurology $\underline{72}, 1994-2001$

Mouillet-Richard S, Ermonval M, Chebassier C, Laplanche JL, Lehmann S, Launay JM, Kellermann O (2000): Signal transduction through prion protein. Science $\underline{289}$, 1925-1928

Nationales Referenzzentrum für die Surveillance transmissibler spongiformer Enzephalopahtien (NRZ für TSE): http://cjd-goettingen.de/aktuell/aktuelle-zahlen/cjk-indeutschland/ (Zugriff 17.05.2020)

Oesch B, Westaway D, Wälchli M, McKinley MP, Kent SB, Aebersold R, Barry RA, Tempst P, Teplow DB, Hood LE (1985): A cellular gene encodes scrapie PrP 27-30 protein. Cell $\underline{40}, 735-746$

Otto A, Zerr I, Lantsch M, Weidehaas K, Riedemann C, Poser S (1998): Akinetic mutism as a classification criterion for the diagnosis of Creutzfeldt-Jakob disease. J Neurol Neurosurg Psychiatry 64, 524-528

Otto M, Wiltfang J, Tumani H, Zerr I, Lantsch M, Kornhuber J, Weber T, Kretzschmar HA, Poser S (1997): Elevated levels of tau-protein in cerebrospinal fluid of patients with Creutzfeldt-Jakob disease. Neurosci Lett $\underline{225}$, 210-212

Parchi P, Saverioni D (2012): Molecular pathology, classification, and diagnosis of sporadic human prion disease variants. Folia Neuropathol 50, 20-45

Parchi P, Castellani R, Capellari S, Ghetti B, Young K, Chen SG, Farlow M, Dickson DW, Sima AA, Trojanowski JQ, et al. (1996): Molecular basis of phenotypic variability in sporadic Creutzfeldt-Jakob disease. Ann Neurol 39, 767-778

Parchi P, Giese A, Capellari S, Brown P, Schulz-Schaeffer W, Windl O, Zerr I, Budka H, Kopp N, Piccardo P, et al. (1999): Classification of sporadic Creutzfeldt-Jakob disease based on molecular and phenotypic analysis of 300 subjects. Ann Neurol $\underline{46}$, 224-233 
Paterson RW, Takada LT, Geschwind MD (2012): Diagnosis and treatment of rapidly progressive dementias. Neurol Clin Pract 2 , 187-200

Pocchiari M, Puopolo M, Croes EA, Budka H, Gelpi E, Collins S, Lewis V, Sutcliffe T, Guilivi A, Delasnerie-Laupretre N, et al. (2004): Predictors of survival in sporadic Creutzfeldt-Jakob disease and other human transmissible spongiform encephalopathies. Brain 127, 2348-2359

Poser S, Zerr I, Schulz-Schaeffer WJ, Kretzschmar HA, Felgenhauer K (1997): Die Creutzfeldt-Jakob-Krankheit: Eine Sphinx der heutigen Neurobiologie. Dtsch Med Wochenschr 122, 1099-1105

Poser S, Mollenhauer B, Krauß A, Zerr I, Steinhoff BJ, Schroeter A, Finkenstaedt M, Schulz-Schaeffer WJ, Kretzschmar HA, Felgenhauer K (1999): How to improve the clinical diagnosis of Creutzfeldt-Jakob disease. Brain 122, 2345-2351

Prusiner SB (1982): Novel proteinaceous infectious particles cause scrapie. Science $\underline{216}, 136-144$

Puoti G, Bizzi A, Forloni G, Safar JG, Tagliavini F, Gambetti P (2012): Sporadic human prion diseases: molecular insights and diagnosis. Lancet Neurol 11, 618-628

Rudge P, Hyare H, Green A, Collinge J, Mead S (2018): Imaging and CSF analyses effectively distinguish CJD from its mimics. J Neurol Neurosurg Psychiatry $\underline{89}, 461-466$

Ruegger J, Stoeck K, Amsler L, Blaettler T, Zwahlen M, Aguzzi A, Glatzel M, Hess K, Eckert T (2009): A case-control study of sporadic Creutzfeldt-Jakob disease in Switzerland: analysis of potential risk factors with regard to an increased CJD incidence in the years 2001-2004. BMC Public Health $\underline{9}, 18$

Sanchez-Juan P, Green A, Ladogana A, Cuadrado-Corrales N, Sáanchez-Valle R, Mitrováa $E$, Stoeck K, Sklaviadis T, Kulczycki J, Hess K, et al. (2006): CSF tests in the differential diagnosis of Creutzfeldt-Jakob disease. Neurology 67, 637-643

Schelzke G, Zerr I (2010): Pathologie und Diagnostik von Prionerkrankungen. DNP $\underline{9}$, 45-54

Schmitz M, Ebert E, Stoeck K, Karch A, Collins S, Calero M, Sklaviadis T, Laplanche J-L, Golanska E, Baldeiras I, et al. (2016): Validation of 14-3-3 Protein as a Marker in Sporadic Creutzfeldt-Jakob Disease Diagnostic. Mol Neurobiol 53, 2189-2199

Schröter A, Zerr I, Henkel K, Tschampa HJ, Finkenstaedt M, Poser S (2000): Magnetic Resonance Imaging in the Clinical Diagnosis of Creutzfeldt-Jakob Disease. Arch Neurol. $\underline{57,1751-7}$

Seitz R, von Auer F, Blümel J, Burger R, Buschmann A, Dietz K, Heiden M, Hitzler WE, Klamm H, Kreil T, et al. (2007): Impact of VCJD on blood supply. Biologicals $\underline{35}$, 7997

Skillbäck T, Rosén C, Asztely F, Mattsson N, Blennow K, Zetterberg H (2014): Diagnostic performance of cerebrospinal fluid total tau and phosphorylated tau in Creutzfeldt-Jakob disease: results from the Swedish Mortality Registry. JAMA Neurol 71, 476-483 
Steinhoff BJ, Kropp S, Riedemann C, Eckardt KM, Herrendorf G, Poser S (1998): Elektroenzephalographische Charakteristika der Creutzfeldt-Jakobschen Krankheit und ihre differediagnose. Fortschr Neurol Psychiatr 66, 357-365

Steinhoff BJ, Zerr I, Glatting M, Schulz-Schaeffer W, Poser S, Kretzschmar HA (2004): Diagnostic value of periodic complexes in Creutzfeldt-Jakob disease. Ann Neurol $\underline{56}$, 702-708

Weber T, Otto M, Bodemer M, Zerr I (1997a): Diagnosis of Creutzfeldt-Jakob disease and related human spongiform encephalopathies. Biomed Pharmacother $\underline{51}$, 381387

Weber T, Zerr I, Bodemer M, Poser S (1997b): Erweitertes Krankheitsspektrum humaner spongiformer Enzephalopathien oder Prionkrankheiten. Nervenarzt 68, 309323

Weingarten MD, Lockwood AH, Hwo SY, Kirschner MW (1975): A protein factor essential for microtubule assembly. Proc Natl Acad Sci USA $\underline{72}$, 1858-1862

Westergard L, Christensen HM, Harris DA (2007): The cellular prion protein (PrPc): Its physiological function and role in disease. Biochim Biophys Acta 1772, 629-644

Wieser HG, Schindler K, Zumsteg D (2006): EEG in Creutzfeldt-Jakob disease. Clin Neurophysiol 117, 935-951

Will RG (2003): Acquired prion disease: iatrogenic CJD, variant CJD, kuru. Br Med Bull 66, 255-265

Will RG, Matthews WB (1984): A retrospective study of Creutzfeldt-Jakob disease in England and Wales 1970-79. I: Clinical features. J Neurol Neurosurg Psychiatry 47 134-140

Will RG, Alperovitch A, Poser S, Pocchiari M, Hofman A, Mitrova E, de Silva R, D'Alessandro M, Delasnerie-Laupretre N, Zerr I, van Duijn C (1998): Descriptive epidemiology of Creutzfeldt-Jakob disease in six European countries, 1993-1995. EU Collaborative Study Group for CJD. Ann Neurol 43, 763-767

Young GS, Geschwind MD, Fischbein NJ, Martindale JL, Henry RG, Liu S, Lu Y, Wong S, Liu H, Miller BL, Dillon WP (2005): Diffusion-weighted and fluid-attenuated inversion recovery imaging in Creutzfeldt-Jakob disease: high sensitivity and specificity for diagnosis. AJNR Am J Neuroradiol 26, 1551-1562

Zerr I, Poser S (2001): Epidemiology and risk factors of transmissible spongiform encephalopathies in man. Contrib Microbiol 7 , 93-104

Zerr I, Poser S (2002): Clinical diagnosis and differential diagnosis of CJD and VCJD. With special emphasis on laboratory tests. APMIS $\underline{110}, 88-98$

Zerr I, Bodemer M, Gefeller O, Otto M, Poser S, Wiltfang J, Windl O, Kretzschmar HA, Weber T (1998): Detection of 14-3-3 protein in the cerebrospinal fluid supports the diagnosis of Creutzfeldt-Jakob disease. Ann Neurol 43, 32-40

Zerr I, Pocchiari M, Collins S, Brandel JP, de Pedro Cuesta J, Knight RS, Bernheimer H, Cardone F, Delasnerie-Lauprêtre N, Cuadrado Corrales N, et al. (2000): Analysis of EEG and CSF 14-3-3 proteins as aids to the diagnosis of Creutzfeldt-Jakob disease. Neurology $\underline{55}, 811-815$ 
Zerr I, Mollenhauer B, Werner C, Poser S (2002): Früh- und Differenzialdiagnose der Creutzfeldt-Jakob Krankheit. Dtsch Med Wochenschr 127, 323-327

Zerr I, Kallenberg K, Summers DM, Romero C, Taratuto A, Heinemann U, Breithaupt M, Varges D, Meissner B, Ladogana A, et al. (2009): Updated clinical diagnostic criteria for sporadic Creutzfeldt-Jakob disease. Brain 132, 2659-2668 


\section{DANKSAGUNG}

Ich möchte meiner Doktormutter Frau Prof. Dr. Inga Zerr für die Anregungen und Hilfestellungen bei der Themenfindung sowie für die Unterstützung bei allen fachlichen Fragestellungen herzlich danken. Frau Prof. Zerr hat mich bei der Anfertigung der Arbeit in jeder Hinsicht unterstützt und mich ermutigt, meine Forschungsergebnisse auf dem European CJD Experts Meeting 2015 auch einem internationalen Publikum zu präsentieren und zur Diskussion zu stellen.

Weiterhin möchte ich Dr. Maria Cramm für die Durchführung der RT-QulC-Untersuchung und die Hilfe bei technischen Fragen danken.

Mein Dank gilt außerdem den medizinisch-technischen Angestellten des nationalen Referenzzentrums für TSE der Universität Göttingen für die Durchführung der Liquoruntersuchungen sowie den Mitarbeiterinnen des Sekretariats, Jolanthe Ehrlich und Maja Schneider-Dominco, für die Hilfe bei administrativen und organisatorischen Fragen.

Schließlich möchte ich meinen ärztlichen Kollegen im NRZ, Claudia Ponto, Stefanie Manger, Alexander Pracht, Stefan Goebel und Peter Hermann, für die Zusammenarbeit und viele hilfreiche Anregungen danken. 